$$
\text { DOE/BP }-990026 / 6
$$

\title{
POWER SUBSCRIPTION STRATEGY
}

\section{ADMINISTRATOR'S RECORD OF DECISION}
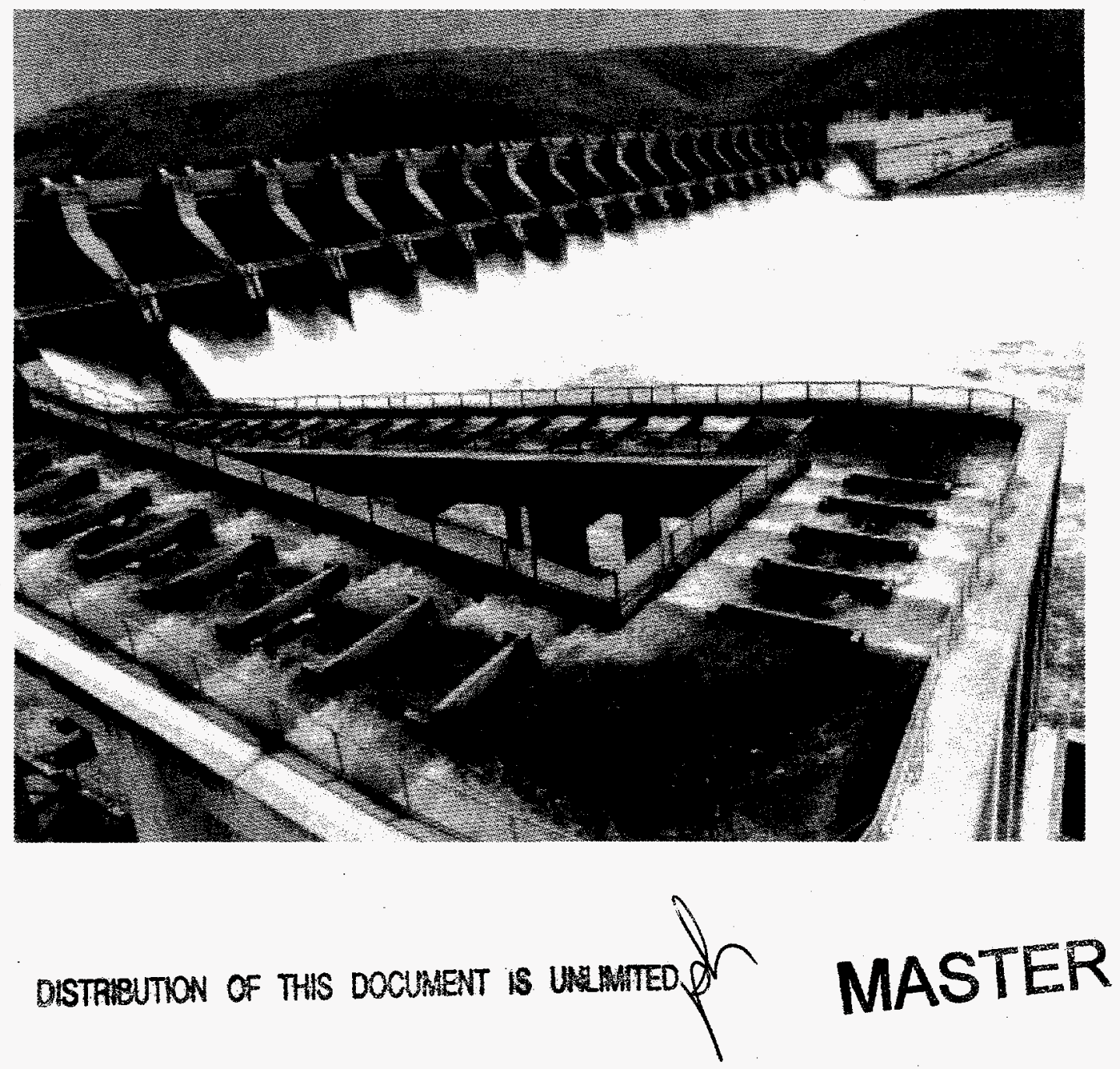


\section{DISCLAIMER}

This report was prepared as an account of work sponsored by an agency of the United States Government. Neither the United States Government nor any agency thereof, nor any of their employees, makes any warranty, express or implied, or assumes any legal liability or responsibility for the accuracy, completeness, or usefulness of any information, apparatus, product, or process disclosed, or represents that its use would not infringe privately owned rights. Reference herein to any specific commercial product, process, or service by trade name, trademark, manufacturer, or otherwise does not necessarily constitute or imply its endorsement, recom. mendation, or favoring by the United States Government or any agency thereof. The views and opinions of authors expressed herein do not necessarily state or reflect those of the United States Government or any agency thereof. 


\section{DISCLAIMER}

Portions of this document may be illegible in electronic image products. Images are produced from the best available original document. 


\section{POWER SUBSCRIPTION STRATEGY}

\section{ADMINISTRATOR'S RECORD OF DECISION}

Bonneville Power Administration

U.S. Department of Energy

December 1998 


\section{TABLE OF CONTENTS}

Page

COMMENTERS CITED IN THE ROD iii

INTRODUCTION - SHARING THE BENEFITS

I. SUBSCRIBING TO FEDERAL POWER ............................................. 11

A. $\quad$ Serving Public Agency Loads ................................................... 16

1. Public Agency Load Growth ............................................. 17

2. Public Agency Annexed Loads ......................................... 19

3. Serving the Load of a New Public Agency .......................... 20

4. New Preference Tribal Utility .............................................. 22

5. Customer Resource Replacement ...................................... 24

6. Surplus Firm Power Contracts .............................................. 25

B. Serving Residential and Small Farm Consumers of the IOUs ........... 27

1. Subscription Sales to IOUs for Residential Consumers .......... $\quad 30$

2. Amount .................................................................... 50

3. Financial Mechanism .................................................. 58

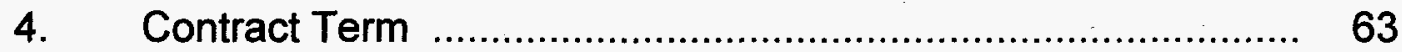

5. Implementation .......................................................... 65

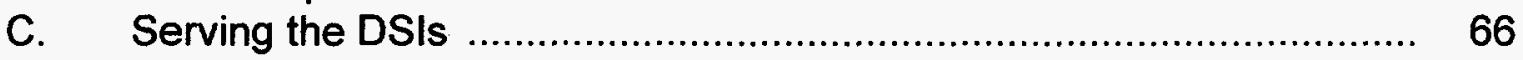

D. Serving Other Loads ............................................................. 71

II. POWER PRODUCTS AND SERVICES …......................................... 72

A. Risk Management Strategy ................................................... 72

1. Reserve Levels ................................................................ 73

2. Cost Recovery ........................................................... $\quad 75$

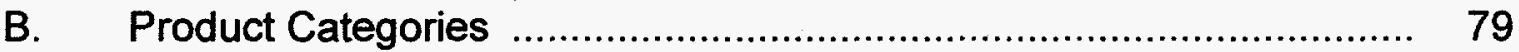

1. Core Subscription Products .............................................. $\quad 79$

2. Customized Subscription Products .................................... 80

3. Non-Subscription Products ............................................. 81

C. Slice of System ................................................................. 81

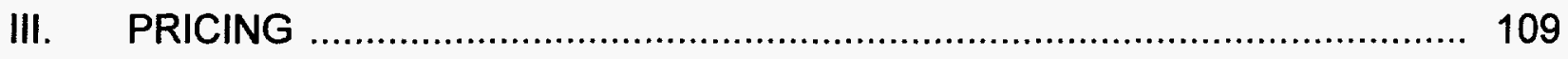

A. Public Agency Customers ….................................................... 109

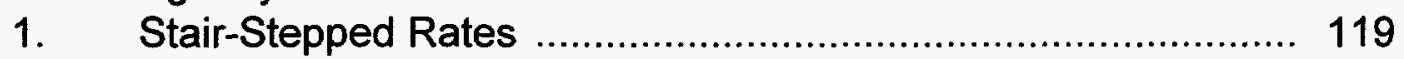

2. Low Density Discount ......................................................... 120

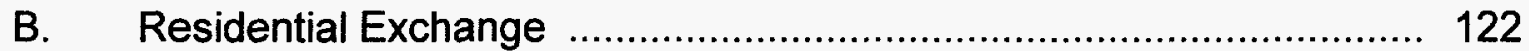

C. IOU Residential and Small Farm Loads ........................................ 123

D. Direct Service Industries ........................................................ 127

E. General Transfer Agreements (GTAs) ........................................ 129

F. Conservation and Renewables ............................................... 136

G. Indexed Cost-Based Rates ........................................................ 146 


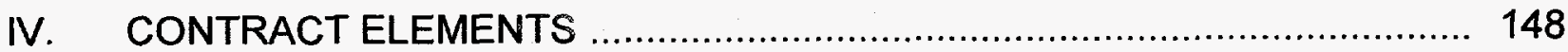

A. Bilateral Contract Negotiations ................................................ 148

B. Standard Contract Provisions .................................................... 149

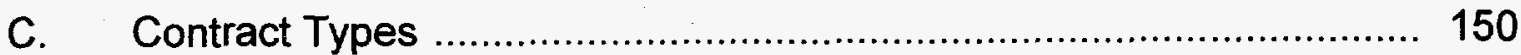

D. Contract Length ..................................................................... 151

E. Future Price Guarantees .......................................................... 154

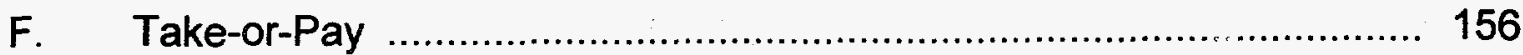

G. Contract Mitigation Measures .................................................... 158

1. Conversion to Excess Federal Power .................................... 158

2. Walled-Off Loads ........................................................... 160

H. Product Mitigation Measures ..................................................... 161

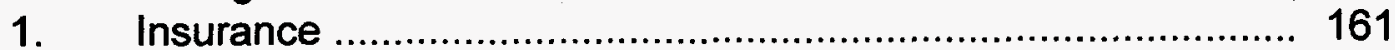

2. Remarketing .............................................................. 162

I. Customer Pooling of Requirements Purchases ............................. 163

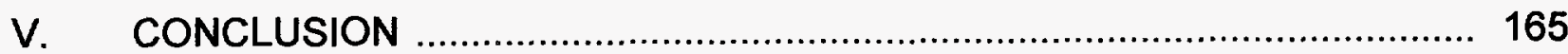

\section{APPENDIX}

A LIST OF COMMENTERS 


\section{COMMENTERS CITED IN THE ROD}

\section{Abbreviation}

EWEB

Springfield

PGE

PPC

Snohomish

Puget

PNGC

ORECA

Litchfield

KPUD

WPAG

McMinnville

Grant

OURCA

Port Angeles

Douglas

Surprise Valley

Clallam

SMUD

MPC

IPC

ICUA

Seattle

PGP

WRECA

WWP

Sumas

Grays Harbor

NRU

PRM

Central Lincoln

[N/A]

Benton REA

Kootenai

Canby

Lower Valley

Tanner

WMG\&T

\section{Commenters' Full Names}

Eugene Water and Electric Board

Springfield Utility Board

Portland General Electric

Public Power Council

Snohomish County PUD

Puget Sound Energy

Pacific Northwest Generating Cooperative

Oregon Rural Electric Cooperatives Assn.

Jim Litchfield, consultant to the IOU

Klickitat Public Utility District

Western Public Agencies Group

McMinnville Water and Light

Grant County PUD

Oregon Utility Resource Coordination Assn.

City of Port Angeles

Douglas Electric Cooperative

Surprise Valley Electric Cooperative

Clallam County PUD

Sacramento Municipal Utility District

Montana Power Company

Idaho Power Company

Idaho Cooperative Utilities Assn.

Seattle City Light

Public Generating Pool

WA Rural Electric Cooperative Assn.

Washington Water Power

City of Sumas

Grays Harbor PUD

Northwest Requirements Utilities

Power Resource Managers

Central Lincoln PUD

Benton PUD

Benton Rural Electric Assn.

Kootenai Electric Cooperative

Canby Utility Board

Lower Valley Power \& Light

Tanner Electric Cooperative

Western Montana Generation \& Transmission Cooperative 
Northern Wasco

Wells

Big Bend

Mundorf

Clark

OMEU

Tillamook
Northern Wasco PUD

Wells Rural Electric Cooperative

Big Bend Rural Electric Cooperative

Terry Mundorf, representative for WPAG

Clark Public Utilities

Oregon Municipal Electric Utilities

Tillamook County PUD

Native American Tribes

Shoshone-Bannock

Shoshone-Bannock Tribe

Spokanes

Makah

Spokane Tribe of Indians

CRITFC Makah Tribal Council

Columbia River Inter-Tribal Fish Commission

\section{Direct Service Industrial Customers}

Murphy

Early

Reynolds

Reynolds

Alcoa

Port Townsend

Vanalco

Kaiser

Elf Atochem
Paul Murphy, representative for Direct Service Industries Michael Early, representative for Direct Service Industries Steve Waddington, Reynolds Metals Company

Reynolds Metals Company

Aluminum Company of America

Port Townsend Paper

Vanalco

Kaiser Aluminum Company

Elf Atochem North America, Inc.

Public Interest/Electric Consumer Groups

NWEC

CUB

Northwest Energy Coalition

NRDC

Citizens Utility Board

[N/A]

Natural Resources Defense Council

[N/A]

Sierra Club

SEAO

Friends of the Earth

RNP

URP

Solar Energy Assn. of Oregon

IIPA

Renewables Northwest Project

Utility Reform Project

PNWA

ICNU

Idaho Irrigation Pumpers Assn.

Georgia Pacific

NW Alloys

Pacific Northwest Waterways Assn.

Industrial Customers of Northwest Utilities

Georgia Pacific Company

Northwest Alloys, Inc. 
States

[N/A]

Kitzhaber

Gov. of Montana

[NRA]

State PUTs

OPUS

[NRA]

[N/A]

Benton

WACTED
Attorney General of Washington

Oregon Governor, John Kitzhaber

Office of the Montana Governor

Office of the Idaho Governor

Four State Public Utility Commissions (OR, WA, ID, MT)

Oregon Public Utility Commission

League of Oregon Cities

Montana League of Cities and Towns

City of Renton

Washington Dept. of Commerce, Trade \& Economics

v 


\section{INTRODUCTION - SHARING THE BENEFITS}

The Bonneville Power Administration (BPA) has decided to adopt a Power Subscription Strategy for entering into new power sales contracts with its Pacific Northwest customers. The Strategy equitably distributes the electric power generated by the Federal Columbia River Power System (FCRPS) within the framework of existing law. The Power Subscription Strategy addresses the availability of power; describes power products; lays out strategies for pricing, including risk management; and discusses contract elements. In proceeding with this Subscription Strategy, BPA is guided by and committed to the Fish and Wildlife Funding Principles for the BPA announced by the Vice President of the United States in September 1998.

This Record of Decision (ROD) addresses the issues raised by commenters who responded to BPA's Power Subscription Strategy Proposal during and after the comment period that began with the release of the Proposal on September 18, 1998. The ROD is organized in approximately the same way as the Proposal and the Power Subscription Strategy that BPA developed based on the comments received. Abbreviations of party names used in citations appear in the section just preceding this introduction; a list of all the commenters follows the text of the ROD.

\section{PUBLIC PROCESS}

Public process is integral to BPA's decisionmaking. With the changing marketplace for electric power, there is considerable regional interest in defining how and to whom the region's Federal power should be sold. The public has been involved at several levels during the development of BPA's Power Subscription Strategy. In addition to the public meetings held specifically on Subscription, BPA sought input from a wide range of interested and affected groups and individuals. BPA collaborated with Northwest Tribes, interest groups, Congressional members, the Department of Energy (DOE), the Administration, and BPA's customers to resolve issues, understand commercial interests, and develop strong business relationships.

The concept of power Subscription came from the Comprehensive Review of the Northwest Energy System, which was convened by the governors of Idaho, Montana, Oregon, and Washington to assist the Northwest through the transition to competitive electricity markets. The goal of the review was to develop recommendations for changes in the region's electric utility industry through an open public process involving a broad cross-section of regional interests. In December 1996, after over a year of intense study, the Comprehensive Review Steering Committee released its Final Report. 
The Final Report recommended that BPA capture and deliver the low-cost benefits of the Federal hydropower system to Northwest energy customers through a Subscription-based power sales approach. Consistent with the new competitiveness in the electricity market, the goals for Federal power marketing were to: align the benefits and risks of access to Federal power; ensure BPA's repayment of the debt to the U.S. Treasury (Treasury); deliver the low-cost benefits of the Federal hydropower system to Northwest energy customers; and retain the long-term benefits of the system for the region. In early 1997, the Governor's representatives formed a Transition Board to monitor, guide, and evaluate progress on these recommendations.

In early 1997, BPA and the Pacific Northwest Utilities Conference Committee (PNUCC) invited 2800 interested parties throughout the Pacific Northwest to help further define Subscription. The collaborative effort to design a Subscription contract process began with a public kickoff meeting on March 11, 1997. At this meeting, a BPAcustomer design team presented a proposed work plan, including a description of the environmental coverage for Subscription. An important element of the work plan was the formation of a Subscription Work Group. The Work Group, which normally met in Portland twice a month from March 1997 through September 1998, was open to the public. On average, 40-45 participants--representing customers, customer associations, Tribes, State governments, public interest groups, and BPA--attended. Three subgroups formed to more intensely pursue the resolution of issues involving business relationships, products and services, and implementation.

Over the past 18 months, BPA, its customers and other interested parties have discussed and clarified many Subscription issues. During this time, BPA and the public confirmed goals, defined issues, developed an implementation process for offering Subscription, and developed proposed product and pricing principles. What follows is a chronology of events.

On March 11, 1997, a public meeting was held in Portland to kick off the Federal Power Marketing Subscription development process. The following topics were discussed at this meeting: the role of the Regional Review Transition Board in the Subscription process; the Draft Work Plan that was developed to guide the development process; the issues that relate to the Subscription process that need to be addressed; and the National Environmental Policy Act (NEPA) strategy for this effort. The Work Plan identified a "self-selected" work group to lead this effort (anyone eligible to participate).

On March 18, 1997, a "Federal Power Marketing Subscription" web site was established at BPA to help disseminate information about the Subscription Process.

On March 19, 1997, the Federal Power Subscription Work Group held its first meeting in Portland, Oregon. The Work Group held a total of 33 meetings (approximately two per month), ending on September 22, 1998. 
On September 9, 1997, a Progress Report was presented to the Transition Board.

On November 25, 1997, an update meeting for stakeholders was held in Spokane to discuss progress to date and next steps. A summary of the meeting, along with the meeting handout/slide presentation and concerns/issues raised, was posted to the web site.

In January 1998, an article entitled "Subscription Process Underway" was published in the BPA Journal.

On April 30, 1998, BPA's Power Business Line (PBL) established a web site to disseminate information about a customer group's Slice of the System Proposal. The Slice proposal was evaluated by the Subscription Work Group, and the proposal as modified by BPA is continuing to be developed in a subgroup through January 1999. BPA's pricing of the Slice product will be part of BPA's initial power rates proposal, to be published early in 1999.

In June 1998, as part of the Issues '98 process, BPA published Issues '98 Fact Sheet \#3: Power Markets, Revenues, and Subscription. The fact sheet discussed implementation approaches being considered by the Subscription Work Group so participants in the Issues ' 98 process could comment. As part of Issues ' 98 BPA conducted a series of meetings around the region. Issues related to Subscription were key topics in the discussions at those meetings. The public comment period for Issues '98 closed June 26, 1998.

On June 8, 1998, BPA's PBL established a web site to disseminate information about development of the power rates that will be used in the Subscription contracts beginning October 1,2001 . Development of the power rates is occurring in a series of informal public meetings and will continue in workshops before the initial proposal is published in early 1999 .

On June 18, 1998, the third Subscription public meeting was held in Spokane to present, discuss, and collect comments on the various components related to Subscription. The meeting slide presentation and summary of the meeting were posted to the web site.

On September 18, 1998, BPA released its Power Subscription Strategy Proposal for public comment. Accompanying the proposal was a press release entitled "Spreading Federal Power Benefits" and a Keeping Current publication entitled "Getting Power to the People of the Northwest, BPA's Power Subscription Proposal for the 21st Century." On September 25th, an electronic version of the BPA Power Product Catalog was posted to the web site. 
On September 22, 1998, the Federal Power Subscription Work Group held its final meeting in Portland, Oregon.

Subscription issues were discussed at the "Columbia River Power and Benefits" conference on September 29, 1998, in Portland, Oregon. Over 250 people attended. Conference notes were posted to BPA's web site.

On September 30,1998, BPA's Energy Efficiency organization established a web site to help disseminate information on the proposal for a Conservation and Renewables Discount. Development of the discount is continuing in a series of meetings through January 1999. Development of the discount will be part of BPA's initial power rate proposal in early 1999.

The public was invited to participate in two comment meetings on the Subscription Proposal, one in Spokane, Washington, on October 8, 1998; the other in Portland, Oregon, on October 14.

BPA developed the Power Subscription Strategy Proposal after considering the efforts of the Subscription Work Group, public comments on Subscription, and the broad information from Issues '98. The Proposal incorporated the information received from customers, Tribes, fish and wildlife interest groups, industries and other constituents. It laid out BPA's strategy for retaining the benefits of the FCRPS for the Pacific Northwest after 2001. The comment period on the proposal closed October 23, 1998, although all comments received after that date were considered in this ROD and the NEPA ROD.

\section{SUMMARY OF KEY ISSUES AND CONCERNS}

BPA received over 200 separate written comments from Tribes, States, utilities, industries, public interest groups, and citizens. Most of the comments presented at the two public meetings were followed with formal written comments. Comments on BPA's Power Subscription Strategy Proposal totaled almost 600 pages. In general, comments were readily grouped by customer class or interest group. Many comments expressed concern over BPA's proposed risk management strategy, especially the potential level of financial reserves and the use of such reserves. Many comments voiced concern about the details of a Cost Recovery Adjustment Clause (CRAC), including the levels and disposition of cash reserves. Also, many comments encouraged BPA to extend the Subscription "window" for three to six months beyond the final rate decisions.

\section{RELATIONSHIP TO OTHER PROCESSES}

Public input on BPA's Power Subscription Strategy Proposal revealed regional interest in several other key issues, notably future fish and wildlife funding and the 1999 Power 
Rate Case, facing BPA and the region. The tiered ROD strategy described in BPA's Business Plan Environmental Impact Statement (BP EIS) (DOE/EIS-0183, June 1995) and the Business Plan Record of Decision (BP ROD), issued August 1995, supports the power contract Subscription process being conducted simultaneously with other processes on these key issues. As anticipated in the BP EIS analysis, BPA has confirmed that prospective customers are not waiting until 2001 to arrange their $21^{\text {st }}$ century power supply (BP EIS, sec. 1.1 and BP ROD, p. 2). Instead, many are looking for sellers who can offer them low, stable, long-term rates now. By offering competitively priced power in a timely fashion, BPA will be able to retain customers and their corresponding revenue. Without sufficient revenue, BPA will be unable to guarantee full funding for its many responsibilities, including conservation, fish and wildlife projects and renewable energy programs (BP EIS, sec. 2.6.1).

BPA's multi-faceted business is complex. To help ensure its success, BPA decided to embark simultaneously upon independent processes addressing these key issues. While power contract negotiators would benefit from absolute knowledge of all future program costs, and program implementers would benefit from absolute knowledge of BPA's future revenue, the realities of a competitive marketplace often preclude waiting for such comprehensive information. To carry out its public responsibilities within a competitive marketplace, BPA must have the freedom to define the scope of individual business decisions without having to resolve all of the region's power supply and fish and wildlife problems at once.

BPA understands the extensive regional interest and concerns regarding future fish and wildlife funding. The Fish and Wildlife Funding Principles were announced by Vice-President Gore on September 21, 1998. The announcement of the Principles followed a process that began in November 1997 and continued until early September of 1998 . This public process included over 60 meetings with concerned citizens, Tribes, State and Federal agencies, BPA customers, and public interest groups. The preamble to the Principles states that the purpose "of these principles is to conclude the fish and wildlife funding process in which BPA has been engaged with various interests in the Region, and provide a set of guidelines for structuring BPA's Subscription and power rate processes. The principles are intended to 'keep the options open' for future fish and wildlife decisions that are anticipated to be made in late 1999 on possible reconfiguration of the hydrosystem and in early 2000 on the Northwest Power Planning Council's (NWPPC) Fish and Wildlife Program."

BPA has examined the issues of fish and wildlife funding under different business conditions and the possible mechanisms to respond to those different outcomes (BP EIS, sec. 2.4.5 and 2.5). Therefore, BPA is well prepared to make separate individual business decisions such as a Power Subscription Strategy and the 1999 Power Rate Case that complement one another and are guided by the Fish and Wildlife Funding Principles. 
Proceeding with the Power Subscription Strategy is vital to providing BPA with the financial predictability and stability it needs to compete in a deregulated wholesale electric marketplace. As explained in detail in the BP EIS and the System Operation Review (SOR) EIS (DOE/EIS-0170, February 1995), BPA will meet its contractual obligations and market its power and services with available resources consistent with the operating constraints that apply to the hydrosystem. (BP EIS, sec. 1.5.6 and $B P R O D, p .4)$. Additionally, the BP EIS details various response strategies designed to address any financial imbalance due to revenue shortfall as a result of unanticipated expenditures (BP EIS, sec. 2.5 and BP ROD, p. 13-14). In circumstances with unforeseen costs or revenue shortfalls, BPA could implement one or more of the response strategies to allow the Agency to continue to compete in the electric utility market and fulfill its responsibilities. The Risk Management Strategy described in the Power Subscription Strategy is consistent with the response strategies discussed in the BP EIS.

During the past year, BPA has worked with interest groups, other agencies, and customers to understand how BPA will address the uncertainty of future fish and wildlife costs in future rates and contracts. BPA is committed to meeting the Fish and Wildlife Funding Principles presented in September 1998. The Subscription process and the power rate proposal are the major means for meeting BPA's commitment. BPA concludes, based on analyses to date, that the Power Subscription Strategy is consistent with the Fish and Wildlife Funding Principles. This conclusion is subject to further test in the Power Rate Case, where the majority of fish and wildlife principle implementation will take place, and adjustments may be made in BPA's implementation methods if necessary.

The Power Subscription Strategy describes BPA decisions on a number of issues. These include the availability of Federal power, the approach BPA will use in selling power by contract with its customers, the products from which customers can choose, and frameworks for pricing and contracts. The Power Subscription Strategy discusses some issues that will not be finally decided in the Strategy. Most of these issues will be finally decided in the 1999 Power Rate Case (also known as the section 7(i) process), although some will be decided in other forums, such as the Transmission Rate Case, which will be concluded before October 2001. For example, while the Strategy documents BPA's intention to implement a rate discount for conservation and renewables resources, the final design of that discount will be decided in the 1999 Power Rate Case. Customers have raised issues regarding the application of other customers non-Federal resources to serve regional load. These resource issues involve factual determinations under section 3(d) of the Act of August 31, 1964, P.L. 88-552, and section 9(c) of the Northwest Power Act, which BPA cannot and has not made a part of the decisions in this ROD. Other issues that will be decided in the 1999 Power Rate Case include the design and application of the CRAC, which rates apply to which sales, and the design of the Low Density Discount (LDD). 
While BPA's Power Subscription Strategy does not establish any rates or rate designs, rate design approaches identified in the Power Subscription Strategy will be part of BPA's initial power rate proposal, which is expected to be published in early 1999. The comments received during the Subscription public process regarding the various rate-related issues will be addressed in the Power Rate Case, which includes extensive opportunities for public involvement.

The Power Subscription Strategy will provide a framework for the 1999 Power Rate Case and Subscription power sales contract negotiations. The Subscription window will remain open 120 days after the Power Rates ROD is signed by the BPA Administrator, providing relatively certain information to potential purchasers regarding rates.

\section{BPA'S POWER SUBSCRIPTION STRATEGY}

The Power Subscription Strategy is BPA's decision on equitably distributing to its customers the electric power generated by the FCRPS, within the framework of existing law. The Strategy outlines the overall process for implementing Federal Power sales Subscription contracts and provides a policy framework for the 1999 Power Rate Case. The Power Subscription Strategy, which provides a comprehensive description of BPA's decision, is available as a separate document. The strategy is briefly summarized as follows.

The Strategy has four principal goals:

- Spread the benefits of the FCRPS as broadly as possible, with special attention given to the residential and rural customers of the region;

- Avoid rate increases through a creative and businesslike response to markets and additional aggressive cost reduction;

- Allow BPA to fulfill its fish and wildlife obligations while assuring a high probability of Treasury payment; and

- Provide market incentives for the development of conservation and renewables as part of a broader BPA leadership role in the regional effort to capture the value of these and other emerging technologies.

\section{Subscribing to Federal Power}

The power sales Subscription window will be open from February 1999 until 120 days after the ROD for the 1999 Power Rate Case is signed. BPA and its customers can bilaterally negotiate and execute power sales contracts at any time during this period. In determining customers' eligibility for net firm load requirements, BPA will apply its standards defining which entities qualify for service. BPA will consider the application 
of section 3(d) of P.L. 88-552 and section 9(c) of the Northwest Power Act. BPA also will review a customer's requests for service in light of any sales of non-Federal power, including power previously applied to loads in the region, for use outside the region. BPA may make this review on a case-by-case basis or in a public process after the power sales Subscription window opens. All contracts will be subject to the final rates established in the Rate Case. BPA proposes to develop rates for Subscription Core power products for the Federal fiscal year (FY) 2002-2006 rate period that are significantly below market and approximately equal for all customer groups.

All public and private utilities serving regional firm consumer load that are eligible under BPA statutes to purchase firm power from BPA may request a contract within the constraints of existing statutes. BPA plans to provide approximately 1800 average megawatts (aMW) worth of benefits for the residential and small farm consumers of investor-owned utilities (IOUs), while meeting all public agency net firm load requirements. BPA expects to be able to meet all direct-service industrial customer (DSI) loads that customers ask BPA to serve. BPA will meet its obligations with its existing Federal power system and, to the extent necessary, cost-effective power purchases consistent with BPA's overall rate and financial goals. BPA expects this plan to be successful. However, BPA also is working with its industrial customers on a variety of measures in the unlikely event that power costs or customer energy demands exceed expectations. These measures will allow BPA to achieve the objective of distributing the benefits of Federal power broadly in the region.

\section{Managing Financial Risk}

BPA's power products and services are based, in part, on the agency's risk management strategy, which must account for uncertainties in future hydro conditions, market prices, operating costs, and fish and wildlife funding. To ensure BPA recovers all of its costs, the agency will use a variety of risk management tools, described in the Strategy.

\section{Products and Services}

BPA will market three categories of products:

- Core Subscription Products - These products are available to customers who request net firm requirements load service to serve regional consumer load, and who accept constraints on their ability to shape their purchases from BPA for any reason other than following variations in consumer load. These undelivered products will be offered at BPA's posted rates.

- Customized Subscription Products - Customized products are available to customers who request net firm requirements load services to serve regional consumer load (Core Products) and who want additional flexibility to reshape 
their purchases from BPA in order to optimize their own resource operations. These products will have bilaterally negotiated pricing for all modifications to Core Products and any additional products and services customers wish to purchase. BPA anticipates that the price for customized products that differ substantially from the core products will be negotiated under the Firm Power Products and Services (FPS) rate schedule.

- Non-Subscription Products - This category broadly includes power products and services that BPA might sell to any customer in the wholesale marketplace. These products will have prices negotiated under BPA's FPS rate schedule within the cost-based cap existing for that rate schedule. For detailed product descriptions, refer to the BPA Power Products Catalog available from BPA account executives or on the PBL web site.

BPA will offer another product, called Slice of the System. The Slice of the System is a net firm requirements load service that includes sales of surplus products. Slice will be offered by contract to public agency customers and priced by a formula to be developed during the Power Rate Case. The final details of this product will be developed through an open process that will be concluded before the end of January 1999. Slice will allow eligible public agency customers to pay a fixed percentage of BPA's costs in return for power based on a fixed percentage of the capability of the FCRPS, and mapped to the customer's net firm requirements load. See ROD section II.C.

\section{Pricing}

BPA intends to propose power rates for Core Subscription products for the 2002-2006 rate period that are significantly below market and approximately equal for all customer groups. Final pricing decisions will be made in the power rate section 7(i) process in 1999. Pricing issues are discussed in ROD section III.

- Subscription power sales (i.e., power contracts signed during the Subscription window) to public agency customers will be at the Priority Firm Power (PF) rate. Subscription sales to IOUs and DSIs would be at applicable rates, which are expected to be approximately equivalent to the PF rate, subject to a section 7 (i) hearing and BPA meeting its statutory rate directives.

- Loads of preference customers that contract for services after the Subscription window will be served at the PF rate, with a targeted adjustment charge, through at least FY 2006. The targeted adjustment charge would recover the difference between the PF rate and the cost of the resources (power) BPA must acquire, if any, to serve the load. The targeted adjustment charge would be determined for each individual purchaser placing new load on BPA and would be applicable until those "new" loads can be reflected in BPA's next general rate adjustment. 
- The proposal for option fees has been dropped. Eligible customers who make long-term commitments to buy power will get a contractual guarantee of BPA's applicable lowest cost-based rates beyond FY 2006.

- BPA will continue the LDD, with minor modifications to be determined in the Power Rate Case, in a manner similar to current practice.

- BPA intends to continue existing General Transfer Agreement (GTA) service to customers for delivery of Federal power through the 2002-2006 rate period. This service will not be available to new preference customers or to existing preference customers for service territory expansions. BPA will attempt to negotiate extensions through 2006 for GTA agreements that expire during this time. If unsuccessful in this attempt, BPA will arrange for open access tariff transmission to replace GTAs for delivery of Federal power to GTA points of delivery. This delivery will be covered by power rates. The costs for delivery of non-Federal power to GTA points of delivery will not be covered by power rates.

- BPA has an important role in fostering and promoting the development of energy conservation and renewable resources in the Northwest. BPA plans to offer a 0.5 mill per kilowatthour Conservation and Renewables Rate Discount to utilities that voluntarily implement measures to develop energy conservation and renewable resources, up to a total of $\$ 30$ million per year. The discount will be dollar for dollar for the first $\$ 30$ million. BPA also is considering whether, if BPA's actual financial performance turns out to be substantially better than the rate case plan, BPA would offer an additional discount. The first $\$ 15$ million of a "dividend" distribution (see ROD section II.A.2.) would go to customers who carry out incremental conservation and renewable activities. To make it simple to administer, BPA plans to rely on a regional forum to propose measures that would qualify for the discount.

\section{Contract Elements}

BPA intends to conduct bilateral negotiations with each of its customers to develop a contract that establishes the specific business relationship between that customer and BPA. All contracts will contain some provisions that generally are non-negotiable, or required by statute, and consistent across all Subscription contracts. Contract issues are discussed in ROD section IV.

- BPA will provide various incentives for customers to choose among three-year contracts, five-year contracts, and contracts longer than five years.

- In limited circumstances, BPA would be willing to negotiate non-requirements surplus firm power contracts with small rural full service customers if they are inordinately affected by rate design changes. 
- Under Subscription contracts, customers bear the risk of losing load due to retail open access. BPA will offer several means to mitigate a customer's financial risk due to retail load loss.

- BPA will offer load growth coverage to public agency customers. Utilities whose loads grow due to annexations and have contracts before the close of the Subscription window will be served with net firm load requirements power at the PF rate. New large single loads (NLSL) will be served at the New Resources Firm Power rate. Public agency requests to BPA for additional service after the Subscription window closes will be subject to the special price and notice provisions described in the Pricing section, III.A.

- A new public utility that forms and is eligible for service under BPA's statutes and signs a Subscription contract within the Subscription window will be offered power at the PF rate for its load obligation, depending on BPA's determination pursuant to section 9(c) of the Northwest Power Act and excepting NLSLs. New tribal preference utilities, which are eligible for service under BPA's statutes, will be treated the same as other new public utilities.

- Under current statutory provisions, customers who purchase for their net firm power requirements load are not able to pool their power purchases with other customers' purchases. If new legislation affecting pooling is passed, BPA will consider modifying its contracts.

\section{SUBSCRIBING TO FEDERAL POWER}

Issue:

How long do customers have to Subscribe?

\section{Subscription Proposal:}

The Proposal calls for a Subscription window from November 15, 1998, through November 30, 1999. The Proposal stated that BPA might extend the window if the rate case ran longer than anticipated. 


\section{Parties' Comments:}

Both Eugene Water and Electric Board (EWEB) and Springfield Utility Board (Springfield) commented that BPA should delay the start of Subscription until all of BPA's product offerings are finalized. EWEB, SUB01-107; Springfield, SUB01-121.

BPA received several comments about when the Subscription window should close. These comments expressed a need for a guaranteed amount of time after rates are established to make informed decisions on BPA purchases. Most comments called on BPA to extend the window to a guaranteed length of six months after the rate case due to logistics. Portland General Electric (PGE), SUB01-071; Public Power Council (PPC), SUB01-097; Snohomish County PUD (Snohomish), SUB01-090; Pacific Northwest Generating Cooperative (PNGC), SUB01-086; Oregon Rural Electric Cooperatives Assn. (ORECA), SUB01-085; EWEB, SUB01-107; Litchfield, SUB01-053; Klickitat PUD (KPUD), SUB01-111; Springfield, SUB01-121. Western Public Agencies Group (WPAG) called for a full year after the rate case. WPAG, SUB01-073. In addition to these specific comments, the Shoshone-Bannock Tribes called for an additional six months to evaluate the proposal, and the Makah Tribe felt it needed 18 months to evaluate the proposal and get ready to act. Shoshone-Bannock, SUB01-119; Makah, SUB01-214.

\section{Evaluation and Decision:}

BPA plans to start Subscription in February 1999. Updated product descriptions are included in the Revised Version of the Product Catalog. The Revised Product Catalog reflects the recommendations for changes suggested by interested customers to date. Development of two products--Slice of the System and Actual Partial Service for Customers with Variable Resources--will continue through January 1999. BPA will be able to begin Subscription after those products are more fully defined.

While BPA will be available to discuss contracts with customers starting in February 1999, BPA is not anticipating that many customers will sign contracts early. Most customers have indicated that they would like to know the outcome of the rate case before they sign contracts. Customers have asked for, rather than an established end date, a guaranteed amount of time to make their decision after the rate case. BPA has recognized this concern and decided to provide a period of 120 days after BPA's rate case ROD. BPA has chosen not to propose a six-month period because of BPA's financial need to conclude Subscription early enough that it can seek alternative markets if power is still available. In addition, leaving the window open longer creates market exposure for BPA because BPA's established fixed price would be compared to constantly changing market information, creating opportunities for alternative suppliers and thereby creating financial risk for BPA. 
The Tribes' concern that they need more time should be somewhat alleviated by BPA's decision to, over time, make power available at a melded PF rate for new publics and tribal utilities. If the Tribes are not able to act during the Subscription window, they still can form a preference utility, qualify for BPA service, and garner future access to power at the applicable PF rate.

\section{Issue:}

How much power is available for Subscription? Should power be made available first to preference customers, then to IOUs, then to DSIs?

\section{Subscription Proposal:}

The Proposal estimated that about 6300 aMW of firm power would be available for Subscription, on an average annual basis for Federal FYs 2002-2006. The proposal estimated that public agencies might subscribe up to about $5500 \mathrm{aMW}$. IOUs or their successors would be assured access to the equivalent of $1500 \mathrm{aMW}$ of firm power. The proposal estimated that about 1000 aMW of firm power might be available for the DSIs and stated that BPA would offer 1000 aMW of interruptible power sales to the DSIs.

The Subscription Proposal stated that it retains not only public power preference but also regional preference. Further, it stated that BPA is committed to passing on the benefits of the Federal System to the residential and small farm customers of the region's IOUs. Also, it states that after meeting the power requests of public agency customers and IOUs, DSIs may execute firm power contracts for remaining firm power.

\section{Parties' Comments:}

Many public agencies and their representatives argue that the IOU residential load should have access to 1500 aMW of Federal power at a melded rate for the 2002-2006 rate period. They assert that this would be accomplished through the Subscription process by giving the public agencies first access to purchase Federal power, the IOU residential loads second access up to 1500 aMW, and the DSIs access to any remaining power. Northwest Requirements Utilities (NRU), SUB01-057; PPC, SUB01-097; Western Montana Generation \& Transmission Cooperative (WMG\&T), SUB01-099; Mundorf, SUB01-175.

Oregon Utility Resource Coordination Assn. (OURCA) and other public agencies argue that any power sale to the IOUs must comply with the public preference provisions of the Northwest Power Act. Further, any sales to the IOUs should not impact the public preference customers' first priority access rights to the Federal Base System (FBS). 
Grant County PUD (Grant), SUB01-058; Springfield, SUB01-121; OURCA, SUB01-116; Washington Rural Electric Cooperation Assn. (WRECA), SUB01-094; Benton PUD, SUB01-101.

IOUs, many customers of IOUs, and interest groups argue that BPA should ensure that the IOUs' needs are met before selling power to DSIs. Further, they argue that they should share equally in the benefits of low-cost Federal power regardless of whether they are served by public or private power producers. Oregon Public Utility Commission (OPUC), SUB01-004; Idaho Power Company (IPC), SUB01-023; Northwest Energy Coalition (NWEC), SUB01-114; Bellevue, SUB01-026; e.g., Smith, SUB01-034. The IOUs called for increased allocations of power at BPA's lowest cost-based rate for the residential and small farm loads of the IOUs. Montana Power Company (MPC), SUB01-062; Litchfield, SUB01-053; and Washington Water Power (MWP), SUB01-066.

The DSIs stated that they are troubled by BPA's apparent lack of commitment to selling firm power to the DSIs, who have been long-term customers of BPA. E.g., Murphy, SUB01-040; Early, SUB01-078. The DSIs stated that BPA should open the Subscription window to all customers at the same time and augment the FBS if necessary to provide them firm power sales. Id.

A number of preference customers, State public utility commissions (PUC) and Tribes argued that BPA's first obligation was to the loads of public bodies and cooperatives and the residential and small farm loads of IOUs. EWEB, SUB01-107; KPUD, SUB01-111; McMinnville Water and Light (McMinnville), SUB01-112; Grant, SUB01-058; OURCA, SUB01-116; Springfield, SUB01-121; City of Port Angeles (Port Angeles), SUB01-064; Douglas Electric Cooperative (Douglas), SUB01-181; ORECA, SUB01-085; Surprise Valley Electric Cooperative (Surprise Valley), SUB01-149; PNGC, SUB01-086; Clallam County PUD (Clallam), SUB01-150; Sacramento Municipal Utility District (SMUD), SUB01-088; Snohomish, SUB01-090; PPC, SUB01-097; State PUCs, SUB01-146; Shoshone-Bannock, SUB01-119; Spokane Tribal Business Council, SUB01-092; NWEC, SUB01-114; and Montana League of Cities and Towns, SUB01-082.

\section{Evaluation and Decision:}

The intent of BPA's Subscription Proposal was to assure that the benefits of the FCRPS are distributed as widely as possible throughout the region. The Proposal relied heavily on the advice contained in the report of the Comprehensive Review, aimed at keeping BPA's costs as low as possible while ensuring adequate funding for BPA's social responsibilities. The DSIs expressed the most dissatisfaction with BPA's Proposal and called on BPA to augment the system if necessary to meet their requests for power. The IOUs primarily requested an increase in the amount of power offered to the IOUs for their residential and small farm customers. The preference customers generally 
called for a removal of tiered rates and associated elements that they felt reduced the value of preference.

While parties argue that Federal power sold in Subscription should be provided first to preference customers, then to IOUs, and then to DSIs, BPA must implement its power sales in accordance with the provisions of the Northwest Power Act and other applicable law. Under the Northwest Power Act, BPA has a statutory obligation to meet the requirements loads of public agencies and cooperatives and has estimated the amount of obligations that such customers may request. BPA has stated it will meet the net firm loads of its preference customers. BPA also has an obligation to offer power to IOUs that request net firm load requirements service, as determined under section $5(b)(1)$ of the Act. BPA is required to give public bodies and cooperatives preference and priority in any disposition or sale of Federal power. BPA also has a statutory obligation to implement the Residential Exchange Program with utilities offering to sell power to BPA under section 5(c) of the Northwest Power Act. BPA's DSI customers do not have a statutory right to requirements power for their loads in the post-2001 period, although BPA may sell power to meet such loads if available. Power that is surplus to BPA's sections 5(b), (c), and (d) requirements obligations will be sold in accordance with public preference and regional preference.

BPA has heard from all of its current regional customers that they wish to buy some amount of Federal power, and it is only the negotiation of contracts that will permit BPA to understand what those requests are. To sequence the negotiation of contracts in the manner prcposed would potentially lead to unnecessary delays and administrative duplication of effort. Many parties will not execute contracts prior to seeing final rates, but commencing negotiations may help to solidify BPA's estimates of its power sales. BPA will commence negotiations of contracts with all customers and will offer power to its customers in a manner consistent with applicable public preference law.

BPA has looked for ways to address these concerns while maintaining the necessary regional balance of the proposal. One key change is that the Subscription Strategy recognizes the potential that BPA will do some limited (in duration and amount) augmentation of its current inventory. During the Subscription window, BPA will update its sales and inventory forecasts. BPA will maintain its flexibility to augment its inventory through economic purchases, keeping in mind two conditions. Augmentation is more likely to occur if BPA concludes that it is necessary to meet the Subscription requests being placed on BPA. In addition, BPA intends that such purchases be made in a way that allows BPA to meet its rate goal without assuming significant resource cost risk. The Subscription Strategy also eliminates differentiated rates for preference customers and increases the amount of power BPA will provide the IOUs for their residential and small farm customers. The Strategy states that BPA expects to be able to serve all DSI load placed on it. All customers can negotiate Subscription contracts for power at the applicable rates during the Subscription window. Specifics about these 
decisions are discussed elsewhere in this ROD. See, for example, section I.C. regarding augmentation for DSI loads. See also ROD section I.B.

\section{A. Serving Public Agency Loads}

Issue:

How will the load of public agency customers be served through Subscription?

\section{Subscription Proposal:}

Public agencies would be able to subscribe at the lowest cost-based PF rate for all load not currently being served by customers' generating resources, including long-term power purchase contracts, as of the release date of the final Subscription Strategy. They would be able to continue Residential Exchange transactions under section 5(c) of the Northwest Power Act at the PF Exchange rate, subject to in lieu transactions.

\section{Parties' Comments:}

Preference customers called on BPA to resist actions that would be perceived as eroding public preference rights. Many of these commenters cited option fees, take-or-pay requirements and tiered rates as BPA actions that would undermine the value of preference. Industrial Customers of Northwest Utilities (ICNU), SUB01-109; Seattle City Light (Seattle), SUB01-104; City of Sumas (Sumas), SUB01-105; Grays Harbor PUD (Grays Harbor), SUB01-108; NRU, SUB01-057; Central Lincoln PUD (Central Lincoln), SUB01-106; KPUD, SUB01-111; OURCA, SUB01-116; Grant, SUB01-058; Springfield, SUB01-121; Benton Rural Electric Assn. (Benton REA), SUB01-075; Kootenai Electric Cooperative (Kootenai), SUB01-060; Lower Valley Power \& Light (Lower Valley), SUB01-081; Port Angeles, SUB01-064; ORECA, SUB01-085; PNGC, SUB01-086; SMUD, SUB01-088; Snohomish, SUB01-090; Tanner Electric Cooperative (Tanner), SUB01-093; WRECA, SUB01-094; WMG\&T, SUB01-099; PPC, SUB01-097.

Some preference customers argued that the "use-it-or-lose-it" aspect of the Subscription Proposal for retaining PF(1) access would needlessly increase the amount of power sold to the publics and reduce the amount available for others. PPC, SUB01-097; WPAG, SUB01-073; PNGC, SUB01-086. The DSIs expressed concern that the Subscription Proposal encouraged public customers to subscribe for more power than they ordinarily would, thereby exacerbating BPA's over-Subscription problems. Murphy, SUB01-040.

Certain representatives of IOUs, States, and Tribes argued that the benefits of Federal power should receive the widest possible dispersal throughout the region within the 
limits of the Northwest Power Act and BPA's other enabling legislation. Litchfield, SUB01-053; Washington State Attorney General, SUB01-059; Spokane Tribal Business Council, SUB01-092.

One citizen argued that BPA should ignore preference rights and send power to the IOUs based on the proportional size of their regional load compared to the preference customers' regional load. Arnold, SUB01-159.

\section{Evaluation and Decision:}

Parties' comments generally supported BPA's proposal to provide power to preference customers for their net firm load requirements. BPA's Subscription Strategy makes a number of changes from the Proposal to address concerns expressed by preference customers about their preference rights. Option fees have been eliminated. BPA will not differentiate its rates into $\mathrm{PF}(1)$ and $\mathrm{PF}(2)$ but instead will rely on notice provisions and a targeted adjustment charge to the PF rate that will reflect any additional costs for serving new public utilities and load annexations that occur after the Subscription window, and BPA will assume more risk for retail access load loss. These changes also were designed to remove any incentive for preference customers to sign up for more power than they otherwise would in order to avoid losing future preference rights. Pricing, option fees, and take-or-pay issues are addressed in other sections of this ROD. BPA will consider the customer's firm resource declarations and changes to its resources or sales of its firm resources on the market in determining the customer's net firm requirements load.

\section{Public Agency Load Growth}

Issue:

Should BPA provide load growth service to public agency customers purchasing Full Service and Partial Service products in Subscription?

\section{Subscription Proposal:}

BPA would offer load growth coverage under the Full Service and Actual Partial Service products to all public agency customers under the same terms and conditions. BPA would determine the cost of providing this service and equitably recover these costs under the Full Service and Actual Partial Service products. 


\section{Parties' Comments:}

Many commenters stated that public power has a preference right to the lowest cost-based power to serve load growth. Northern Wasco PUD (Northern Wasco), SUB01-048; Clearwater Power Company (Clearwater), SUB01-049; NRU, SUB01-057; Port Angeles, SUB01-064; WPAG, SUB01-073; Tanner, SUB01-093; Wells Rural Electric Cooperative (Wells), SUB01-095; PPC, SUB01-193; Benton PUD, SUB01-101; Big Bend Rural Electric Cooperative (Big Bend), SUB01-141.

Some parties commented that if BPA changes the Load Shaping billing determinant to Load Variance, the pricing methodology calculation should remain consistent with the present rate charged under the Load Shaping billing determinant. NRU, SUB01-057; Benton PUD, SUB01-101; Big Bend, SUB01-141.

The PPC stated that the residential and small farm load rate of the IOUs (NR(1)) should be equal to the rate charged to publics for load growth. PPC, SUB01-193.

\section{Evaluation and Decision:}

BPA historically has met the increase in demand for electricity of its net firm load requirements customers. Current regional estimates of individual utility load growth range from less than 1 to 3 percent annually. Based upon this rate of "historical" demand BPA proposes to meet such load growth and, if necessary, acquire resources to meet load growth of customers purchasing either the Full Service or the Actual Partial Service products. The rate at which BPA serves load growth will be determined in the Power Rate Case. Load growth coverage will not be included in the product offered to customers purchasing under the Firm Power Block product or the Slice product. Should such customers want BPA to cover their load growth, they may acquire it under the FPS rate schedule.

Comments on BPA's proposal to change the Load Shaping billing determinant to Load Variance suggested that the pricing methodology calculation should remain consistent with the present rate charged under the Load Shaping billing determinant. NRU, SUB01-057; Benton PUD, SUB01-101; Big Bend, SUB01-141. BPA intends to propose in its initial rate proposal a Load Variance product to succeed the current Load Shaping product. This product will follow all the variations of a customer's load. BPA is considering, for customers purchasing the Load Variance product, having the billing determinant for the product be the customer's Total Retail Load. The actual increase in heavy load hour (HLH) and light load hour (LLH) energy would be charged the PF rate.

The PPC stated that the rate charged IOUs for their residential and small farm loads should be equal to the rate charged public agency customers for load growth. BPA's proposal for pricing power sold for the IOUs' residential and small farm loads is discussed in section III.C of the Strategy. 


\section{Public Agency Annexed Loads}

Issue:

How should existing public utilities with annexations be served under Subscription?

Subscription Proposal:

Public agency customers that acquire load through annexation and the load that had been served at PF(1) would continue to serve those loads at PF(1). Any other annexations would be served at PF(2)/NR(2). Loads that are being served at the $\mathrm{PF}(2) / \mathrm{NR}(2)$ rate would be served at that rate regardless of the serving entity, with one exception for new tribal utilities. NLSLs would be served at the NR(2) rate. IOU residential and small farm load receiving BPA power or other benefits, if annexed, would continue to receive its prorated share of power or financial benefit. BPA proposed to serve any post-Subscription public agency requests for additional requirements service at the $P F(2)$ rate, to reflect the cost of acquiring additional resources.

\section{Parties' Comments:}

Most public agencies expressed concern that to differentiate between future annexed loads and existing customer loads would lead to tiered rates, which they oppose.

(See ROD section III.A. for a full discussion of public comments on tiered rates.) They urged BPA to serve annexed load at a single melded PF rate, either immediately or after some notice provision. WPAG, SUB01-073; PPC, SUB01-097; NRU, SUB01-057; Utility Reform Project (URP), SUB01-120; Springfield, SUB01-121; Montana League of Cities and Towns, SUB01-082; the League of Oregon Cities, SUB01-037. Port Angeles suggested that BPA allow retail access load decreases and increases to be netted against each other. Port Angeles, SUB01-064.

\section{Evaluation and Decision:}

BPA has an obligation to meet the net firm load power needs of public agency customers pursuant to contracts under section 5(b) of the Northwest Power Act. The amount of power BPA is obligated to provide to an individual customer may increase as that customer's net power load requirements increase. BPA must meet these increases, and also must anticipate acquiring additional resources to do so. BPA believes it is reasonable to set a time period between now and the end of the Subscription window, when new contracts are being negotiated, to set BPA's load obligation for the subsequent rate period. This information is important to BPA's resource planning. It also is important to determine BPA's load obligation so that BPA's rates will be established to allow full recovery of BPA's costs. 
It is unreasonable to expect BPA to absorb the costs, after the Subscription window closes, of increases in load obligations due to independent utility decisions that affect BPA's load and resources. Utility load increases due to annexations are the result of utility decisions, and the utility may apply its own resources to its loads. BPA believes it is reasonable that such annexed load increases occurring after the close of Subscription be served according to the notice and rate treatment described in sections I.A. and III.A., allowing for recovery of new costs.

Therefore, BPA has decided that a public utility whose load grows due to annexations and that enter into contracts with BPA to serve such load before the close of the Subscription window will have access to net firm load requirements power at BPA's lowest-cost PF rate. Public agency requests to BPA for additional load service after the Subscription window closes will be subject to the price and notice provisions and the targeted adjustment charge explained in sections I.A. and III.A. Annexed loads that had been served with PF power will continue to be served at that rate, regardless of the serving entity. An increase in a public utility's load due to annexation that was previously residential or small farm load served by an IOU will continue to receive its prorated share of the power delivery or financial benefits during the interim notice period as if it had remained an IOU load.

\section{Serving the Load of a New Public Agency}

Issue:

How should new public utilities be served under Subscription?

\section{Subscription Proposal:}

A new public agency would be offered power at the PF(1) rate for an amount of its net firm requirements load service that was previously served by another preference customer at BPA's lowest cost-based rate (PF(1)). New publics also would be eligible for a proportional share of net firm requirement load service at the NR(1) rate and financial elements for any eligible IOU residential load it acquired. All other power needs it placed on BPA would be served at the PF(2) rate.

\section{Parties' Comments:}

Many customers and customer groups commented on the standing of new public agencies in Subscription. Some opined that access to power at the lowest cost-based rate should be limited to those able to form and sign contracts by the end of the Subscription window. PPC, SUB01-097; NRU, SUB01-057; Springfield, SUB01-121; WPAG, SUB01-073; Mundorf, SUB01-175. Others felt that access to power at the 
lowest cost-based rate should exist at any time for preference entities, old and new. League of Oregon Cities, SUB01-037; Montana League of Cities and Towns, SUB01-082; PNGC, SUB01-086; OURCA, SUB01-116; Power Resources Managers (PRM), SUB01-087; URP, SUB01-120; WMG\&T, SUB01-099. Most preference customers opposed any BPA proposal to tier the preference rates; hence they also commented that new public agencies should have access to net firm requirements load service at the same rate as existing public agencies. Snohomish stated that a tiered rate directed at new public utilities would deter the growth of public power. Snohomish, SUB01-090.

WPAG recommended that BPA serve new public agencies requesting service from BPA during the Subscription window at BPA's lowest cost-based rate. WPAG, SUB01-073; Mundorf, SUB01-175. They stated that loads of new publics brought to BPA after the close of the Subscription window should be served at the PF rate if adequate resources are available. Otherwise such loads should be served at a surplus rate reflecting the costs of resources acquired to serve such loads until the start of the next rate period. Id.

In general, the IOUs expressed support for BPA's proposal to establish tiered rates in order to maintain the benefits of the Federal System (for a complete discussion of public comments on tiered rates please see section III.A.).

\section{Evaluation and Decision:}

Section 5(b) of the Northwest Power Act requires BPA to offer a power sales contract to a qualified public agency customer whenever requested. It makes no difference if the public agency is newly formed or not. The rate at which Federal firm power is sold to public agencies under section 5(b) is established under section $7(b)(1)$ of the Northwest Power Act. Section 7(b)(1) provides for a rate or rates of general application to meet the general requirements of such customers. BPA will meet requests of its preference customers for section 5(b) net load power service by offering to sell firm power under the posted PF rate established under section 7(b) of the Act.

There was a general lack of support from the preference customer class to tier the PF rates. As discussed fully in section III.A., new public customers that are formed and qualify for service may enter into contracts with BPA during the Subscription window and will be offered firm net load power service at BPA's lowest cost-based PF rate. The amount of power public agencies will be eligible to purchase will depend on BPA's determination pursuant to section 9(c) of the Northwest Power Act. New public agencies making requests to BPA for service after the Subscription window closes will be subject to the notice and pricing provisions, including the targeted adjustment charge, explained in sections I.A. and III.A. Loads of new public agencies that previously were served with PF power will continue to be served at the PF rate during the interim notice period, regardless of the serving entity. New public agency load that 
is residential and small farm load previously served by an IOU will continue to receive, if applicable, a prorated share of the power delivery or financial benefits during the interim notice period as if it had remained an IOU load. NLSLs will be served at the NR rate.

\section{New Preference Tribal Utility}

Issue:

Should BPA give preference status to non-profit tribal electric cooperatives that are formed within reservation boundaries and serve their members?

\section{Subscription Proposal:}

The Proposal stated that a Northwest Tribe that formed a non-profit cooperative utility during the Subscription window would be eligible to purchase its general requirements for service to residential and small farm loads at the PF(1) rate. The loads of new tribal non-profit cooperative utilities that formed after Subscription ends would be treated the same as other new publics.

\section{Parties' Comments:}

The Spokane Tribe of Indians (Spokanes) expressed appreciation and support for the new preference tribal utility proposal, but opposed limiting the lowest cost-based power to residential and small farm consumers. Spokanes, SUB01-092. They suggest that tribal preference utilities also should be able to purchase lowest cost-based power for "governmental, educational, and commercial loads within reservation boundaries." Id.

The Shoshone-Bannock Tribes commented that Tribes should be eligible for rates below PF(1) that "reflects the intent of BPA to fulfill their Trust Responsibility to Tribes." Shoshone-Bannock, SUB01-119. They also commented that all Tribes within the Columbia and Snake River basins should be eligible to receive allocations of hydropower generated from the Federal dams on the Columbia and Snake River systems. Id. In addition, the Shoshone-Bannock Tribes pointed out a need for planning and technical assistance funding to prepare for the potential economic development opportunities inherent in such allocations. Id. The Makah Tribal Council commented that the Subscription timeframe was not long enough to allow them to analyze and evaluate their options. Makah, SUB01-214.

\section{Evaluation and Decision:}

The Shoshone-Bannock Tribes argue that a Tribe, if it forms an electric cooperative to provide service to its members at cost, should be able to purchase its power service 
from BPA at below the cost of the PF rate which otherwise would be applicable to the service. Such a proposal is problematic given BPA's statutory rate directives. Under section 7 of the Northwest Power Act, BPA's rates must be designed to fully recover all of BPA's costs of service. There is no provision in the Act for a rate discount for tribal utilities.

The suggestion that a Tribe should be able to receive an "allocation" of hydropower from Federal dams on the Columbia River ignores that BPA sells Federal power from its system for service to customers under its section $5(b)(1)$ requirements contracts. Such contracts are for sales of electric power from the full Federal System and not a specific type of Federal resource. By providing service to a properly formed electric cooperative of a Tribe that meets BPA's standards of service and is ready, willing, and able to take power service from BPA, BPA has fulfilled its obligations under Federal statute to sell power to an eligible customer.

The Spokanes' comment that BPA should be willing to sell to all of a Tribe's loads, not simply its residential and small farm loads, is correct. If a Tribe forms a cooperative and it is ready, willing, and able to take power, BPA would be willing to serve its net firm requirement loads, subject to BPA's determination pursuant to section 9 (c) of the Northwest Power Act. The price at which such service is provided will be the applicable rate or rates and charges established by BPA in its next rate case. What BPA was trying to convey in its Proposal was that service to the cooperative's retail residential and small farm consumers would be at BPA's lowest cost-based rate even if those retail loads had not previously received service from BPA, as in the instance of being served by an IOU.

The Makah Tribal Council believes that the proposal does not allow enough time for it to analyze and evaluate its options. BPA's Subscription window does not limit the Makah from forming an electric cooperative utility. BPA is willing to sell power to Tribal electric cooperative utilities whenever they form and have the ability to take and deliver the power.

New tribal electric cooperative utilities that are formed, qualify for service, and are eligible to buy within the Subscription period will have the same opportunities as other new public utilities. This decision makes BPA's lowest cost-based power available to all of the Tribes' loads, not just the residential and small farm loads as suggested in the Subscription Proposal. Overall, this is a better outcome for Tribes than BPA's original proposal. 


\section{Customer Resource Replacement}

Issue:

To what extent may customers dispose of firm resources currently used to serve firm requirements and replace such resources with purchases of firm power from BPA at its lowest cost-based rate?

\section{Subscription Proposal:}

BPA's Proposal stated that load(s) served by a customer's own resources or a customer's market purchases, and therefore not placed on BPA during the Subscription window, would not be eligible for future service at BPA's lowest cost-based rate. Such load would be served at $\mathrm{PF}(1)$ surcharge or the $\mathrm{PF}(2)$ rate.

\section{Parties' Comments:}

Snohomish and Clark Public Utilities (Clark) stated that BPA is reinterpreting section 5(b)(1) of the Northwest Power Act. Snohomish, SUB01-090; Clark, SUB01-077. These parties state that BPA proposes to blur the distinction between $5(b)(1)(A)$ and $5(b)(1)(B)$ resources and call on BPA to reverse its proposed policy. Id. WPAG argues that "[i]n computing net requirements for utilities, $5(b)(1)(A)$ and $(B)$ resources should be treated separately, and their capability should be subject to the adjustments recognized in the statute. Generating resources that came online after passage of the Regional Power Act and that have not been dedicated to load under a Regional Power Act contract should not be treated as 5(b)(1)(B) resources." WPAG, SUB01-073. PPC argues that "BPA should calculate customers' net requirements pursuant to law and eliminate the proposed improper treatment of customers' $5(\mathrm{~b})(1)(A)$ and $5(b)(1)(B)$ resources." PPC, SUB01-097.

\section{Evaluation and Decision:}

Preference customers uniformly opposed the idea that any returning load be served at other than BPA's lowest cost-based rate. They also stated that BPA was misinterpreting the Northwest Power Act as it applies to customer firm resources applied to customer firm load. BPA's treatment of customer resources currently serving load in the region and the net firm requirements load of the customer is consistent with the Northwest Power Act. Section 5(b)(1) provides that customer resources which have been applied to serve load of the customer are treated as "continuing to be so used" subject only to retirement, obsolescence, loss of the resource, loss of a contract right (for contract resources) and the Administrator's consent. This treatment applies to both $5(b)(1)(A)$ and $-(B)$ resources.

BPA therefore proposes to continue to interpret section 5(b) of the Northwest Power Act as BPA has done in the past; i.e., the Administrator must determine if a resource has 
been lost, retired or has become obsolete. For its regional loads which are served on the date of the Subscription Strategy by $5(b)(1)(A)$ resources and $5(b)(1)(B)$ generating resources or long-term power purchase contracts, , BPA service will be provided at the PF surcharge rate. The PF surcharge rate will reflect the cost of new resources that BPA anticipates will be needed to serve such loads. BPA also will review any sales of such resources by a customer under section 3(d) of P.L. 88-552 and section 9(c) of P.L. 96-501.

It should be noted that BPA's Subscription Strategy does not establish any rates or rate designs. The establishment of rates and use of rate design can be determined only in a formal rate hearing under section 7 (i) of the Northwest Power Act. The rate comments referenced above will be addressed in BPA's rate development process, which includes extensive opportunities for public involvement. While final rate design decisions are not being made in the Subscription Strategy, rate design approaches identified in the Subscription Strategy will be part of BPA's initial power rate proposal, which is expected to be published early in 1999.

\section{Surplus Firm Power Contracts}

Issue:

Should BPA be willing to negotiate surplus firm power contracts under the FPS rate schedule separate from Subscription to help mitigate inordinately severe rate impacts on certain customers because of rate design changes in BPA's upcoming rate case?

\section{Subscription Proposal:}

BPA's Proposal stated that certain groups of customers may be inordinately affected by rate design changes and have no ability to respond to these changes. The Proposal stated that BPA is willing to negotiate non-requirements surplus firm power contracts and other mechanisms to help mitigate rate design changes that negatively affect such customers inordinately more than other customer groups.

\section{Parties' Comments:}

NRU, comprised of 38 members, supports BPA's proposal to negotiate surplus firm contracts to mitigate the negative rate impacts on summer seasonal loads. NRU, SUB01-057. PNGC also expressed support for BPA's willingness to "mitigate" large cost shifts for small and rural systems. PNGC, SUB01-086. Benton PUD strongly supports "Surplus Firm contracts or other mechanisms" for summer seasonal loads. Benton PUD, SUB01-101. 
Kaiser Aluminum Company (Kaiser) opposes "special, below cost rates for customers adversely affect by cost-based rates." Kaiser, SUB01-096.

Northern Wasco commented that BPA's proposal to offer surplus firm power contracts to any subgroup of customers that may be inordinately impacted by the new rate design may be contrary to the Northwest Power Act. Northern Wasco, SUB01-048.

Northern Wasco stated that any special offer of power must be made to all public preference customers at equal price and with equal opportunity to participate. Id.

\section{Evaluation and Decision:}

Northern Wasco's comment that the offer of surplus firm power contracts would be inconsistent with the Northwest Power Act is based upon a misunderstanding of the Act. Under section $5(f)$ of the Act, if and to the extent that BPA has surplus firm power available in a seasonal period, such as early spring to summer, BPA is authorized to market that power. BPA will provide its customers the opportunity to purchase available surplus power in accordance with public preference and regional preference, which means that public utilities will have the first opportunity to buy such power. However, the Act does not specify to which preference customer(s) BPA must sell available surplus power. BPA has discretion as to which public utilities among its preference customers it may first offer the power. City of Santa Clara v. Andrus, 572 F.2d 660, 667 (9th Cir. 1978) (preference clause does not limit the Secretary of Energy discretion in marketing all power to a single public customer).

While Kaiser is concerned about possible effects of special sales to parties inordinately affected by rate design changes, as noted in more detail below, BPA proposes to make such sales available to only a limited group of customers. BPA expects the cost, if any, of sales to such customers to be quite low. BPA will consider the development of such contracts in a manner similar to the implementation of such contracts in the past.

When BPA proposed offering surplus power sales contracts under the FPS rate schedule to mitigate inordinate rate impacts on certain groups of customers, it anticipated certain rate design changes for the 2002-2006 rate period. In preliminary analyses the demand charge and summer seasonal rates were anticipated to increase significantly over 1996 rate levels; BPA was considering changing the demand billing determinant to be the coincidental peak of the customers' systems; and BPA was considering changing the LDD formula to reduce costs to BPA. Currently BPA anticipates the rate level and design changes to be smaller in magnitude than in those preliminary analyses, although they are subject to further refinement in BPA's Power Rate Case in 1999.

However, BPA's basic PF summer rates, particularly in May through July, are still anticipated to increase significantly. For the foregoing reasons, it is still appropriate to address the potential inordinate impact of rate design changes on utilities, but BPA will 
further limit the customers to whom these sales are made. BPA has decided to offer to negotiate FPS contracts with small rural full service customers with heavy irrigation load, if rate design changes have inordinate effects on these customers.

\section{B. Serving Residential and Small Farm Consumers of the IOUs}

\section{Residential Exchange Program}

Issue:

Should BPA negotiate new Residential Purchase and Sale Agreements (RPSAs)?

\section{Subscription Proposal:}

The Subscription Proposal states that because the RPSA that implement the Residential Exchange Program have been terminated or will terminate in 2001, new RPSAs must be negotiated for any utilities choosing to participate in the Residential Exchange Program after 2001.

\section{Parties' Comments:}

The IOUs argue that BPA should negotiate new RPSAs as soon as possible. Litchfield, SUB01-053; MPC, SUB01-062; Gov. of Montana, SUB01-068; IPC, SUB01-070; PGE, SUB01-071.

\section{Evaluation and Decision:}

As noted in BPA's Subscription Proposal, the RPSAs will terminate by 2001. BPA and exchanging utilities must negotiate new RPSAs before that time in order to permit future participation in the Residential Exchange Program. The date for negotiation of new RPSAs is not a part of BPA's Subscription Strategy but will be announced at a later time.

Issue:

Should the current Average System Cost (ASC) Methodology be revised?

\section{Subscription Proposal:}

The Subscription Proposal states that the current ASC Methodology will be used for any Residential Exchange forecasts. 


\section{Parties' Comments:}

The IOUs argue that BPA's negotiation of new RPSAs should address changes to the ASC Methodology, including the removal of the "temporary" exclusions of a past era. Litchfield, SUB01-053, MPC, SUB01-062; Gov. of Montana, SUB01-068; IPC, SUB01-070; PGE, SUB01-071. Lower Valley argues that the ASC Methodology should be revised to prevent IOUs from artificially increasing their ASC to increase exchange benefits. Lower Valley, SUB01-081. The DSIs argue that the ASC Methodology should be amended to provide certainty that the IOUs will receive durable financial benefits. Reynolds Metals Company (Reynolds), SUB01-039, SUB01-122; Murphy, SUB01-040.

\section{Evaluation and Decision:}

The Subscription Proposal did not include any proposal for a new ASC Methodology or a recommendation regarding revision of the current ASC Methodology. Changes to the ASC Methodology require a separate public process involving consultation with regional parties. Such a process would occur separately from the Subscription process. The Subscription Strategy does not propose and will not direct any changes to the ASC Methodology at this time.

Issue:

Should negative deemer account balances be paid off before participation in: (1) the Residential Exchange Program after 2001; and (2) Subscription purchases after 2001?

\section{Subscription Proposal:}

BPA's Subscription Proposal noted that utilities with negative account balances under previous RPSAs must pay BPA the full amount of their negative deemer account balances before being eligible to receive any benefits under the Residential Exchange Program after 2001. The Proposal also noted that BPA must make a determination, after receiving comments from the State PUCs, on whether negative deemer account balances should be paid off before participation in Subscription purchases.

\section{Parties' Comments:}

The IOUs argue that the decision on deemer accounts should not be addressed as singular issues but should be incorporated into future RPSA negotiations. Litchfield, SUB01-053, MPC, SUB01-062; Gov. of Montana, SUB01-068; IPC, SUB01-070; PGE, SUB01-071. PPC and WMG\&T argue that IOUs must reach agreement with BPA on the disposition of deemer balances before purchasing Subscription power. PPC, SUB01-097; WMG\&T, SUB01-099; WPAG, SUB01-073, Mundorf, SUB01-175.

Lower Valley argues that deemer balances must be taken into account before money is exchanged with the IOUs. Lower Valley, SUB01-081. WWP argues that it should not 
be required to pay off its deemer balance before participating in Subscription. WWP, SUB01-016. The DSIs argue that it would be inappropriate for the PUCs to determine whether an IOU with a negative deemer account balance should be eligible to purchase Subscription power without first paying off such balances. Murphy, SUB01-040.

\section{Evaluation and Decision:}

Two issues are presented regarding negative deemer balances accrued under the Residential Exchange Program. The first issue regards whether utilities must pay off their negative deemer account balances before participating in the traditional Residential Exchange Program after 2001. After reviewing the comments, it is well taken that the resolution of deemer balances is an issue that is best reviewed in the circumstances of the subsequent contractual agreements that implement the Residential Exchange Program. The Subscription Strategy need not resolve this issue. It must be noted, however, that the current RPSAs include a provision which states: "Upon termination of this agreement, any debit balance in such separate account shall not be a cash obligation of the Utility, but shall be carried forward to apply to any subsequent exchange by the Utility for the Jurisdiction under any new or succeeding agreement." It is therefore BPA's expectation that deemer account balances would be required to be paid off prior to renewed participation in the Residential Exchange Program.

Arguments that a particular utility might have not entered into the Residential Exchange Program, and therefore would have no deemer balance, if it had known that the ASC Methodology would be revised in 1984 are not compelling. The 1984 ASC Methodology was established by BPA and confirmed by the Federal Energy Regulatory Commission (FERC). The Methodology also was upheld on appeal in the United States Court of Appeals for the Ninth Circuit. Therefore, a utility's deemer balance is properly calculated based on the 1984 ASC Methodology. Indeed, BPA would be precluded from using any other Methodology in the calculation of deemer balances. The suggestion that the express language of the RPSA requiring the carryover of any deemer balances to the next exchange agreement was limited to the 1981 Methodology is refuted by the RPSA itself. Section VI of Exhibit C to the RPSA expressly provides for the amendment of the ASC Methodology, thereby establishing that the carryover of deemer balances would occur regardless of changes in the ASC Methodology. A utility also could terminate the RPSA under the provisions of section 9 of the RPSA in order to avoid accumulation of deemer balances. While BPA is not making a determination regarding deemer balances and subsequent participation in the Residential Exchange Program at this time, the foregoing discussion provides a proper context for future discussion of this issue.

A second issue concerns whether negative deemer account balances should be paid off before participation in the purchase of Subscription power for the period after 2001. BPA's Subscription Proposal provided for a settlement of the Residential Exchange 
Program based on the sale of requirements power and the payment of monetary amounts based on the difference between market and the NR(1) rate. With input from the State PUCs, BPA proposed to determine the relevance of the deemer balances to the amounts of Subscription power made available to individual IOUs under the settlement. The DSIs argue that it would be inappropriate for the PUCs to determine whether an IOU with a negative deemer account balance should be eligible to purchase Subscription power without first paying off such balances. Murphy, SUB01-040. The DSIs have misunderstood BPA's proposal. BPA did not suggest that the PUCs would have the decisionmaking authority to determine whether IOUs could purchase Subscription power without paying off deemer balances. This is a determination that only BPA can make. BPA proposed that the PUCs would determine what they believed was an appropriate resolution of negative deemer balances with regard to Subscription sales and advise BPA. As noted elsewhere, however, BPA will provide a separate comment process for all interested parties, including the State PUCs. In that process BPA will receive recommendations on the manner, if any, in which negative deemer balances should be considered in determining individual IOU Subscription amounts in the settlement of the Residential Exchange Program. BPA then will make a final decision.

In summary, BPA will determine the payment of negative deemer balances at the time BPA negotiates new RPSAs and prior to utilities' participation in the Residential Exchange Program after 2001. BPA will determine the effect of negative deemer balances, if any, on individual IOU Subscription amounts of power or dollars for settlement of the Residential Exchange Program after reviewing the comments of interested parties, including the State PUCs.

\section{Subscription Sales to IOUs for Residential Consumers}

Issue:

What is the proper manner for providing Subscription power to the IOUs?

\section{Subscription Proposal:}

The Subscription Proposal states that an IOU may continue participation in the Residential Exchange Program or may enter into a settlement of the Residential Exchange Program. Under a settlement, IOUs would be able to purchase a specified amount of power under Subscription for their residential and small farm consumers at the New Resources NR(1) rate, a rate approximately equivalent to the lowest-cost PF Preference $\mathrm{PF}(1)$ rate. 


\section{Parties' Comments:}

The DSIs argue that the objective of providing durable benefits to the residential and small farm customers of IOUs must be met by fixing the Residential Exchange and not by replacing the Residential Exchange with a direct sale to IOUs. Reynolds, SUB01-039, SUB01-122; Murphy, SUB01-040; Early, SUB01-078. They further argue that Congress never intended that the benefits of Federal power be provided to the residential and small farm consumers of IOUs by the direct and unreplaced sale of power for use by such consumers. Id.

\section{Evaluation and Decision:}

In their comments, the DSIs review the history of the Northwest Power Act. Murphy, SUB01-040. The DSIs argue that the Northwest Power Act was structured to allow BPA to achieve permanent load/resource balance. Id. BPA was authorized to meet the loads placed on it by regional utilities and the existing loads of its DSIs. Id. BPA was granted the authority to acquire resources and cost-effective conservation to meet these loads. Id. The DSIs also acknowledge, however, that while BPA was required to offer initial long-term contracts to its existing DSI customers, BPA was authorized, but not required, to continue to serve the DSI loads after that period. Id. The DSIs also note that both preference customers and IOUs have the ability to place their net firm requirements loads on BPA. Id.

The DSIs essentially dismiss the ability of IOUs to have significant amounts of net firm power requirements loads and conclude that BPA should limit any transactions for firm power sales to the IOUs to only section 5(c) exchanges or those that would not reduce power available for DSI loads. The DSI analysis, however, is flawed. As the DSIs correctly recognize, BPA has an obligation under section $5(\mathrm{~b})$ of the Northwest Power Act to meet the net firm power requirements loads of its preference and IOU customers. That obligation arises whenever a public or IOU utility requests service and does not already have a section 9 (b) power sales contract. While requirements loads can be placed on BPA by Pacific Northwest utilities, 16 U.S.C. $839 c(b)$, they are subject to other applicable provisions such as 9 (c). However, there is no corresponding statutory provision for the DSIs to place loads on BPA. Compare 16 U.S.C. $839 \mathrm{c}(\mathrm{d})$.

BPA has the authority to acquire resources to meet the firm load obligations placed on it under section 5(b) utility contracts and section 5(d) contracts. However, after the initial 20-year DSI contracts, there is no requirement to serve the DSIs and, therefore, no requirement to acquire power to meet such loads. Congress realized that the world might change after the initial 20 years of the Northwest Power Act. By making sales to DSIs discretionary for the period after the first 20 years, Congress provided BPA the ability to respond to changing circumstances, including, for example, circumstances where BPA might need its existing resources to meet its firm power requirements loads. 
While the Act permits BPA to offer contracts to meet the DSI loads, there is no requirement that it do so.

The DSIs argue that since passage of the Northwest Power Act, no IOUs have placed any requirements loads on BPA. Murphy, SUB01-040. This statement is inaccurate. While several IOUs have not placed firm load obligations upon BPA, instead applying their own non-Federal resources to their loads, others have placed firm requirements loads on BPA. For example, Puget Sound Power \& Light Company previously placed A net firm requirements load on BPA under its contract up until the early 1990s. PGE placed a net firm peaking load on BPA following the retirement of its Trojan nuclear powerplant in the 1990s. After arguing that the IOUs did not place requirements loads on BPA, the DSIs leap to the conclusion that the IOUs currently have no net firm load requirements that could be served by BPA under section 5(b) of the Northwest Power Act. This conclusion is inconsistent with the Act and depends upon each utility's loads and resources circumstance.

The DSIs ignore that the statutory test for whether a utility has a net firm power load requirement is not whether a utility previously placed requirements load on BPA, but rather whether the utility has firm consumer load in the region which exceeds its firm resources as defined under section 5(b) of the Northwest Power Act. When a utility requests service for its firm power load in the region, BPA determines whether there is a difference between BPA's forecast of the utility's regional consumer loads and the utility's firm resources applied to its regional load. BPA has the obligation to offer a contract for the sale of electric power to the utility to the extent the utility's firm load exceeds its firm resources, subject to other applicable provisions of BPA statutes.

Section 5(b)(1) of the Northwest Power Act expressly provides:

Whenever requested, the Administrator shall offer to sell to each requesting public body and cooperative ... . and to each requesting investor-owned utility electric power to meet the firm power load of such public body, cooperative or investor-owned utility in the Region to the extent that such firm power load exceeds

(A) the capability of such entity's firm peaking and energy resources used in the year prior to December 5,1980 , to serve its firm load in the region, and;

(B) such other resources as such entity determines, pursuant to contracts under this chapter, will be used to serve its firm load in the region.

16 U.S.C. $\S 839(c)(b)(1)$ (emphasis added).

BPA uses this formula, plus the application of other relevant provisions of the Act such as section $9(\mathrm{c})$, to determine an IOU's or a public utility's regional net firm load for which 
it will be eligible for BPA service. Each IOU's ability to take firm power load requirements service from BPA will depend upon its own loads and resources and any determination made under section 9 (c). Some IOUs may have only a small portion of their firm loads met by BPA, depending upon their firm resources applied to load.

BPA's Subscription Proposal acknowledges that an IOU may place a firm requirements load on BPA and provides for the sale of requirements power to the IOUs. However, BPA has not yet determined whether the power made available under Subscription to the IOUs in the settlement of the Residential Exchange Program should occur under sections 5(b), (c), or (f) of the Northwest Power Act, and under other statutory authority. BPA will make this determination after further discussions with interested parties.

The DSIs argue that BPA has recognized that its proposal to sell power to the IOUs irrespective of the existence of any net firm requirements load on the purchasing IOU's system can enable the export of low-cost resources outside the region. Murphy, SUB01-040. This argument misstates BPA's Subscription Proposal. BPA's Subscription Proposal never proposed to make sales to IOUs irrespective of the application of the section 5(b)(1) calculation of any IOU's net requirements or application of section 9(c). To the contrary, as noted above, BPA would determine the IOU'' net firm load requirements in order to make an offer of a firm requirements power sales contract. Furthermore, to the extent that the IOUs had net firm load requirements, such load would be in excess of the firm resources the IOU is applying to its load. Section 5(b)(1) treats customer firm resources, whether contract or generation resources. as continuing to be applied to load except for specific conditions. Instead of BPA's proposal enabling the export of low-cost resources outside the region, it does the contrary by counting on the continued application of such firm resources in calculating BPA's obligation to serve IOU loads. The Proposal is consistent with both the directives of sections 5(b) and 9(c) and BPA's other statutory directives regarding regional preference and the sale of surplus Federal power as replacement for non-Federal resources disposed by customers outside the Pacific Northwest. See 16 U.S.C. $839 \mathrm{f}(\mathrm{c})$; 16 U.S.C. $837 \mathrm{~b}(\mathrm{~d})$. However, any specific determination of a customer's net firm requirements load would depend upon facts which BPA has not reviewed as part of this process and proposal. BPA may address such specific customer resource findings in a general or case-by-case review of section 9(c). Again, BPA has not determined which statutory contract authorization will be used to effect the power sale component for settlement of the Residential Exchange Program, but BPA intends that its Strategy will benefit consumers and not transfer a windfall of benefits to IOU shareholders.

The DSIs believe that the IOUs' desire to purchase power from BPA under Subscription rests solely with the instability of benefits available under the Residential Exchange Program. Murphy, SUB01-040. The DSIs recommend that BPA address this concern directly by revising its approach to the Residential Exchange Program. Id. They argue that BPA could revise the current ASC Methodology to provide that each utility's ASC 
would remain unchanged for the entire 2002 to 2006 rate period and therefore the exchanging utilities would know their level of benefits and the benefits would not be subject to manipulation. Id.

In response to the DSIs' recommendation, BPA does not agree that the sole interest of the IOUs is the stability of Residential Exchange benefits. The IOUs have indicated an interest in purchases of Federal power. Furthermore, the Residential Exchange Program will continue to be offered by BPA in accordance with section 5(c) of the Northwest Power Act. The issue of stabilization of Residential Exchange benefits can be addressed in the public processes that deal with Residential Exchange issues. For example, the ASC Methodology referenced by the DSIs is not being revised in the Subscription process. A separate consultation proceeding is used for the development of the ASC Methodology. In the event that BPA conducts a proceeding to revise the ASC Methodology, the proposal raised by the DSIs could be considered in that process.

The DSIs argue that BPA could sell power directly to IOUs under in lieu transactions pursuant to section 5(c)(5) of the Northwest Power Act and replace the power to the extent needed for sale to other customers. Murphy, SUB01-040. BPA recognizes that BPA has the authority to sell power to IOUs under section 5(c)(5) of the Northwest Power Act. While this is not the method for sales of power to the lOUs contained in the Subscription Proposal, BPA has not precluded the use of this approach for Subscription power sales to the IOUs. Under the Northwest Power Act, there are a number of ways in which BPA can supply power to the IOUs. For example, BPA can make net firm load requirements sales to the IOUs under section $5(\mathrm{~b})$, as discussed above; BPA can make in lieu sales under section 5(c)(5); and BPA can make surplus sales under section 5(f). BPA also has the authority to sell power under the Bonneville Project Act and the Flood Control Act of 1944. BPA will ensure that any Subscription power sales to the IOUs are made in a manner consistent with BPA's governing statutes.

The DSIs also argue that several exchanging utilities are seeking authorization to sell resources currently meeting their residential loads that would then be served with market purchases. Early, SUB01-078. The DSIs note that the power market is volatile, while residential consumers require stable rates. Id. The DSIs believe that the proposal would transfer the obligation for providing rate stability for the residential loads from the IOUs to BPA, while this responsibility properly rests with the IOUs and their regulators. Id. This argument is difficult to understand. Under the Subscription Proposal, an IOU would receive specified amounts of power (within the utility's net firm requirements load) and a monetary payment. This would provide stability to the residential consumers in knowing what would be provided from BPA. The responsibility for rate stability for residential consumers would still rest with the IOUs and the PUCs.

In summary, BPA has the authority to sell power to the IOUs under sections $5(\mathrm{~b}), 5(\mathrm{c})$, and $5(f)$ of the Northwest Power Act, consistent with the provisions of these sections 
and other applicable sections such as 9(c), in addition to other statutory authority. BPA wishes to conduct further analysis of these power sale options and have further discussions with BPA's customers before establishing the particular manner in which BPA would make Subscription sales to the IOUs.

\section{Issue:}

Should BPA ensure that any resource freed up by Subscription will be offered to BPA, and if so, how?

\section{Subscription Proposal:}

The Subscription Proposal states that an important consideration in BPA's Proposal to sell firm power for service to residential and small farm customers of IOUs is that these sales not displace low-cost non-Federal resources currently serving regional loads, which then would be used to serve loads outside the region.

\section{Parties' Comments:}

The DSIs argue that the Subscription Proposal violates both regional preference and the prohibition against the resale of Federal power. Murphy, SUB01-040; Early, SUB01-078. They state that BPA's Proposal to sell to the lOUs irrespective of the existence of any net IOU requirements can enable the export of low-cost resources outside the region. Id. They say that this, in effect, constitutes the "arbitrage" of Federal power. Id.

The DSIs recommend that BPA should condition a direct sale to IOUs on a continuing offer by the IOU to sell to BPA, on a long- and short-term basis, an equivalent amount of power at the lower of the cost of specified IOU resources or at a predetermined strike-price as a surrogate for a market price. They state that "cost" and "market" will be determined in the rate case. Early, SUB01-078; Murphy, SUB01-098.

Public agencies, their representatives and DSIs commented that BPA should ensure that IOU generation resources freed up by BPA sales are sold in the Region, and possibly made available for BPA to purchase. They do not want displaced IOU resources sold outside the Region for profit. NRU, SUB01-057; Benton REA, SUB01-075, WRECA, SUB01-094; PPC, SUB01-097; Benton PUD, SUB01-101; McMinnville, SUB01-112; Murphy, SUB01-040; PRM, SUB01-087; Surprise Valley, SUB01-149. Springfield suggests that a BPA power sale to an IOU displaces the IOU's generation, which could be sold for a profit on the market. Springfield, SUB01-121. Cost liability for new resource additions to replace the existing FBS should be borne first by IOUs up to the amount of replacement, which equals IOU power purchases. Id. Springfield notes that to the degree an IOU divests itself of resources or structures, a retail access policy that would result in lower direct sales to residential and small farm 
customers, its ability to qualify to receive Exchange Benefits (including the "lease" power sale arrangement) should be reduced to the amount it is selling only to direct end-users. Id. PNGC states that section 9(c) of the Northwest Power Act addresses the issue of the IOUs selling their low-cost resources out of the region and should be used as a tool to prevent this from occurring. PNGC, SUB01-086.

The Office of the Governor of Montana argues that section 9(c) of the Northwest Power Act clearly provides the Administrator discretion on whether sales can be made to a non-Federal Pacific Northwest customer, even if the utility disposed of its generation outside the region. Gov. of Montana, SUB01-068.

The PUCs, Citizens Utility Board (CUB), and NWEC state that they fully expect the benefits of the freed up resources (either sold in or out of the region) to return to regional residential ratepayers. They argue that BPA has little authority to demand that the freed up assets be dealt with in a particular manner. State PUCs, SUB01-146; CUB, SUB01-103; NWEC, SUB01-114.

PRM states that if IOUs agree, under section 9(c) of the Northwest Power Act, not to export the output of their resources for sale to customers in states outside the Northwest, they could face serious liability under antitrust laws, which tend to frown on agreements in restraint in interstate commerce and trade. PRM, SUB01-087.

\section{Evaluation and Decision:}

Comments made in response to this proposal focus on the application and meaning of section 9(c) of the Northwest Power Act and section 3(d) of the Northwest Preference Act to the firm customer resources serving loads of BPA's Pacific Northwest customers. 16 U.S.C. $\$ 839 f(c) ; 16$ U.S.C. $\$ 837 \mathrm{~b}(\mathrm{~d})$. The primary concern is whether IOUs will begin exporting resources that have been used or currently serve their regional consumer loads, if BPA sells Federal power directly to the IOUs for their residential and small farm loads. In short, with BPA serving a portion of IOU loads, could IOUs pull resources off load service and sell them in the market? Section 9(c) of the Northwest Power Act requires BPA to make a determination of whether the disposition of a customer's resources outside of the region will result in an increase in the electric power requirements of that customer or any of BPA's other customers in the Pacific Northwest. If so, then BPA must also determine whether the resource could be conserved, kept available for use by the customer or otherwise retained in the region for service to regional load by reasonable means. If BPA's determination results in a finding that the disposition of a resource would result in an increase in BPA's power requirements, and the resource could have been conserved or otherwise retained to serve regional loads, then BPA must exclude from its firm power load obligations to that customer the amount of power and energy sold for the duration of the sale. Under section 3(d) of P.L. 88-552, a similar determination requirement is imposed on BPA regarding the sale and export of any customer's hydroelectric resources out of region. 
In both cases BPA may sell as replacement for any exported resource so excluded, only energy that would otherwise be surplus. These determinations are factual ones which are based on the specific circumstances of a customer's resources and loads.

In 1994, BPA adopted an interpretation of section 9(c) of the Northwest Power Act and section 3(d) of the Northwest Preference Act as part of its policy on Non-Federal Participation Capacity Ownership. BPA reviewed prior policies and interpretations under sections 9 (c) and 3(d) and further addressed section 9 (c) issues raised by non-Federal utility participation in the Third AC Intertie. BPA's current policy on sections 9 (c) and 3(d) does not address the issue of whether BPA should have the right to buy IOU resources displaced as a result of power sold to IOUs. BPA is not obligated to make such purchases of resources as the DSIs propose, but whether the resources are offered to BPA is one part of the factual determination BPA would make under those sections of statute. BPA has not made any specific determination of a customer's loads and resources in this ROD In light of the issues and concerns expressed in parties' comments but which are not issues included as part of the Subscription Strategy, BPA may consider its section 9(c) policy in the future.

The DSIs recommend that BPA condition the sale of firm power to any IOU for residential consumers on the IOUs' offer to sell BPA the power from IOU resources that is thereby freed up at a market-based price, which could be established by negotiation or based on BPA's estimate of market price used in the rate case. Murphy, SUB01-040. The DSIs argue that this would allow BPA to cap its purchase price exposure while it executed its Subscription sales, and BPA would purchase only the amount of power actually required to balance loads and resources. Id. The DSIs do not identify the statutory basis for this approach. While BPA could offer power with the condition noted by the DSIs, such a condition is not required under section 9 (c), $5(\mathrm{~b})$, or section 5(c) of the Northwest Power Act, and it might affect the marketability of the power sold by BPA. BPA, however, shares the DSIs' concern regarding any BPA sales that might facilitate the sale of low-cost IOU resources outside of the region. As stated above, section 9(c) of the Northwest Power Act addresses the consequences for sales of non-Federal resources that can or have served utility loads in the region.

The DSIs argue that BPA's Subscription Proposal is inadequate to address BPA's responsibilities for regional preference. Murphy, SUB01-098; Early, SUB01-078. The DSIs point out that although BPA's proposal acknowledges concern regarding regional preference, the Proposal is devoid of substantive provisions. BPA's Subscription Proposal was not intended to make substantive modifications in BPA's treatment of non-Federal utility resources that have been applied to load. BPA last addressed its policy on export or sales of such resources in 1994 in the ROD supporting BPA's policy on Non-Federal Participation Capacity Ownership. BPA may have to address further issues prior to making power sales, but here has only noted that issues may arise over some customer's firm resources. As BPA made clear in its section 9(c) policy, the section does not legally prevent any utility from exporting a non-Federal resource used 
to serve load. It simply calls for a set of factual determinations to be made in the event such a sale is made, and specifies a consequence depending upon the determination.

The DSIs assume that the IOUs have no net firm load requirements and, therefore, any sales to IOUs would displace resources currently serving the IOUs' loads. As noted previously, the DSIs' assumption is not correct, and BPA may have a statutory responsibility to meet a portion of the lOUs' net firm load requirements if requested to do so. Where the IOUs have an excess of firm regional loads over firm resources as calculated under section 5(b) of the Northwest Power Act, the IOUs would not necessarily displace their own resources for extraregional sale but may retain them or sell them to another regional BPA customer. The DSIs argue, however, that if BPA's sales were to displace IOU resources, then BPA may not treat the load served by the displaced resources as part of the utility's net firm requirements load if the resources are not sold to Northwest utilities for service to other regional loads. However, this is only one of the factual determinations that must be made under section 9(c) before BPA could reach the conclusion the DSIs seek.

The DSIs recommend two "concrete" steps that BPA can take to address this concern. Murphy, SUB01-098 at 3. First, whenever BPA offers to make a direct sale to an IOU or to sell power to a preference customer that would displace existing resources, BPA should require the utility customer to grant BPA an option to purchase an amount of power from the utility's resources equal to the new sale of Federal power by BPA at a price not exceeding the market price. If BPA decided not to purchase, the power would then be offered to other Pacific Northwest customers for loads not served by BPA and then to the remainder of the region. Murphy, SUB01-098 at 4; Early, SUB01-078. Second, BPA should clarify in its PF and IP rate schedules that these rates are available for the sale of surplus Federal power (e.g., secondary energy) to regional loads that requested Subscription service but did not receive a full allocation before such power is offered outside the region. Murphy, SUB01-098 at 4.

In response to the DSIs' recommended two-step approach to extraregional exports of regional resources, BPA has a section 9(c) policy to address a utility's exports of non-Federal firm resources based on the factual determinations required by law. This does not prevent the export of the non-Federal resource but may have the consequence of BPA reducing its firm power requirements obligation to the exporting utility if such an export results in an increase to BPA's firm power requirements obligation. BPA may sell as replacement for any amount of energy so excluded only energy that would otherwise be BPA surplus power. Whether or not any specific sale of non-Federal resources would cause such a result cannot be determined in the Subscription Strategy based on broad generalities, given that section 9 (c) specifies a set of factual determinations that must be made. Increased open competition on the wholesale level causes BPA to understand that the region faces issues regarding an IOU or other utility's sale of its resources. However, nothing in the Subscription Strategy or in contracts is intended to preclude BPA from carrying out the directives of 
section 9(c). In developing new Subscription contracts BPA will define a set of firm power load obligations of its customers to which section 9(c) will apply.

As to the proposed purchase of non-Federal resources by BPA as an option on how low-cost non-Federal resources may be retained for the benefit of Pacific Northwest loads, such an option could be beneficial and appropriate. One, but only one, aspect of the section 9(c) determination that would be made is whether BPA or another BPA customer could use the resource. Assumedly this approach would require a purchase or acquisition of the non-Federal resource by BPA or another regional customer after an offer by the utility. However, the issues that such a mechanism would entail are beyond the scope of the Subscription Strategy and ROD.

With regard to the pricing second step proposed by the DSIs, the use of the IP and PF rates for surplus power sales appears to be inconsistent with the Northwest Power Act. The PF rate is established for regional utilities' firm power requirements (and for the Residential Exchange Program) under section 5(b) of the Northwest Power Act. The IP rate is established for regional DSIs' firm power purchases under section 5(d) of the Act. The PF and IP rates therefore do not apply to sales of surplus Federal power. Rates for sales of surplus Federal power must be established under section $7(f)$ of the Northwest Power Act.

The DSIs argue that a direct sale to an IOU may transfer benefits to IOU sharehoiders because the purchase of power from BPA would replace an amount of IOU resources. Early, SUB01-078. The DSIs argue that if the IOU resource is sold outside the region, then the direct sale by BPA has circumvented regional preference. Id. Also, if the resource were low-cost, the sale would produce a profit. Id. The DSIs note that BPA does not address who would receive this profit. Id. The DSIs argue that BPA's failure to address these issues would allow the PUCs and IOUs to decide without any Federal guidance. Id. As noted above, the statutes applicable to a customer's sale of non-Federal resources outside the Pacific Northwest region do not prevent such sales of power. The statutes only prescribe a treatment for determining BPA's firm requirements load obligations to the customer making the export sales. BPA cannot stop the export of a utility's resources. BPA stated this interpretation in 1994 when BPA's public utility customers were seeking to export some 725 aMW of non-Federal resources. By defining its firm power load obligations to regional utility customers, BPA is not circumventing the directives of applicable statutes on extraregional sales of non-Federal resources. As far as the conveyance of any benefits from such a sale to ratepayers or to stockholders, that is an issue within the province of the State regulatory bodies and State legislatures. It is not a determination made by BPA. 
Issue:

If IOU resources are displaced and resold, will they comply with the prohibition on the resale of Federal power?

\section{Subscription Proposal:}

The Subscription Proposal states that the region needs to clarify how the benefits of low-cost, in-region, non-Federal resources are preserved to benefit regional residential and small farm ratepayers. Further, an important consideration in BPA's Proposal to sell power for service to residential and small farm customers of IOUs is that these sales not displace low-cost non-Federal resources currently serving regional loads and be used to serve loads outside the region.

\section{Parties' Comments:}

The DSIs argue that the Subscription Proposal as it is currently outlined violates both regional preference and the prohibition against the resale of Federal Power. Murphy, SUB01-098; Early, SUB01-078. They argue that the BPA Proposal to sell to the IOUs, irrespective of the existence of any net IOU requirements and without mechanisms such as the two-step approach they recommend, can enable the export of low-cost resources outside the region, which can result in an "arbitrage" of Federal power. Murphy, SUB01-098 at 4.

\section{Evaluation and Decision:}

The DSIs argue that BPA's proposal appears to directly violate the prohibition on resale of Federal power to IOUs. Murphy, SUB01-040. The DSIs argue that while characterized as a section 5(b) sale to the IOUs, BPA actually proposes to transfer to State PUCs the authority to dispose of the power to IOUs of the PUCs' choosing. Id. The DSIs argue that the PUCs, not BPA, would be disposing of Federal power to IOUs in violation of section 5 of the Bonneville Project Act. Id.

The foregoing arguments are founded on mischaracterizations of BPA's proposal or are based on misstatements of law. First, the DSIs' assertion that there is a prohibition on the resale of Federal power that applies to BPA's sale of firm power to IOU customers is confusing. If a sale of Federal power is made under section $5(b)(1)$ of the Northwest Power Act to an IOUs net firm requirements load in the region, then BPA's longstanding interpretation has been that such Federal power must be used to serve consumer load and not resold on the wholesale market. Sales under section $5(b)(1)$ create the "prohibition" the DSIs discuss and such sales do not contradict the requirement that the utility must use the power for its regional consumer load. Therefore the DSIs should support such sales. 
If the DSIs' concern is with the sale of non-Federal resources, then this issue has been addressed above in prior responses to comment. If the concern is that BPA, by entering into $5(b)(1)$ contracts with an $10 U$, is in violation of section 9(c) of the Northwest Power Act or section 3(d) of the Northwest Preference Act by making such a sale, then BPA has noted that: (1) specific factual determinations must be made before applying any reduction in obligations; and (2) having a firm load requirements sale contract in place creates the BPA obligation against which any such reduction would apply. Entering into contracts for the sale of power which permit modification of the obligations under the contract is not inconsistent with a determination of a reduction in those obligations if required by statute. However, BPA is unwilling to reach a conclusion that IOUs should not be offered contracts simply because actions later taken by a party, or a determination made later, may cause the obligations thereunder to change.

Furthermore, BPA's sales to IOUs would not constitute an arbitrage of Federal power. BPA's Subscription sale of power to IOUs, whether made pursuant to section 5 (b) or section 5(c) of the Northwest Power Act, must be used to meet Pacific Northwest loads. Sales pursuant to section $5($ b), by definition, must be used to meet "firm power load in the Region." 16 U.S.C. 839 c(b)(1). Sales pursuant to section 5 (c) are for sale to a utility's residential users within the region. 16 U.S.C. $839 c(c)(1)$. See also Bonneville Project Act, 16 U.S.C. 832; Flood Control Act of 1944, 16 U.S.C. 825s. Because the Federal power must be used for IOU customers' regional loads, it cannot be sold outside the region and there would not be an arbitrage of Federal power.

Finally, BPA's Subscription Proposal did not propose to transfer to State PUCs the authority to dispose of Federal power. Instead, with BPA remaining the ultimate decisionmaker, the Proposal suggested that, to the extent permitted by law, the State PUCs would determine what to suggest to BPA regarding the amounts of power that should be available for sale to individual IOUs in the Pacific Northwest. Given the misunderstanding of BPA's Proposal, BPA has clarified this section of BPA's Subscription Strategy. BPA proposes to take comments from all customers and interested parties regarding how available power should be sold to individual IOUs.

Issue:

Should IOUs settle their rights to participation in the Residential Exchange Program for the power and monetary payments identified in Subscription? Should additional benefits be offered for this purpose?

\section{Subscription Proposal:}

The Subscription Proposal suggests that IOUs settle their rights to the Residential Exchange Program by purchasing a specified amount of power under Subscription for 
their residential and small farm consumers at the New Resources NR(1) rate. Therefore, residential and small farm loads of the IOUs may receive benefits from the Federal System through one of two ways. An IOU may participate in the Residential Exchange Program or it may settle its rights to the Residential Exchange as identified in the Subscription Proposal.

\section{Parties' Comments:}

Idaho State government representatives commented that a commitment of $2200 \mathrm{aMW}$ for residential and small farm consumers who take service from IOUs amounts to a rationing of the BPA system to these citizens. They argue that this rationing concept appears to violate the Northwest Power Act. Idaho Senate, SUB01-051.

The PPC, WMG\&T, and OURCA argue that IOUs must forego their participation in the Residential Exchange under section 5(c) in order to participate in Subscription. PPC, SUB01-097; WMG\&T, SUB01-099; OURCA, SUB01-116. Further, public agencies and their representatives argue that the IOUs' participation in the current RPSA should be waived for a 10-year contract period. NRU, SUB01-057; Benton PUD, SUB01-077; Snohomish, SUB01-090; WRECA, SUB01-094; PPC, SUB01-097; Mundorf, SUB01-175; Springfield, SUB01-121.

The State PUCs state that IOUs could waive their rights to the Residential Exchange Program contingent upon BPA providing access to 1800 aMW of power for the 2002-2006 period and 2200 aMW of power for 2007-2011. The duration would be for the contract period. State PUCs, SUB01-146.

Litchfield notes that any waiver of exchange rights would be for the contract period that ensures benefits for residential and small farm consumers of IOUs. Litchfield, SUB01-053.

A few parties commented that BPA should make available additional exchange benefits to the remainder of the residential and small farm load not supplied by the Subscription benefits by: (1) allowing an IOU to exchange private power for public power as provided for in the Act; or (2) making dollar exchange benefits available. Idaho Senate, SUB01-051; Puget Sound Energy (Puget), SUB01-055; Idaho Irrigation Pumpers Assn. (IIPA), SUB01-056.

\section{Evaluation and Decision:}

The IOUs have a right to place their net firm power requirements loads on BPA, if they request such service, and also have the right to require BPA to participate in the Residential Exchange Program in the amount of the IOUs' residential loads. BPA will offer to meet the IOU' net firm power load requirements as calculated under section 5(b)(1) and subject to section 9(c) of the Northwest Power Act, in full, at the NR 
rate schedule. The IOUs also may participate fully in the Residential Exchange Program. However, the IOUs can agree to settle their participation in the Residential Exchange Program. BPA's proposed offer under Subscription for settlement of the Residential Exchange Program is comprised of a power sale and a monetary payment. The proposed settlement is conditioned on the waiver of rights to the Residential Exchange Program. Because existing statutory rights continue to be available, because any sale of power would be consistent with the statutory provisions applicable to that type of sale, and because the Subscription settlement proposal is not imposed on any party, the Subscription settlement proposal does not violate the Northwest Power Act.

Some parties argue that both Subscription benefits and Residential Exchange benefits should be available to IOUs. BPA believes that the amount of power and monetary payments available in the Subscription settlement proposal is an appropriate level for settlement of the Residential Exchange Program. From the inception of discussions regarding Subscription sales to IOUs, such sales involved the settlement of rights to the Residential Exchange Program. Allowing IOUs to receive benefits under the Subscription settlement proposal and to continue the Residential Exchange Program would provide the IOUs with excessive benefits. This is particularly true given that BPA has increased the power available under Subscription to the IOUs to 1800 aMW. BPA does not believe the other regional parties, who opposed providing more than 1500 aMW to the IOUs in conjunction with settlement of the Residential Exchange Program, would support an increase in Subscription power and continued participation in the Program. In addition, continuing the Residential Exchange Program while providing Subscription power to the IOUs, even if the exchange benefits were based on less than total residential loads, would require BPA to incur virtually all of the costs and administrative burdens of implementing the Program. This would be in addition to the costs of continuing administrative and judicial litigation historically engendered by the Residential Exchange Program.

For these reasons, the IOUs should participate in the Residential Exchange Program or in a settlement of that Program through Subscription, but not both. The ability of preference customers to participate in the Residential Exchange Program does not change this conclusion. The Residential Exchange benefits available to preference utilities are dramatically less than the benefits available to IOUs. Furthermore, any preference customers participating in the Residential Exchange Program after 2001 are subject to in lieu transactions. In the event BPA's PF Exchange rate is above market, exchanging preference utilities that are subject to in lieu transactions may receive no benefits whatsoever under the Residential Exchange Program. 
Issue:

If an IOU chooses to participate in the Residential Exchange Program instead of accepting a settlement of the Residential Exchange Program through the Subscription offer, does the total amount of power available to the other IOUs for Subscription get reduced?

\section{Subscription Proposal:}

The Subscription Proposal did not address this issue specifically. However, the intent behind the Proposal was that 1500 aMW represented the total settlement amount available for the residential and small farm customers of IOUs. Therefore, if an IOU chose to request Residential Exchange benefits under section 5(c), the Subscription amount for all the IOUs would be reduced by the amount that would have gone to the exchanging utility.

\section{Parties' Comments:}

The DSIs argue that the Subscription Proposal is unclear as to whether or not the total availability of Subscription power is 1500 aMW. Murphy, Public Meeting Transcript, Oct. 8, 1998. In other words, if an IOU chooses to remain with the Residential Exchange and requests benefits under section 5(c), does the amount of Subscription power decrease relative to the "share" of the IOU that chose not to take its "share" or does the total 1500 aMW of Subscription power get divided among those who chose to participate in Subscription? Id.

\section{Evaluation and Decision:}

The amount of power offered to the IOUs (1500 aMW in the initial Subscription Proposal, 1800 aMW in the final Subscription Strategy) assumes that all IOUs participate in the purchase of such power. The total amount of power made available in Subscription is the amount that BPA believes would be appropriate for the settlement of the Residential Exchange Program with the IOUs. If an IOU chooses to forego settlement of the exchange through Subscription, it may participate in the Residential Exchange Program. In such event, the amount of power that was available to that individual utility should be removed from the total amount of power made available to the IOUs. Determinations of the individual amounts available to IOUs must be made by BPA, also considering the type of contract power service requested, prior to an IOUs' election of the exchange or Subscription power. In summary, if an $10 U$ chooses to request Residential Exchange benefits under section 5(c) of the Northwest Power Act, then the Subscription settlement amount for all the IOUs will be reduced by the amount that would have gone to the exchanging utility. 
Issue:

Should BPA offer to sell all requirements products to IOUs?

\section{Subscription Proposal:}

The Subscription Proposal states that BPA will serve IOUs' Subscription requirements requests at the $N R(1)$ rate. If IOUs do not wish to purchase requirements under Subscription, their requirements would be served at the $N R(2)$ rate.

\section{Parties' Comments:}

Puget argues that BPA should offer the same service alternatives to preference customers and the IOUs. Puget, SUB01-055.

\section{Evaluation and Decision:}

Pursuant to section 5(b)(1) of the Northwest Power Act, IOUs may request service from BPA for their firm power consumer requirements loads, net of their firm resources used to serve such loads. The rate for these loads is established pursuant to section $7(f)$ of the Northwest Power Act. In purchasing their net firm load requirements, IOUs may purchase, as applicable, requirements products that are available to other customers with the exception of the Slice of System product, which is available only to preference customers (for a discussion of the availability of the Slice product to IOUs, (see section I.C.) Such requirements purchases are at the NR rate. BPA also is making an offer to the IOUs for settlement of the Residential Exchange Program comprised of a specified amount of power and monetary payments. The terms and conditions of the settlement proposal are prescribed in order to establish what BPA believes is an appropriate value for the settlement of the Residential Exchange Program. Thus, most of the service alternatives available to preference customers for requirements service continue to be available to the IOUs under traditional requirements contracts and rate schedules. The Subscription settlement power sales, however, are available only under the prescribed conditions.

\section{Issue:}

Should the shape of the IOU sales be flat?

\section{Subscription Proposal:}

The Subscription Proposal states that the actual power deliveries for the residential and small farm loads of IOUs will be in equal hourly amounts over the contract period. 


\section{Parties' Comments:}

MPC, PPC, and CUB state that BPA should show flexibility in crafting the cost-based $I O U$ residential and small farm product that takes into account the shape of residential load. MPC, SUB01-062; PPC, SUB01-097; CUB, SUB01-103.

The State PUCs state that BPA should consider proposals that might combine a flat product with the opportunity to shape a portion of the power deliveries. State PUCs, SUB01-146. The commissions assert that BPA could make available its market-priced shaping products to IOUs as a purchase option to shape the flat product to better match residential load. Id.

\section{Evaluation and Decision:}

Some parties argue that BPA should show flexibility in the shape of the sales to the IOUs for their residential and small farm consumers. In determining the shape of sales to the IOUs, however, BPA must view the shape of all BPA sales to customers and the impact of the shape of such sales on BPA's system. BPA anticipates meeting substantial loads of preference customers which have shaping needs throughout the year. BPA cannot operate as economically or efficiently as desired if all loads have changing load shapes. There are operational benefits to BPA of customers taking energy around the clock, all year, without a significant amount of variation. Because BPA desires to operate its system efficiently, BPA is making this shape available to the IOUs. This will enable BPA to make direct power sales to the IOUs for their residential and small farm consumers while at the same time meeting the operational need of selling a significant flat block of energy to regional loads. Further, BPA observes that its service to residential and small farm loads will be only a portion of the utility's total load, and such loads have baseload needs that BPA would be able to serve in this manner. It is important to note that IOUs may request shaping services or other power products from BPA under the applicable rate schedule.

\section{Issue:}

Should BPA expand the FBS to accommodate physical sales to IOUs for their residential and small farm customers?

\section{Subscription Proposal:}

The Subscription Proposal suggests that there would be some augmentation of BPA's system to accommodate sales to the IOUs if the public agencies subscribed to power in amounts which did not permit the service of power to IOUs from existing resources for a minimum of $1000 \mathrm{aMW}$. 


\section{Parties' Comments:}

Public agencies state that BPA should acquire additional power supplies only as needed to serve public agency requirements loads and the specified portions of the IOU residential loads ( 1500 aMW for the 2002-2006 period and 2200 aMW for the 2007-2011 period). NRU, SUB01-057; Snohomish, SUB01-090; PPC, SUB01-097; WMG\&T, SUB01-099; Mundorf, SUB01-175. They argue that such resource additions would be treated as FBS replacements and would be included in a melded rate for requirements sales to public agencies and sales to the specified portions of the IOU residential loads. Id.

A public agency and a marketer argue that BPA should not expand its market power for firm service. Enron, SUB01-022; Seattle, SUB01-104. They claim that BPA should return to its historical role of marketing power generated by the FCRPS. Id

Some parties argue to expand the FBS to meet all of BPA's customers' needs. Wash. House, SUB01-176; Aluminum Company of America (Alcoa), SUB01-050.

\section{Evaluation and Decision:}

There are three schools of thought among the parties commenting on the augmentation of the FBS: Augment to accommodate all customers; augment to accommodate, in part, some customers; and do not augment to accommodate any customers. BPA's authority under the Northwest Power Act obligates BPA to acquire power if necessary to serve BPA's firm load obligations and also permits BPA to replace reductions in the capability of the FBS. A determination of need is made by the Administrator in exercising her discretion and in consideration of the alternative means BPA has to meet load.

The Subscription Proposal estimates that there would be some augmentation to BPA's system to accommodate sales to the IOUs if the public agencies subscribed to their full eligibility. Fundamentally, augmentation will be limited by its cost impact on BPA's rates due to price elasticity. Therefore, BPA will add power purchases if such augmentation is necessary to serve the IOUs with at least 1000 aMW of physical deliveries of power. Additional augmentation may be appropriate, but BPA will determine the most cost-effective approach to accommodating the sales to the IOUs--either additional physical deliveries or financial payments. BPA also has the authority, but not the requirement, to acquire power to meet DSI loads. BPA will make power sales in Subscription based on requests for service and meet those obligations by using its existing Federal power system and, to the extent necessary, cost-effective power purchases consistent with BPA's overall power supply, rate and financial goals. 
Issue:

Should power made available to the IOUs be subject to recall to meet preference loads?

\section{Subscription Proposal:}

The Subscription Proposal does not specifically address the issue of recall of sales to IOUs to meet preference loads.

\section{Parties' Comments:}

Puget argues that to the extent power sales to IOUs are subject to recall to meet preference loads, the contracts should provide for equivalent financial benefits for the recalled power. Puget, SUB01-055. The financial benefits should equal the amount, if any, by which the lowest-cost BPA power rate is less than the market rate for an equivalent power product. Id.

Northern Wasco, Springfield, and OURCA argue that contracts with the IOUs must include recall provisions or use short-term contract periods in order to ensure that the FBS is available to serve the public preference load. Northern Wasco, SUB01-048; Springfield, SUB01-121; OURCA, SUB01-116.

\section{Evaluation and Decision:}

BPA has identified two primary approaches to providing Federal power in Subscription to the IOUs. One approach is an in lieu sale of power pursuant to section $5(\mathrm{c})$ of the Northwest Power Act. Pursuant to section 5(c)(6) of the Northwest Power Act, "[e]xchange sales to a utility pursuant to this subsection shall not be restricted below the amounts of electric power acquired by the Administrator from, or on behalf of, such utility pursuant to this subsection." 16 U.S.C. $839 c(c)(6)$. Section $5(c)$ power sales are therefore not subject to recall.

A second approach for BPA's proposed Subscription sales to IOUs is a sale of net firm power requirements to the IOUs pursuant to section 5(b)(1) of the Northwest Power Act. Section 5(b)(2) of the Northwest Power Act provides that "[c]ontracts with IOUs shall provide that the Administrator may reduce his obligations under such contracts in accordance with section 5(a) of the Bonneville Project Act of 1937." 16 U.S.C. $839 c(b)(2)$. Section 5(a) of the Bonneville Project Act provides that "in the case of a contract with any purchaser engaged in the business of selling electric energy to the general public, the contract shall provide that the Administrator may cancel such contract upon five years' notice in writing if in the judgment of the Administrator any part of the electric energy purchased under such contract is likely to be needed to satisfy the requirements of the said public bodies or cooperatives referred to in this chapter, and 
that such cancellation may be with respect to all or any part of the electric energy so purchased under said contract to the end that the preferential rights and priorities accorded public bodies and cooperatives under this chapter shall at all times be preserved." 16 U.S.C. $832 \mathrm{~d}(a)$. In its initial $5(\mathrm{~b})(1)$ power sales contracts with its IOU customers BPA included a provision which permitted "recall" on five years' notice to the IOUs. BPA's requirements contracts with IOUs will be consistent with section 5(a) of the Bonneville Project Act.

In its Subscription Proposal for settlement of the Residential Exchange rights of the IOUs, BPA has proposed a combination of a power sale and a financial component. In order to address the possibility, however unlikely, that power is recalled to meet preference loads and BPA cannot purchase power to meet the IOU Subscription sales, BPA and the IOUs may negotiate contract terms to address such circumstances. Such terms may be different than those suggested by Puget.

\section{Issue:}

Should requirements power sales to the IOUs be reduced in the event that BPA experiences reductions in system capability.

\section{Subscription Proposal:}

The Subscription Proposal states that subject to meeting its public agency service obligations, expiring contracts should make it possible to reach the State PUCs' goal of 2200 aMW available for IOU residential consumers, absent significant reductions in BPA system capability.

\section{Parties' Comments:}

The NWEC argues that if the system is reduced (e.g., by the shutdown of WNP-2), an unacceptable outcome would be to reallocate the reduced supply by recalling power from the IOU residential customers to serve preference agencies. NWEC, SUB01-114.

\section{Evaluation and Decision:}

As noted previously, BPA has identified two primary approaches to providing Subscription power to the IOUs. One approach is an in lieu sale of power pursuant to section 5(c) of the Northwest Power Act. Once a contract has been signed to provide in lieu power, BPA must meet its contractual obligations. In the event that Federal resources were used as in lieu resources and reductions in system capability affected BPA's in lieu power sales, BPA would have to find other sources of power to continue the in lieu sales. BPA also may sell power to meet the net firm load requirements of IOUs under Subscription pursuant to the terms of section $5(b)(1)$ of the Northwest 
Power Act. Once BPA executes a requirements contract, BPA is obligated to provide the amount of requirements power specified in the contract in accordance with the contract terms and applicable statutes. In the event BPA has insufficient power available to meet the net firm load requirements of an IOU, BPA must acquire power to meet its net requirements load obligation. Only in the event that BPA were unable to acquire power to meet the requirements load of an IOU would BPA have to consider the reduction of its net requirements sales to IOUs.

In the event that reductions in system capability impaired BPA's ability to meet its public body and cooperative requirements loads, section 5(a) of the Bonneville Project Act and section 5(b)(2) of the Northwest Power Act grant BPA the authority to recall requirements sales to IOUs on five years' notice to meet the requirements loads of public body and cooperative customers. BPA and the IOUs may negotiate contractual terms to address BPA's potential inability to purchase or acquire power to meet $10 \mathrm{U}$ loads after reductions in BPA system capability.

\section{Amount}

Issue:

Should the amount of power available to the IOUs under Subscription for settlement of the Residential Exchange Program be 1500 aMW or 1800 aMW (both power and financial)?

\section{Subscription Proposal:}

BPA's intent in the Subscription Proposal was to spread the benefits of the FCRPS as broadly as possible, with special attention given to the residential and rural customers of the region. The Proposal enabled the benefits of the FCRPS to flow throughout the region, whether currently served by public or private power utilities.

The Subscription Proposal provided that residential and small farm loads of the IOUs, through settlement of the Residential Exchange Program, would be provided access to the equivalent of $1500 \mathrm{aMW}$ of Federal power for the 2002-2006 period. At least 1000 aMW of the 1500 aMW would be served with actual BPA power deliveries. The remainder would be provided through either a financial arrangement or additional power deliveries depending on which approach was most cost-effective for BPA.

\section{Parties' Comments:}

Many public agencies and their representatives commented that the IOU residential loads should have access to 1500 aMW of Federal power at a melded rate for the 2002-2006 rate period. NRU, SUB01-057; PPC, SUB01-097; WMG\&T, SUB01-099; 
Mundorf, SUB01-175. If there were insufficient power to serve the IOU residential loads at 1500 aMW after the public agencies subscribe, BPA would secure the additional power supply necessary for service at that level and the costs would be included in a melded rate. Id.

The DSIs argue that it is improper to provide direct and unreplaced power sales to IOUs for the benefit of their residential and small farm consumers. Murphy, SUB01-040; Early, SUB01-078.

IOUs and other parties argue that 1800 aMW is the minimum amount of power that should be made available for IOU residential loads, and this can be met from the outset, or 1500 aMW plus a guarantee of the first 300 aMW of power not claimed by preference customers. Litchfield, SUB01-053; Wash. Attorney Gen., SUB01-059; CUB, SUB01-103; NWEC, SUB01-114.

\section{Evaluation and Decision:}

The DSIs' arguments regarding power sales to the IOUs have been addressed previously. The public agencies note that 1500 aMW of Federal power is an acceptable level for spreading the benefits to the residential and small farm consumers of IOUs. On the other hand, the IOUs and the PUCs state that at least $1800 \mathrm{aMW}$ is the appropriate level. This level of sales, 1800 aMW, represents approximately 50 percent of IOU residential and small farm load in the region that was most recently actively participating in the Residential Exchange Program. The determination of an appropriate offer for settlement of the Residential Exchange Program is a difficult task, requiring the exercise of judgment based on all of the facts. After consideration of the Comprehensive Review, the public discussions during the Subscription process, and the comments of all interested parties, BPA believes that 1800 aMW is the appropriate amount of combined power and financial benefits for the settlement of the Residential Exchange Program for the 2002-2006 period. In order to offer 1800 aMW, BPA must provide for flat sales to the IOUs and must establish a means for determining the monetary component of the settlements that provides BPA cost certainty during the rate period.

Issue:

Should the amount of power available to the IOUs be 2200 aMW for the post-2006 period (both power and financial)?

\section{Subscription Proposal:}

The Subscription Proposal states that expiration of existing long-term extraregional power sales contracts will make approximately another 1000 aMW available for 
Subscription after 2006. Subject to meeting its public agency service obligations, this amount of power should make it possible to reach the State PUCs' goal of 2200 aMW available for IOU residential consumers, absent significant reductions in BPA system capability.

\section{Parties' Comments:}

Many public agencies and their representatives argue that the IOU residential load should have access to 2200 aMW of Federal power at a melded rate for the 2007-2011 rate period. NRU, SUB01-057; Snohomish, SUB01-090; PPC, SUB01-097; WMG\&T, SUB01-099; Mundorf, SUB01-175.

The DSIs argue that it is improper to provide direct and unreplaced power sales to IOUs for the benefit of their residential and small farm consumers. Murphy, SUB01-040; Early, SUB01-078.

IOUs and their representatives state that there needs to be a real commitment to serve 2200 aMW of IOU residential and small farm load post-2006. OPUC, SUB01-004; League of Oregon Cities, SUB01-037; Kitzhaber, SUB01-067; Litchfield, SUB01-053; Wash. Attorney Gen., SUB01-059; Gov. of Idaho, SUB01-084; CUB, SUB01-103; NWEC, SUB01-114; State PUCs, SUB01-146.

\section{Evaluation and Decision:}

The DSIs' arguments regarding power sales to the lOUs have been addressed previously. Both public agencies and IOUs suggest that BPA make a more explicit commitment to make available 2200 aMW to IOUs for their residential and small farm consumers. This level of sales, $2200 \mathrm{aMW}$ for the post-2006 period, represents approximately 50 percent of $10 \mathrm{U}$ residential and small farm load in the region. In the Subscription Proposal, BPA states that reaching the 2200 aMW level may be possible due to expiring contracts, after meeting its public agency contract obligations, and in the absence of significant reductions in system capability. However, this does not guarantee this amount of power being available. If BPA is to make a guarantee of 2200 aMW to the IOUs for their residential and small farm consumers, it is necessary for BPA to plan its load obligations and resource availability accordingly. Therefore, BPA will offer to the IOUs two contract terms that address post-2006 energy availability.

\section{Five-Year Contracts Offered}

BPA will offer 1800 aMW of power or benefits for the 2002-2006 period with no expressed guarantee of 2200 aMW of power or benefits for the 2007-2011 period. The waiver of the IOUs' rights to request Residential Exchange benefits under section 5(c) will be in effect until the end of the contract term--5 years. The portion of 
the 1800 aMW comprised of power in the 2002-2006 period will depend in part on preference customer load obligations and any reductions in BPA's system capability.

\section{Ten-Year Contracts Offered}

BPA will offer and guarantee 1800 aMW of power or benefits for the 2002-2006 period and 2200 aMW of power or benefits for the 2007-2011 period. The rate that applies to the post-2006 sales would, like the rate proposed for the post-2001 period, be approximately equal to the PF Preference rate, subject to establishment in a section 7 (i) rate hearing. The waiver of the IOUs' rights to request Residential Exchange benefits under section 5(c) will be in effect until the end of the contract term--10 years. The portion of the 2200 aMW comprised of power in the 2007-2011 period will depend in part on preference customer load obligations and any reductions in BPA's system capability.

\section{Issue:}

What is the mechanism for making power available to the IOUs from expiring contracts for the post-2006 period?

\section{Subscription Proposal:}

The Subscription Proposal did not address this issue specifically. It simply states that expiration of existing long-term extraregional power sales contracts will make approximately another 1000 aMW available to meet Northwest loads after 2006.

Subject to meeting its public agency service obligations, this should make it possible to reach the State PUCs' goal of 2200 aMW available for IOU residential consumers, absent significant reductions in BPA system capability.

\section{Parties' Comments:}

The public agencies suggest that all power returning to the Northwest from Southwest sales would be added to the FBS and sold at a melded rate as needed to serve public agencies and the specified portions of the IOU residential loads. PPC, SUB01-097; Mundorf, SUB01-175.

PNGC argues that returning long-term extraregional sales should first be used to meet public agency service obligations. PNGC, SUB01-086.

\section{Evaluation and Decision:}

When power becomes available from expiring contracts with extraregional purchasers, such power will be used to meet BPA's then current firm load obligations to its 
customers. BPA intends to meet such load obligations in full using its system resources. The power from an expiring contract becomes part of BPA's inventory. When BPA enters into power sales contracts, it must meet its obligations under those contracts. If power freed up from expiring extraregional sales is needed to meet BPA's existing contractual obligations, it is used in that manner. In the event that existing contractual agreements do not require the power, the power is offered first to BPA's preference customers to meet additional firm load obligations they may be eligible to purchase from BPA. To the extent the power is not needed to meet public agency requests, the power would be sold to other eligible non-preference customers.

issue:

How should BPA determine the amounts of Subscription power provided to each IOU?

\section{Subscription Proposal:}

The Subscription Proposal states that to the extent permitted by law, the State PUCs will jointly determine the share of power that goes to the residential and small farm customers of each IOU that chooses to participate in Subscription. The State commissions also would determine how the benefits of the Subscription sales will be passed on to residential and small farm consumers. These determinations would be suggested to BPA, which makes the final decision.

\section{Parties' Comments:}

IOUs, public agencies, and URP state that BPA cannot permit the PUCs to make a determination of the shares of Subscription power that are offered for settlement of the Residential Exchange Program because this is a determination for BPA to make. Northern Wasco, SUB01-048; Gov. of Montana, SUB01-068; Idaho Cooperative Utilities Assn. (ICUA), SUB01-072; Lower Valley, SUB01-081; PRM, SUB01-087; Litchfield, SUB01-053; Puget, SUB01-055; NRU, SUB01-057; WWP, SUB01-066; PPC, SUB01-097; WMG\&T, SUB01-099; KPUD; SUB01-111; URP, SUB01-120. Some parties state that BPA should reach agreement with the PUCs regarding the IOUs' transactions in order to assure that IOU residential and small farm customers benefit as intended. Litchfield, SUB01-053; Puget, SUB01-055; NRU, SUB01-057; WWP, SUB01-066; PPC, SUB01-097; WMG\&T, SUB01-099; KPUD, SUB01-111.

The IOUs and the State PUCs argue to allow the Commissions the opportunity to suggest to BPA how the power and financial benefits should be provided to the residential and small farm customers of IOUs. WWP, SUB01-016; 23; Litchfield, SUB01-053; Wash. Attorney Gen., SUB01-059; WWP, SUB01-066; IPC, SUB01-070; PGE, SUB01-071; State PUCs, SUB01-146. 
The DSIs argue that there is no logic in allowing the PUCs to make certain determinations regarding eligibility for Subscription power. Murphy, SUB01-040. The DSIs also express concern about the possibility that the PUCs might be unable to determine the amounts of power for individual IOUs. Early, SUB01-078.

\section{Evaluation and Decision:}

While the Subscription Proposal states that the PUCs, to the maximum extent permitted by law, should determine the amounts of power made available to individual IOUs, BPA recognized that there were constraints regarding what a non-Federal entity can decide regarding a Federal issue. BPA did not intend that any approach developed by the PUCs would be a final determination of this issue. Rather, BPA intended that the PUCs would advise BPA of the manner in which the PUCs would resolve this issue. For this reason, there would be no difficulty in resolving this issue if the PUCs failed to reach an agreement. As comments correctly point out, BPA must make this determination. The comments of the PUCs, however, are of particular interest to BPA. At a later time, BPA will solicit comments from all interested parties regarding the manner in which individual IOUs should receive particular amounts of the total power made available for the proposed settlement of the Residential Exchange Program, including amounts of power and amounts of monetary payments. BPA will then determine the final amounts available to individual IOUs.

Issue:

Should the amount of power available to the IOUs be capped?

\section{Subscription Proposal:}

Although the Subscription Proposal does not specifically address a cap for IOU purchases, a cap is implied. In Subscription, BPA proposes that residential and small farm loads of the IOUs be assured access to the equivalent of 1500 aMW of Federal power for the 2002-2006 period. At least 1000 aMW of the 1500 aMW would be served with actual BPA power deliveries. The remainder may be provided through either a financial arrangement or additional power deliveries depending on which approach is most cost-effective for BPA.

\section{Parties' Comments:}

Many residential customers of IOUs argue that BPA should remove the cap on the amount of electricity available for IOUs. OPUC, SUB01-004; IIPA, SUB01-056;

Kirkland, SUB01-061; City of Renton (Renton), SUB01-076; Parkland, SUB01-139; e.g., McGaerigle, SUB01-123. 
IOUs, their representatives, and the State PUCs object to a cap of 1500 aMW for the IOUs' residential and small farm customers. They argue that $1500 \mathrm{aMW}$ does not meet the minimum objective of 50 percent of current residential and smail farm load of IOUs. OPUC, SUB01-004; League of Oregon Cities, SUB01-037; Litchfield, SUB01-053; IIPA, SUB01-056; Wash. Attorney Gen., SUB01-059; Kitzhaber, SUB01-067; CUB, SUB01-103; NWEC, SUB01-114; State PUCs, SUB01-146. Further, some want the IOUs and the DSIs to share in any excess power over the $1800 \mathrm{aMW}$. OPUC, SUB01-004; Litchfield, SUB01-053; IIPA, SUB01-056; Wash. Attorney Gen., SUB01-059; Gov. of Idaho, SUB01-084.

\section{Evaluation and Decision:}

IOUs and their representatives object to a cap of 1500 aMW for the IOUs' residential and small farm customers for the 2002-2006 period. While opposing power sales being limited to 1500 aMW, the IOUs and other parties support Subscription power sales of 1800 aMW. The provision of Subscription power for the IOUs for their residential and small farm consumers is a proposed settlement of the Residential Exchange Program. SPA will provide 1800 aMW to the lOUs for the 2002-2006 period, which is approximately 50 percent of the residential and small farm load of IOUs most recently participating in the Residential Exchange Program. Further, consistent with its statutory and contract obligations, BPA will make available 2200 aMW for the period after 2006.

However, BPA currently has a limited amount of Federal power. While BPA can acquire power to meet its loads, such acquisitions affect the price of BPA power and BPA's competitiveness in the wholesale power market. BPA does not know with certainty the amount of power that will be purchased by BPA's preference customers under Subscription. In the event that preference customers purchased virtually all BPA's inventory, BPA would be required to acquire resources to meet the loads of other customers. Such acquisitions might have the effect of increasing BPA's rates and threatening BPA's competitiveness. For this reason, the Subscription Proposal included specific amounts of power for sale to the IOUs. However, in the unlikely event BPA has excess inventory, BPA will consider additional Subscription sales to the IOUs.

\section{Issue:}

Should there be at least 1000 aMW of physical deliveries?

\section{Subscription Proposal:}

In the Subscription Proposal, BPA proposed that residential and small farm loads of the IOUs be assured access to the equivalent of 1500 aMW of Federal power for the 2002-2006 period. At least 1000 aMW of the 1500 aMW would be served with actual BPA power deliveries. The remainder may be provided through either a financial 
arrangement or additional power deliveries depending on which approach is most cost-effective for BPA.

\section{Parties' Comments:}

The DSIs argue that it is improper to provide direct and unreplaced power sales to IOUs for the benefit of their residential and small farm consumers. Murphy, SUB01-040; Early, SUB01-078. Parties did not directly address this issue in their comments.

\section{Evaluation and Decision:}

The DSIs' arguments regarding power sales to the IOUs have been addressed previously. BPA did not receive any specific comments on the issue of providing a minimum of 1000 aMW of power to the IOUs. BPA will continue to ensure a minimum of 1000 aMW in power to the IOUs. BPA also will retain the flexibility to provide the remainder through either a financial arrangement or additional power deliveries depending on which approach is most cost-effective for BPA.

\section{Issue:}

Will BPA make a one-time determination of the amount of power and the amount of financial benefits or can the amounts change over the contract period?

\section{Subscription Proposal:}

Although the Subscription Proposal did not address this issue specifically, it implied that the amounts may change over time. The Subscription Proposal stated that at least 1000 aMW of the 1500 aMW would be served with actual BPA power deliveries. The remainder would be provided through either a financial arrangement or additional power deliveries depending on which approach is most cost-effective for BPA.

\section{Parties' Comments:}

IOUs and their representatives argue that switching between money and power may be disruptive and prevent a utility from providing the most cost-effective service to its customers. They argue that they cannot support conversion between a financial transaction and a power sale--and vice-versa--during the contract term. Litchfield, SUB01-053, Puget, SUB01-055, PGE, SUB01-071.

\section{Evaluation and Decision:}

BPA recognizes that switching between physical and financial deliveries within the contract period may be problematic for the IOUs. However, BPA must make power 
sales that are consistent with the statutory directives governing those sales. Depending on the nature of the power sale, there may be events that would limit BPA's ability to provide the specified amounts of power. BPA and each IOU will agree to the physical and financial components of the Subscription amount, by year, in the negotiated Subscription contracts. BPA and the IOUs also must negotiate contract provisions addressing the potential need for changes in the amount of the power sale and the complementary amount of the financial component during the contract term.

\section{Financial Mechanism}

Issue:

What is the appropriate manner for determining a monetary component for the proposed settlement of the Residential Exchange Program?

\section{Subscription Proposal:}

The Subscription Proposal states that BPA will make available up to 1500 aMW of power benefits for the residential and small farm loads of IOUs for settlement of the Residential Exchange Program. At least 1000 aMW will be actual power deliveries. For the remaining 500 aMW, BPA may deliver additional power and/or provide a cash payment that reflects the difference between the actual market price of power and the $N R(1)$ rate. However, the "actual market price for power" may be addressed in a variety of different ways.

\section{Parties' Comments:}

Public agencies and their representatives argue that the proposed financial benefit (cash payment based on difference between NR(1) and market price of power) should be eliminated. NRU, SUB01-057; Benton PUD, SUB01-077; Snohomish, SUB01-090; WRECA, SUB01-094; PPC, SUB01-097; Mundorf, SUB01-175.

The DSIs question how "market" is defined, and whether it can be defined in a manner that does not cause BPA's financial risk to change during the 2002-2006 rate period. Early, SUB01-078. The DSIs also question the statutory basis for the cash payment. They suggest that if BPA must rely on section 5(c), then it has proposed two measures of ASC--a resource measure and a market measure. Early, SUB01-078.

IOUs and their representatives argue that financial benefits should be calculated based on the difference between the market price of power and the NR rate that is roughly equivalent to the lowest priced public preference rate. Litchfield, SUB01-053; Puget, SUB01-055; PGE, SUB01-071; State PUCs, SUB01-146. 


\section{Evaluation and Decision:}

BPA's Subscription Proposal for settlement of the Residential Exchange Program provides for sales to IOUs and a monetary payment based on the difference between market and the NR(1) (now RL or PF) rate. While certain public agencies oppose the monetary payment, it is a necessary element of a proposed settlement package. BPA's proposed settlement begins with the determination of an amount of power that would be reasonably sufficient to settle the Residential Exchange Program. However, BPA currently has a specific inventory of Federal power. BPA does not know the amount of power that will be purchased by preference customers in Subscription. While BPA can augment its firm inventory through power purchases, such augmentation would increase BPA's costs and thus BPA's rates, with consequent effects on BPA's competitiveness. Due to this uncertainty, BPA requires flexibility in the structure of the Subscription settlement offer for the Residential Exchange Program, which is accomplished through a combination of power and monetary benefits. The establishment of a monetary alternative is therefore important to the flexibility and viability of the proposed settlement.

The DSIs ask how "market" is defined and whether it can be defined in a manner that does not cause BPA's financial risk to change during the 2002-2006 rate period. Early, SUB01-078. There are a number of ways in which the market component of the financial formula could be established. BPA proposes, however, to establish ihis in BPA's upcoming rate case. This would afford all interested parties the opportunity to address this issue in a formal evidentiary proceeding. This also would provide BPA with a definition that would not cause BPA's financial risk to change during the 2002-2006 rate period. BPA proposes to base the monetary component of the settlement on the difference between the market forecast established in the rate case and the rate for Subscription sales to IOUs. This would establish a fixed financial obligation for the proposed settlement that would not subject BPA to changing risk. BPA needs a predictable cost in order to ensure a high Treasury payment probability and competitive rate levels. If BPA used an actual market price to calculate the financial component, and not a mechanism to establish the cost (such as a market forecast), and BPA did not achieve a high enough level of planned net revenues for risk embedded in its cost-based rates to account for the risk associated with the uncertainty of the market, BPA's Treasury payments could be jeopardized.

The DSIs question the statutory basis for the cash payment. Early, SUB01-078. They suggest that if BPA must rely on section 5(c), then it has proposed two measures of ASC--a resource measure and a market measure. Id. Under the Subscription Proposal, BPA noted that IOUs may choose not to participate in the Subscription settlement offer for the Residential Exchange Program. If an IOU does not participate in the settlement, it will continue its normal participation in the Residential Exchange Program. Under the Residential Exchange Program, a utility's ASC is determined pursuant to the ASC Methodology. If an IOU wishes to participate in the proposed 
Subscription settlement of the Residential Exchange Program, it may receive power and a monetary payment based on the difference between the market and the applicable rate. The authority for the monetary element of the proposed settlement is found in section 2(f) of the Bonneville Project Act, which provides BPA with broad discretion in the settlement of contracts and other agreements. BPA is therefore not proposing two different measures of ASC.

The DSIs question whether BPA can limit cash payments, based on the difference between market and BPA's cost-based rates, to a fraction of the residential loads of the exchanging utilities. Early, SUB01-078. Similarly, the DSIs question whether the test for eligibility for Residential Exchange benefits and the measure of such benefits changes from a resource cost measure to a market measure and whether BPA can deny the payment to any residential load. Id. As noted previously, IOUs under the Subscription Proposal can continue to participate in the Residential Exchange Program for their entire residential loads. The IOUs also have the ability to agree to a settlement of the Residential Exchange Program in which they purchase power from BPA and receive a monetary payment from BPA. If the IOUs accept the settlement, all benefits from the settlement must be passed through directly to the utilities' residential loads. The monetary component is therefore not limited to receipt by a fraction of the utility's residential loads. Also, the test for eligibility for the Residential Exchange is not changing and does not deny payment to any residential load.

In summary, BPA will establish the mechanism for determining the monetary component of the Residential Exchange settlement through the rate case. The financial mechanism should be the difference between the market forecast established in the rate case and the rate for Subscription power sales to IOUs. It should be noted that BPA's Subscription Strategy does not establish any rates. The establishment of rates can only be determined in a formal rate hearing under section 7 (i) of the Northwest Power Act. While final rate decisions are not being made in the Subscription Strategy, rate design approaches identified in the Subscription Strategy will be part of BPA's initial power rate proposal, which is expected to be published early in 1999.

Issue:

Should there be a cap on the amount of financial benefits provided?

\section{Subscription Proposal:}

The Subscription Proposal does not address a cap on the amount of financial benefits provided. It simply states that for the remaining $500 \mathrm{aMW}$ (over the $1000 \mathrm{aMW}$ of firm deliveries), BPA may either deliver additional power and/or provide a cash payment that reflects the difference between the actual market price of power and the $N R(1)$ rate. However, the "actual market price for power" may be addressed in a variety of different ways. 


\section{Parties' Comments:}

The State PUCs argue that to the extent a portion of the Federal System benefits are provided through cash, there should be no cap on the level of equivalent cash benefits. State PUCs, SUB01-146.

A public agency argues that BPA should drop the financial mechanism based on market without a cap, because this amount could grow too large and put upward pressure on lowest cost-based rates. Benton PUD, SUB01-101.

\section{Evaluation and Decision:}

Virtually any approach to determining the difference between market and the applicable BPA rate imposes a cap on financial benefits. Even if market were determined by a market index, the monetary amounts would be capped by the level of the index at any particular time. BPA proposes that the difference between a market forecast and the applicable rate for IOU Subscription sales, as established in BPA's upcoming rate case, will determine the amount of monetary benefits. Formula: (Fixed Market Forecast--IOU Subscription Rate) * (Fixed Amount) = Costs. Under this approach, the amount of the monetary payments would be known, and this amount would ensure a fixed financial exposure over the rate period. Parties also would be unable to manipulate the monetary amounts over the rate period. By using the market forecast as established in BPA's rate case, which is a formal evidentiary proceeding, there should be a reasonable amount of assurance that the financial component will be fairly established. While this approach would provide an effective ceiling to the monetary payments, it is an appropriate approach to address BPA's concerns regarding the establishment of a fair amount of monetary benefits and the protection of BPA from excessive financial risk. Moreover, by using a mechanism to establish the cost of this component of this settlement, it is not necessary to include high planned net revenues for risk associated with this element in BPA's rates. If BPA used an actual market price to calculate the financial component, and not a mechanism to establish the cost (such as a market forecast), and BPA did not achieve a high enough level of planned net revenues for risk embedded in its cost-based rates to account for the risk associated with the uncertainty of the market, BPA's Treasury payments could be jeopardized.

In addition, in order to move from 1500 aMW to 1800 aMW of Subscription power sales to IOUs, it is necessary to know the costs associated with the financial component of the Subscription sales to IOUs. This will protect BPA from excessive financial risk. BPA and most public agencies supported the level of 1500 aMW of Subscription sales to IOUs for their residential and small farm load in the Subscription Proposal. However, public agencies and public interest groups want the full amount of Subscription sales to IOUs to be power deliveries with no financial component. One downside to the financial component, as described by the public agencies, is that the financial component reflecting an actual market price would put undue financial risk on BPA 
costs. A rising market price would greatly increase the risk of BPA not recovering its costs, thereby either putting BPA's Treasury repayment at risk or increasing the likelihood of the CRAC triggering.

The IOUs, the State commissions, and the public interest groups have made persuasive arguments as to why at least 1800 aMW, not 1500 aMW, for Subscription sales to IOUs for their residential and small farm load is the proper level for settlement of the Residential Exchange Program. As a compromise to the differing views of parties in the Region, BPA will meet the 1800 aMW level. However, BPA still needs to maintain the discretion of using power or financial deliveries over the 1000 aMW level, depending on which is most cost-effective within BPA's financial and rate goals. In summary, in order to give other regional parties and BPA cost certainty to this settlement, and in light of increasing the Subscription sales to IOUs to $1800 \mathrm{aMW}$, the market forecast in the rate case should be used to reflect the market price when calculating the financial component.

It should be noted that BPA's Subscription Strategy does not establish any rates. The establishment of rates can only be determined in a formal rate hearing unider section 7 (i) of the Northwest Power Act. While final rate decisions are not being made in the Subscription Strategy, rate design approaches identified in the Subscription Strategy will be part of BPA's initial power rate proposal, which is expected to be published early in 1999.

Issue:

Should there be arbitration of disputes regarding the calculation of financial benefits?

\section{Subscription Proposal:}

The Subscription Proposal does not address whether there should be arbitration of disputes regarding the calculation of financial benefits.

\section{Parties' Comments:}

The State PUCs argue that if a dispute arises as to the calculation of the financial benefits, such disputes should be arbitrated by an independent third party.

State PUCs, SUB01-146. Further, if possible, the calculation of the financial benefits themselves should be adjudicated by an independent third party. Id.

\section{Evaluation and Decision:}

As noted above, BPA has proposed that the manner for determination of financial settlement payments be established based upon the difference between the market 
forecast adopted in BPA's rate case and the applicable rate for IOU Subscription sales. Under this proposal the determination of monetary benefits would simply be a mathematical calculation. Where the determination of benefits is established in this way, arbitration is unnecessary. Arbitration of contract disputes generally, however, will be addressed separately in the development of Subscription contracts.

\section{Contract Term}

Issue:

Should the settlement of rights to the Residential Exchange Program be for the contract period?

\section{Subscription Proposal:}

The Subscription Proposal states that the IOUs have the ability to participate in the Residential Exchange Program. The IOUs also may settle their rights to the Residential Exchange Program through the combination of a purchase of a specified amount of power and monetary payments: The Proposal did not specify the term for which the IOUs' Residential Exchange rights would be settled

\section{Parties' Comments:}

The IOUs argue that any waiver of exchange rights should be for the contract period that ensures benefits for residential and small farm consumers of IOUs. Litchfield, SUB01-053. The PUCs state that they would support the settlement of their utilities' Residential Exchange rights contingent upon BPA's performance of the power and payments provided in Subscription. State PUCs, SUB01-146.

\section{Evaluation and Decision:}

As noted above, IOUs may continue participation in the Residential Exchange Program. Alternatively, the IOUs may settle their rights to the Residential Exchange through the purchase of power and the receipt of monetary payments provided in Subscription. The IOUs correctly point out that the settlement of any Residential Exchange rights should be for the contract period.

Issue:

Should the term of the $10 \mathrm{U}$ contracts be 10 years? 


\section{Subscription Proposal:}

The Subscription Proposal did not address the term of contract for the IOUs, it simply states that residential and small farm loads of the IOUs be assured access to the equivalent of 1500 aMW of Federal power for the 2002-2006 period. The Subscription Proposal does state that a variety of contract durations will be encouraged to avoid risk of a "financial cliff" occurring if all power contracts terminate on the same date.

For IOU requests for net firm power load requirements service at the NR(2) rate, BPA is attempting to provide various incentives for customers to choose between three-year contracts, five-year contracts, and contracts longer than five years. To accommodate concerns about the need for flexibility in an unpredictable market, BPA has proposed staggered contract terms. BPA is offering a five-year fixed rate, with the first three years at one rate and the final two years stepped up at a higher rate. Customers who choose not to buy for five years can buy the three-year package. Staggering contract length will give both BPA and its customers greater flexibility to address market changes and changes that could occur in BPA's fish and wildlife responsibilities.

\section{Parties' Comments:}

Many public agencies and their representatives argue that the IOU residential load should have access to 2200 aMW of Federal power at the melded rate for the 2007-2011 rate period. The IOU residential power sales would be memorialized in a 10-year contract. BPA should make a clear, long-term commitment to the residential consumers of IOUs. NRU, SUB01-057; PPC, SUB01-097; WMG\&T, SUB01-099; Mundorf, SUB01-175.

\section{Evaluation and Decision:}

Both public agencies and IOUs suggest that BPA make a more explicit commitment to make available 2200 aMW to IOUs for their residential and small farm consumers. This level of sales, 2200 aMW for the post-2006 period, represents approximately 50 percent of IOU residential and small farm load in the region. In the Subscription Proposal, BPA states that reaching the 2200 aMW level may be possible due to expiring contracts and in the absence of significant reductions in system capability. However, this does not guarantee that this level will be available. If BPA is to make a guarantee of 2200 aMW to the IOUs for their residential and small farm consumers, it is necessary for BPA to plan its obligations and resource availability accordingly.

Therefore, BPA will offer to the IOUs two contract terms that address post-2006 energy availability.

\section{Five-Year Contracts Offered}

BPA will offer 1800 aMW of power or benefits for the 2002-2006 period with no guarantee of $2200 \mathrm{aMW}$ of power or benefits for the 2007-2011 period. The waiver of 
the IOUs' rights to request Residential Exchange benefits under section 5(c) will be in effect until the end of the contract term-five years. The portion of the 1800 aMW comprised of power in the 2002-2006 period will depend in part on preference customer load obligations and any reductions in BPA's system capability.

\section{Ten-Year Contracts Offered}

BPA will offer and guarantee 1800 aMW of power or benefits for the 2002-2006 period and $2200 \mathrm{aMW}$ of power or benefits for the 2007-2011 period. The rate that applies to the post-2006 sales would, like the rate proposed for the post-2001 period, be approximately equal to the PF Preference rate, subject to establishment in a section 7(i) rate hearing. The waiver of the IOUs' rights to request Residential Exchange benefits under section 5(c) will be in effect until the end of the contract term-10 years. The portion of the 2200 aMW comprised of power in the 2007-2011 period will depend in part on preference customer load obligations and any reductions in BPA's system capability.

\section{Implementation}

Issue:

Will BPA establish procedures for audits to ensure that the Subscription benefits/power for settlement of the Residential Exchange Program is being passed through directly to residential consumers?

\section{Subscription Proposal:}

The Subscription Proposal did not address this issue specifically, but did state that the State commissions would help determine how the benefits of the Subscription sales would be passed on to residential and small farm consumers.

\section{Parties' Comments:}

The DSIs and PPC note that BPA must assure that the intended beneficiaries of Federal power are the actual beneficiaries under BPA's Proposal. They argue that BPA, not the "region," has the obligation to assure that the benefits of the Federal hydropower go to consumers and not utilities. Murphy, SUB01-040; PPC, SUB01-097.

The State PUCs suggest that BPA should ensure that all Federal System benefits are flowed through to customers. State PUCs, SUB01-146. 


\section{Evaluation and Decision:}

BPA believes that it has an obligation to ensure that the benefits of Federal power are provided to the intended recipients. For this reason, BPA will propose that the Subscription contracts with IOUs will include a provision permitting BPA to review the manner in which the benefits of the Federal System through Subscription settlement of the Residential Exchange are being provided to the intended beneficiaries.

\section{Serving the DSIs}

Issue:

Should BPA develop a special surplus product for the DSIs?

\section{Subscription Proposal:}

BPA proposed to sell 1000 aMW of interruptible power to the DSIs. In meetings with customer group representatives, BPA outlined its proposal for supplying the DSIs with firm and nonfirm secondary power, on a take-or-pay basis, at a price discounted from some agreed-upon market index.

\section{Parties' Comments:}

In general, the DSI customers did not respond positively to the proposed special surplus product. Reynolds, a DSI customer, stated that the proposed product is unacceptable. Reynolds, SUB01-039, at 2. Reynolds stated that the product was designed in such a way that BPA would often "face the tradeoff of selling to the DSIs or gaining more revenue by selling to market." Id. Reynolds also noted that its experience with so-called "top quartile" service (interruptible service provided in the past to a portion of the DSIs load) made it "very wary" of the proposal. Id. The perception and concern that a large portion of the product would be available only at BPA's discretion also was expressed by other DSIs. Murphy, SUB01-040, at 13. DSI customer Kaiser stated that an interruptible product with market-based prices "merely adds risks of interruption to market risks." Kaiser, SUB01-096. Some DSIs also noted that because the product was expected to be priced below market it would be viewed by other customer groups as a subsidy to the DSIs. E.g., Reynolds, SUB01-039; Murphy, SUB01-040.

The DSIs did not completely reject the idea of an interruptible product. Vanalco indicated that an interruptible product may be an attractive part of their supply portfolios, but that the proposed product simply lacked enough detail to determine its value. Vanalco, SUB01-054. Other DSIs also indicated an interest in a "properly designed" interruptible product. Murphy, SUB01-098, at 3. Others suggested 
the product should be developed as an alternative "if the amount of system augmentation is insufficient to meet Subscription requests for firm power." Early, SUB01-078, at 9 . The State PUCs were the only entity to express unqualified support for the proposal, and stated they believed the product proposal was an "innovative method for providing benefits to the DSIs." State PUCs, SUB01-146, at 3.

Other customers and customer group representatives objected to the proposed product on the basis that it violates public preference. Springfield, SUB01-021, at 3; Clark, SUB01-077; Snohomish, SUB01-090; PPC, SUB01-097; NRU, SUB01-057; WPAG, SUB01-073. Customers also stated that pricing the proposed product at a discount from a market index would also "result in an increase to the lowest-cost rate charged for service to public agencies and the IOU residential loads." WPAG, SUB01-073, at 7; see also Clark, SUB01-077, at 3. Some customers also noted that the proposed product undercuts the economic attractiveness of the Slice product by allocating a large portion of nonfirm power to the DSIs. Snohomish, SUB01-090; PPC, SUB01-097; WPAG, SUB01-073. One party asserted that the proposed product constituted the "highest quality" nonfirm energy, and that it should be sold at market prices "in competition with other potential buyers." URP, SUB01-120, at 1.

\section{Evaluation and Decision:}

With the exception of State PUCs, no party commenting on this issue supports the proposed DSI surplus product in its present form. As a consequence, BPA will not move forward with the proposed product at this time. However, as BPA moves toward the Power Rate Case and through the Subscription process, it may propose an alternative DSI surplus power proposal that attempts to address the concerns expressed by parties in their comments.

\section{Issue:}

Should BPA negotiate power sales contracts during Subscription with all customers, including the DSIs, to meet whatever load the customer chooses to place on BPA?

\section{Subscription Proposal:}

BPA proposed to negotiate and execute power sales contracts with DSI customers only after Subscription concluded for public preference customers and for the IOU small farm and residential loads, and to serve the DSIs with up to 1000 aMW of firm power, if available.

\section{Parties' Comments:}

The DSIs commented that BPA should open Subscription sales to all historical customers at the same time, and not sequence negotiations as proposed. Reynolds 
stated that making them await the contracting decisions of BPA's other customers "creates an untenable planning uncertainty for Reynolds." Reynolds, SUB01-039. Other DSis echoed this concern, Murphy, SUB01-040, and added that as a consequence of being prohibited from negotiating with BPA until after other customers have taken what they want, the DSIs are placed in a disadvantageous negotiating position vis-a-vis other power suppliers. Id. at 14; Kaiser, SUB01-096; see also Elf Atochem North America, Inc. (Elf Atochem), SUB01-200 (BPA should conduct concurrent negotiations with all customers).

One public preference customer group, WPAG, also commented that the proposed sequencing was both "cumbersome and burdensome for the DSIs, and unnecessary to protect the interests of the public agencies and the residential customers of the IOUs." WPAG, SUB01-073, at 9. WPAG proposed that BPA should negotiate with the DSIs beginning in the second half of the Subscription period, if BPA has a "reasonable expectation" that power will be available to serve DSI load. Id. Other customers commented that BPA's proposal on sequencing was appropriate and consistent with public preference and the DSIs' regional preference rights. PPC, SUB01-097; see also Clallam, SUB01-150.

Some parties stated BPA should not offer any firm power to the DSIs until the IOUs have taken up to 1800 aMW for the 2002-2006 rate period to serve their residential bad. State PUCs, SUB01-147; State of Oregon, SUB01-067; NWEC, SUB01-114; see also URP, SUB01-120 (no basis in law to favor the DSIs over IOU residential load). BPA also received a number of comments from residential customers of IOUs requesting such loads receive priority over DSI loads. E.g., Fahland, SUB01-177. The Sierra Club stated that the DSIs have no legal claim to any Federal power and have "sought to shirk their responsibility for paying costs" incurred by BPA to serve them, and urged BPA not to offer any "cost-based, firm power contracts to the DSIs during the 2001-2006 rate period." Sierra Club, SUB01-089; see also Friends of the Earth, SUB01-169 (no cost-based, firm power contracts to the DSIs during the 2001-2006 rate period).

In addition to proposing that BPA negotiate with all customers simultaneously, the DSIs also urge that BPA not limit to 1000 aMW the amount of firm load that they may place on BPA in Subscription, but rather negotiate to serve all historical load placed on BPA. Murphy, SUB01-040; Early, SUB01-078. The DSIs believe that any administrative allocation of Federal power, if it becomes necessary because of public preference considerations, is better left until the end of the Subscription period. Murphy, SUB01-040; Early, SUB01-078. They reason that negotiating with all customers simultaneously to meet all load requests, while sending appropriate price signals by proposing that power subscribers pay for all related power costs and risks, will lessen the likelihood that an administrative allocation will be required. Murphy, SUB01-040; Early, SUB01-078; Kaiser, SUB01-096. Several DSIs also stated that BPA's proposal is at odds with the final recommendations of the Comprehensive Review, which they 
assert proposed to allocate power to the DSIs based on the current purchases of all the DSIs. Reynolds, SUB01-122; Murphy, SUB01-040; Early, SUB01-078. While WPAG proposed that BPA should negotiate contracts with the DSIs in the second half of Subscription, it also stated that such loads should not exceed 1000 aMW. WPAG, SUB01-073.

Building on their proposal that BPA negotiate with them during Subscription to meet their total load, some DSIs further propose that in the event that BPA is oversubscribed at the end of the Subscription period, that BPA augment the Federal System to meet the incremental load increase over system resources, execute an administrative allocation, and/or restructure the DSIs' contracts in some way. Early, SUB01-078; Kaiser, SUB01-096; Murphy, SUB01-040; Elf Atochem, SUB01-200; Vanalco, SUB01-054. In general, it appears that the DSIs believe, if their other recommendations are followed, that any augmentation necessary to serve DSI loads would be minor, and should be melded into BPA base power rates. E.g., Murphy, SUB01-098, at 1; Kaiser, SUB01-096. Other parties urge BPA not to augment, or to augment only "on a purely bilateral basis," as recommended by the Comprehensive Review. Seattle, SUB01-104; see also Spokanes, SUB01-092 (no augmentation); PPC, SUB01-097 (no augmentation for DSI loads); WMG\&T, SUB01-099 (no augmentation for DSI loads); WPAG, SUB01-073 (no augmentation for DSI loads). WPAG proposes that any power sales contract executed by BPA with a DSI during the Subscription period should provide BPA with the unilateral right on 90 days' notice to reduce the amount of power to be sold by BPA to the DSI if the power is needed to meet public preference or IOU (up to 1500 aMW) residential load. WPAG, SUB01-073, at 9 .

\section{Evaluation and Decision:}

BPA is persuaded by the comments stating that delaying negotiations with the DSIs until after Subscription closes for the public preference and IOU customers would work an unnecessary hardship on the DSIs. Reynolds, SUB01-039; Kaiser, SUB01-096; Murphy, SUB01-040; WPAG, SUB01-073. As noted by WPAG, BPA can negotiate Subscription contracts with the DSIs that protect the interests of public preference customers and the residential customers of the IOUs. In negotiating contracts with the DSIs early in the Subscription window, BPA intends to discuss contract provisions that would, under certain circumstances, permit the adjustment of the volume of sales to the DSIs; adjust the shape of deliveries of power; provide for risk-sharing pricing arrangements; and allow for interruption. In light of these measures, and for other reasons discussed below, BPA does not believe it is necessary to wait until the second half of Subscription to negotiate with the DSIs, as recommended by WPAG. WPAG, SUB01-073, at 9 . BPA does not agree with the suggestion by some parties that BPA should "withhold from the DSIs any uncontracted power." Sierra Club, SUB01-089; see also Friends of the Earth, SUB01-169 (DSIs have no legal claim to any allocation of power from the Federal System). The DSIs remain valuable customers that BPA will 
attempt to serve with firm power at competitive rates, if possible, consistent with its statutory preference and ratesetting obligations. Furthermore, to the extent that BPA is undersubscribed, or has surplus firm or nonfirm power for sale, the DSIs, if offered a contract, would have a statutory regional preference to such power over out-of-region customers. See 16 U.S.C. $§ \S 837$, et seq.; 16 U.S.C. $\S 832 \mathrm{~m}$.

In addition to negotiating with all customer groups, including the DSIs, during the Subscription period, BPA has decided that it will not cap, at this time, the amount of Subscription power that it may sell to the DSIs. BPA agrees with the DSIs that establishing a cap of 1000 aMW of DSI sales at the beginning of the Subscription process would unnecessarily lessen their ability to effectively negotiate with other suppliers. Reynolds, SUB01-039; Kaiser, SUB01-096; Murphy, SUB01-040. BPA also concurs with the DSIs that if the Federal System becomes oversubscribed it can deal with the issue at that time, by invoking the contract measures described above, by administratively allocating existing power consistent with preference provisions, and/or by augmenting the system, if consistent with BPA's rate goals, to bring resources into balance with loads. Early, SUB01-078.

Under some circumstances BPA may have sufficient resources to serve only a portion of the DSI load. One DSI indicated that, in such a case, BPA should give special consideration to serving those DSIs that placed the highest percentages of their load on BPA in the current rate period. Port Townsend Paper (Port Townsend), SUB01-132. The only other DSI to comment on this issue suggested that if BPA managed its resources properly there would be no need to allocate power between or within customer classes, but that favoring some DSIs over others on the basis of the load placed on BPA in 1995 was misplaced. Vanalco, SUB01-054. In the event that BPA is able to serve only a portion of the DSI load placed upon it in Subscription, BPA might use an allocation scheme within the DSI class to establish a service priority to those DSIs that purchased during the current rate period the largest percentage of their load from BPA. But BPA will delay such a decision until circumstances demonstrate that such an intra-class allocation is needed.

Many of the DSIs advocate the augmentation of the Federal System in the case of over-Subscription, with the costs of augmentation melded into BPA's base rates. Early, SUB01-078; Kaiser, SUB01-096; Murphy, SUB01-040; Elf Atochem, SUB01-200; Alcoa, SUB01-050; Vanalco, SUB01-054. Some DSIs proffered market scenarios which purport to demonstrate that under virtually any circumstance where BPA costs are below market, BPA can augment the system and meld the costs without large increases to its base rates. Kaiser, SUB01-096; see also Murphy, SUB01-098. Other customers oppose augmenting the system, and melding the costs of such augmentation into BPA's base rates, to serve DSI loads. Seattle, SUB01-104; Spokanes, SUB01-092; PPC, SUB01-097; WMG\&T, SUB01-099; WPAG, SUB01-073. $B P A$ is not prepared at this time to make any final decisions regarding augmentation. However, BPA does not intend to meld the costs of any augmentation into base rates if 
doing so would increase those rates above BPA rate targets. Therefore, BPA will not cap the DSI purchase amount.

\section{Serving Other Loads}

Issue:

How should BPA's Subscription Strategy address extraregional sales?

\section{Subscription Proposal:}

BPA stated that the Proposal retained public power preference and regional preference. The Proposal does not address Federal power sales to extraregional customers.

\section{Parties' Comments:}

SMUD stated that "all Federal power which is surplus to Bonneville's statutory load obligations in the Pacific Northwest first [should] be offered to the preference entities like SMUD, before being sold to non-preference entities." SMUD, SUB01-088. SMUD wishes to know what opportunities exist for out-of-region preference entities to buy BPA power. Id.

\section{Evaluation and Decision:}

The focus of the Subscription Strategy is new post-2001 firm load power sales to Pacific Northwest customers and spreading the benefits of the FCRPS throughout the region, especially to residential and rural consumers. The intended results of the Subscription process include wholesale power rate stability, assurance of support for BPA's fish and wildlife obligations, and encouragement of conservation and renewable resources. Sales to extraregional entities are a possibility only if BPA does not subscribe all of its Federal power to Pacific Northwest customers. Such sales are not the focus of the Subscription process, but BPA intends that any power remaining after all requests from regional loads are met will be offered to extraregional public customers consistent with public preference and other customers under the applicable provisions of Northwest preference statutes. 


\section{POWER PRODUCTS AND SERVICES}

\section{A. Risk Management Strategy}

Issue:

What tools should BPA use to manage its risk?

\section{Subscription Proposal:}

BPA proposed a risk management framework with a set of tools to manage the risks associated with Treasury Payment Probability and implementation of the Fish and Wildlife Funding Principles announced by Vice-President Gore on September 21, 1998. BPA's pricing approach reflects BPA's business risk and costs and will ensure as much as possible that the cost of additional risks incurred by BPA is paid by those customers for whom the risks are taken. The specific mix and design of the risk mitigation tools will be determined in the upcoming Power Rate Case. In the Proposal, the list of possible tools included: cost cutting; staggered contract terms; option fees; cost-based indexed prices; use of start-of-rate-period reserves; $4(h)(10)(C)$ credits; the Fish Cost Contingency Fund; a CRAC for power; and as a last resort, a limited "loan" from BPA's transmission business.

\section{Parties' Comments:}

BPA received over 60 comments on the proposed risk mitigation strategy. The comments generally supported BPA's plan to have a menu of risk mitigation tools available to manage risk. There were many divergent opinions about how best to implement that menu, particularly BPA's proposal on cost recovery. In general, comments expressed support for BPA cost cutting. Other comments expressed concern over staggered contract terms (see ROD section IV.D.), cost-based indexed rates (see ROD section III.G.) and especially option fees (see ROD section IV.E.). Comments on reserves, CRAC, and the proposed transmission surcharge are addressed below. No comments specifically addressed the tools of $4(h)(10)(C)$ and the Fish Cost Contingency Fund.

\section{Evaluation and Decision:}

Comments generally supported BPA's risk management framework and use of a set of risk management tools. BPA concludes that it is necessary to develop a risk management framework and tools to manage hydro, market price, resource, cost and other risks. BPA's pricing will reflect business risk and costs and will ensure as much as possible that the cost of additional risks incurred by BPA is paid by those customers for whom the risks are taken. The specific mix and design of the risk mitigation tools 
will be determined in the upcoming Power Rate Case. The list of possible tools includes: cost cutting; staggered contract terms; cost-based indexed prices; use of start-of-rate-period reserves; $4(h)(10)(C)$ credits; the Fish Cost Contingency Fund; a CRAC for power; and as a last resort, a limited "loan" from BPA's transmission business. BPA will not offer option fees, as discussed in section IV.E. BPA will include a CRAC that is applicable to all firm requirements rate schedules in its power rate proposal. After consideration of comments recommending a rate reduction rebate mechanism, the proposed CRAC will include not only an upward adjustment mechanism, but a "dividend" distribution mechanism (the so-called "Reverse CRAC"). BPA intends to implement the Fish and Wildlife Funding Principles by ensuring that the design of contracts and rates is consistent with those principles. Analysis of the comment received on financial reserves and cost recovery follow below.

\section{Reserve Levels}

Issue:

What reserve levels should BPA assume for the Power Rate Case?

\section{Subscription Proposal:}

The Proposal addressed reserves only by stating that one of BPA's risk management tools would be to use reserve balances carried into the 2002-2006 rate period from the prior period. Reserve levels are a rate case issue.

\section{Parties' Comments:}

Comments from public utilities and their representatives acknowledged BPA's need to have sufficient reserves to run its business, but their comments were uniformly opposed to BPA building up too large a level of reserves. EWEB, SUB01-107; PNGC, SUB01-086; NRU, SUB01-057; Public Generating Pool (PGP), SUB01-069; PRM, SUB01-087; Tanner, SUB01-093; Benton PUD, SUB01-101; KPUD, SUB01-111; Springfield, SUB01-121; Surprise Valley, SUB01-149; PPC, SUB01-097. PPC cautioned BPA against setting rates "artificially high" for the purpose of an increase in reserves. PPC, SUB01-097 at 9. WMG\&T called a high level of reserves "an attractive nuisance for all kinds of spending proposals." WMG\&T, SUB01-099 at 4. The ICUA and the Pacific Northwest Waterways Assn. (PNWA) objected to BPA building too large a level of reserves to pay for dam modifications not authorized by Congress. ICUA, SUB01-109; PNWA, SUB01-117.

In contrast, the Sierra Club commented that BPA was taking a prudent business course by committing to build "sufficient" reserves. Sierra Club, SUB01-089. Friends of the 
Earth expressed its support for BPA establishing reserve levels to cover fish and wildife costs into the future. Friends, SUB01-169. The Spokanes expressed support for strategies that would result in a "healthy" level of reserves going into the 2006 rate period. Spokanes, SUB01-092 at 4. Governor Kitzhaber of Oregon also supported establishing reserves to help BPA to meet fish and wildlife obligations post-2006. Kitzhaber, SUB01-067. Columbia River Inter-Tribal Fish Commission (CRITFC) commented that "BPA must not assume that carry forward of unexpended fish and wildlife balances under the fish and wildlife funding Memorandum of Agreement are part of BPA's general reserves for 2002-2006." CRITFC, SUB01-142 at 4.

Some comments discussed the amount of money BPA should plan to include for fish recovery in the upcoming rate case to keep the options open. For example, the DSIs commented that the cost of fish and wildlife alternatives being considered was too high. Murphy, SUB01-098. Tillamook County PUD (Tillamook) commented that BPA must establish a limit to what fish restoration can be funded. Tillamook, SUB01-052. NWEC recommended that BPA design its rates and contracts to cover the highest-cost fish scenario now being studied by National Marine Fisheries Service and the other responsible agencies. NWEC, SUB01-114. CRITFC commented that BPA's approach does not "set budget levels sufficient to implement drawdown" but instead relies on "unrealistic BPA cost reductions" and "contingent cost recovery mechanisms." CRITFC, SUB01-142 at 1.

At the Power Subscription Strategy Public Meeting on October 8, 1998, held in Spokane, Washington, both the WMG\&T and the Sierra Club questioned the probabilistic treatment BPA plans to apply to the projected costs of 13 different fish and wildlife mitigation scenarios. WMG\&T asserted that certain higher-cost scenarios should not be included because they were unworkable. Transcript, Power Subscription Strategy Public Meeting, Spokane, Washington, (Oct. 8, 1998) at 78-79. Sierra Club asserted that certain lower-cost scenarios were unworkable. Id. at 85 . Several written comments also addressed the application of probabilities to the costs associated with the 13 different fish and wildlife mitigation scenarios.

\section{Eyaluation and Decision:}

BPA will address reserves in the initial proposal for the upcoming Power Rate Case. BPA intends to meet its rate commitment and its probability target, and implement the Fish and Wildlife Funding Principles and the Cost Review recommendations. Therefore, it will not set its rates "artificially" high in order to build high levels of reserves. Rates set to build reserves comparable to historical levels may be adequate to meet the desired Treasury Payment Probability on a planning basis. However, BPA will not necessarily design rates to preclude large reserve balances. As addressed in the next issue, BPA intends to propose a "reverse CRAC," which will address concerns of building reserve levels excessive to needs. Any such mechanism will be designed in a manner consistent with the Fish and Wildlife Funding Principles. The comments also 
reflect opposing views on how the probabilistic approach should be adapted, demonstrating the difficulty of consensus on this issue. Details about the use of probabilities will be included in the initial proposal for the Power Rate Case. BPA intends to implement the Fish and Wildlife Principles and will set rates consistent with those Principles.

\section{Cost Recovery}

Issue:

What risk mitigation tools should BPA use in developing rates?

\section{Subscription Proposal:}

The Proposal listed several cost recovery mechanisms that may be used to manage risk and ensure recovery of all of BPA's planned net revenues. These include the use of reserve balances carried over from the previous rate period, $4(h)(10)(C)$ credits, the Fish Cost Contingency Fund, additional cost reduction efforts, staggered contract terms, price stability as guaranteed by option fees, and cost-based indexed pricing for some products. Also mentioned were a CRAC for power rates and a last-resort "loan" from the transmission business in the form of a transmission surcharge.

\section{Parties' Comments:}

BPA received over 50 comments on the subject of cost recovery. The comments were fairly well split between groups calling for more reliance on CRAC and groups calling for a greater reliance on a transmission surcharge. In between these groups were comments calling for no limit to either. The sections below summarize the comments on CRAC, a "Reverse CRAC," and a transmission surcharge.

CRAC: One group of comments focused on removing or reducing the limits on the amount of the CRAC mechanism. The DSIs argued that since power customers receive the benefit of Federal power, they should bear the risk associated with that power. Murphy, SUB01-040; Early, SUB01-078; Kaiser, SUB01-096). Some made comments that a CRAC be allowed to rise to market rates. Murphy, SUB01-040; Litchfield, SUB01-053; Puget, SUB01-055; MPC, SUB01-062; Washington Dept. of Commerce, Trade \& Economics (WACTED), SUB01-063; Gov. of Montana, SUB01-068; CRITFC, SUB01-142. NWEC urged BPA to adopt a CRAC with an upper limit higher than $\$ 50$ million. NWEC, SUB01-114. The Transition Board believes an important principle to be reflected is that customers who purchase little or no power from BPA should not be subject to power-related costs if power customers are paying below-market rates. Transition Board, SUB01-204. The Sierra Club commented that if 
power customers do not face market rates before BPA triggers the transmission surcharge, "there will be questions in the halls of congress." Transcript, Power Subscription Strategy Public Meeting, Spokane, Washington, (Oct. 8, 1998) at 87. WWP and the State PUCs went even further and proposed no limit on CRAC. WWP, SUB01-066; State PUCs, SUB01-146.

Another group asserted that the proposed CRAC was onerously high or unnecessary. Benton PUD, SUB01-101; Clallam, SUB01-150; Northern Wasco, SUB01-048. While not disputing $\$ 100$ million as the annual limit, WPAG felt a $\$ 200$ million limit should be put in place for the rate period. WPAG, SUB01-073. Georgia Pacific Company (Georgia Pacific) asserted that neither they nor Central Lincoln should be required to pay the CRAC. Georgia Pacific, SUB01-165. Lower Valley asked that they be allowed to void contracts if CRAC is implemented. Lower Valley, SUB01-081. Grant PUD and the PGP felt that CRAC should not apply to the Slice product. Grant, SUB01-058; PGP, SUB01-069. Commenters also looked for BPA assurances that CRAC would apply to IOU and DSI sales. Several commenters mentioned their belief that the trigger event for CRAC should not be based on BPA projections and should be based on events outside of BPA's control. MPC also questioned BPA's proposal to offer customers the ability not to take CRAC by paying a higher rate. Some comments recommended that BPA adopt the Transition Board's version of a CRAC. NWEC, SUB01-114; MPC, SUB01-062.

Reverse CRAC: A number of parties commented that if BPA implements a CRAC for potentially adverse conditions, BPA also should propose a rate reduction rebate that triggers when reserves reach too high a level. WMG\&T, SUB01-099; Inland, Transcript, Power Subscription Strategy Public Meeting, Spokane, Washington, (Oct. 8, 1998) at 67; Northern Wasco, SUB01-048; NRU, SUB01-057; Grant, SUB01-058; PGP, SUB01-069.

Transmission Surcharge: Comments on the transmission surcharge generally were divided between those who felt BPA's proposed "last resort" reliance on a surcharge would be too onerous and those who felt BPA did not rely on the surcharge enough. CRITFC commented that the Federal transmission system has caused damage to fish and wildlife and should not be limited when called upon to mitigate for this damage. CRITFC, SUB01-142. The PUCs commented that the proposed charge violated BPA's commitment to the full separation of PBL and Transmission Business Line (TBL) and should happen only in emergency conditions. State PUCs, SUB01-146. CUB commented that no one, including the DSIs, should escape the transmission surcharge if it is used. CUB, SUB01-103. OURCA is concerned that a limitation of the transmission surcharge may change the security afforded the net-billed bonds.

OURCA, SUB01-116. NWEC recommended that BPA make clear that the limit of $\$ 25$ million per year is a goal, and will not become part of contracts or other formal agreements with customers. NWEC, SUB01-114. 
Other comments expressed concern that the proposal to surcharge transmission rates would allow BPA to subsidize its power business and keep its power rates unfairly below market. Enron, SUB01-022; Murphy, SUB01-040; Litchfield, SUB01-053; Puget, SUB01-055. These comments reflect the view that BPA should allow CRAC to float to market. Some parties commented that the transmission surcharge should be targeted to power purchasers. Other parties expressed opposition to the use of a surcharge. WWP, SUB01-066; Georgia Pacific, SUB01-165; Early, SUB01-078; WMG\&T, SUB01-099. Other parties questioned whether BPA has the authority to implement this charge. Litchfield, SUB01-053; WWP, SUB01-066.

Several parties stated that it is inappropriate or unnecessary to limit BPA's use of the transmission system to recover costs. PPC, SUB01-097 at 11; Benton, SUB01-101; NRU, SUB01-057; EWEB, SUB01-107; URP, SUB01-120; CRITFC, SUB01-142; Sierra Club, SUB01-089. EWEB asked BPA not to limit the use of the transmission surcharge due to the existence of the CRAC. EWEB, SUB01-107.

\section{Evaluation and Decision:}

CRAC: As summarized above, comments on CRAC were mixed. To the extent possible, BPA intends for the benefits and risks of purchasing BPA power to go hand in hand. The DSIs commented that the amount of CRAC should not be prejudged in advance of the rate case. Murphy, SUB01-040. BPA concurs with this comment. Any limits on the size of a CRAC and its application are required to be addressed in a rate proceeding, so will be set in the upcoming Power Rate Case.

The frequency with which a CRAC can be triggered, the threshold at which it triggers, the initial rate level, other tools used, and other factors, all taken together, can determine the size of any CRAC. For this reason, the design of the proposed CRAC, including the size, will be developed in the Power Rate Case. BPA must reject Lower Valley's suggestion that customers be allowed to void contracts if BPA triggers CRAC, because this would expose BPA to excessive financial risk.

Another area addressed in the comments was whether BPA should give customers the option of choosing a higher rate rather than subjecting themselves to CRAC. MPC expressed concern about this approach. MPC, SUB01-062. While BPA believes it can implement both approaches, BPA will reduce the complexity of the upcoming rate case by not offering the higher rate option.

In summary, CRAC will not be optional, and its size and implementation details will be addressed in the upcoming Power Rate Case.

Reverse CRAC: Based on the comments, BPA has decided that in the upcoming Power Rate Case it will propose criteria and mechanisms for distributing "dividends" to key stakeholders during the 2002-2006 rate period if actual financial 
performance is substantially better than the rate case plan. The "dividends" would be distributed first to support incremental customer-sponsored conservation and renewable activities (see ROD section III.F.), then among customers, Treasury, and other public purposes. BPA will propose that the threshold for triggering a "dividend" distribution be based on net revenues accumulated. The threshold would be set at a level substantially above the rate case plan. BPA does not intend to set its rates to guarantee excessive reserves. BPA will make the decision to distribute "dividends". mindful of its commitment to the Fish and Wildlife Funding Principles. The mechanism would not trigger if post-2006 expenses are expected to rise substantially or if the uncertainties related to fish costs have not been resolved. If such a mechanism is put in place, it will need to allow BPA to make prudent business decisions based on expected future costs.

Transmission Surcharge: Much like the comments on CRAC, comments on the transmission surcharge represented a range of views. The range of comments on either side of the BPA Proposal leads BPA to believe that consensus is not possible. BPA will retain the option to implement a surcharge as a last resort. In Subscription contracts, like pre-Subscription contracts, both parties will preserve existing rights regarding transmission surcharges, as discussed below.

Several commenters noted that BPA's Proposal did not establish a limit on the surcharge but expressed BPA's intention to keep it to a \$25 million "loan." As suggested by certain IOUs, BPA has decided to use language similar to language in the pre-Subscription contracts, which establishes BPA's right to impose a surcharge on transmission but preserves the rights of customers to dispute BPA's assertion. Surcharge design and parameters must be resolved in a transmission rate case. BPA intends to design its power rates and adopt other risk mitigation tools to meet its Treasury Payment Probability target without a transmission surcharge. OURCA's concern regarding the security for the net-billed bonds is well-taken; however, BPA sees no change the security of the bonds in that BPA's proposal does not limit the surcharge to $\$ 25$ million.

In summary, power rates will be set to meet Treasury Payment Probability targets without reliance on a transmission surcharge. In Subscription contracts, like pre-Subscription contracts, both parties will preserve existing rights regarding transmission surcharges. 


\section{B. Product Categories}

\section{Core Subscription Products}

Issue:

What are the Core Subscription Products BPA will offer to serve Requirements Load?

\section{Subscription Proposal:}

Core Subscription Products are available to customers who request net firm power requirements load service to serve regional consumer load, and who accept constraints on their ability to shape their purchases from BPA for any reason other than following variations in consumer load. All standard Core Subscription Products are undelivered. All Core Subscription Products will be offered at BPA's posted rates.

\section{Parties' Comments:}

BPA received several comments that noted that BPA's products required additional development. Parties suggested that the basic Power Products should be completeiy defined prior to the commencement of the Power Rate Case. PPC and others suggested that the final Subscription Strategy should determine product policy and the final product details should be left to a different forum. PPC, SUB01-097.

EWEB suggested that BPA delay opening the Subscription window until the Core Products are finalized. EWEB, SUB01-107.

\section{Evaluation and Decision:}

BPA has completed the primary policy development of the Core Subscription Products (i.e., Full, Partial, Block, and Factoring Service). BPA staff will continue to meet with interested parties to discuss and clarify implementation details for the Slice of the System product, Partial Service for customers with dispatchable resources, Block with factoring, and other products as requested. BPA staff also will work to resolve the remaining issues around equitable comparability between Full and Partial service products.

Updated product descriptions are included in the Revised Version of the Product Catalog. The revised Product Catalog reflects the recommendations for changes suggested by interested customers to date. For example, the Actual Partial product for customers with variable resources contains the customer revisions from the meeting on November 10, 1998. 
The product descriptions for the Core Products will establish the services a customer may expect at the posted rates (e.g., HLH/LLH energy, load variation, demand, etc.) and will be the basis for the initial proposal in BPA's upcoming rate case.

\section{Customized Subscription Products}

Issue:

What types of products will be offered to customers that request Requirements Service and require additional operational flexibility?

\section{Subscription Proposal:}

Customized Products are available to customers who request net firm power requirements load service to serve consumer loads (Core Products) and who want additional flexibility to reshape their purchases from BPA in order to optimize their resource operations. These products will have bilaterally negotiated pricing for all modifications to Core Products and any additional products and services customers wish to purchase. Examples of customized products include Slice of the System and Renewable and Environmentally Superior Products.

\section{Parties' Comments:}

Few comments were received related to BPA's intent to offer Customized Subscription Products. Port Angeles noted that while it is too early in the process to determine which products best satisfy the needs of their customers, they are pleased to know they will not be limited to a single power product for all their loads. Port Angeles, SUB01-064.

OURCA noted that BPA should establish cost-based rates for all of its Core, Customized and Non-Subscription Products to serve the net requirements of the public preference customers. OURCA, SUB01-116.

\section{Evaluation and Decision:}

The following clarifies the applicable rate schedules that will apply as a result of any bilateral negotiations for Customized Subscription products. It is appropriate to charge customers based on the additional flexibility they require, because each customer will have different needs. BPA will offer Customized Products that are combinations of posted Core Products and customized features. The portions of these Customized Products that are the same as the posted Core Products will be priced at the applicable 
posted rate. The pricing for any customized services that substantially differ from the posted Core Product descriptions will be bilaterally negotiated under the FPS rate schedule. BPA will establish cost-based rates for the Core Products.

\section{Non-Subscription Products}

Issue:

What is the purpose of the Non-Subscription Products?

\section{Subscription Proposal:}

Non-Subscription Products are products that serve customer needs other than those firm power requirements loads served by the posted Core Products. It also includes products that BPA may offer when inventory exceeds that needed to meet BPA's total net firm load requirements service and its other firm obligations. This category broadly includes power products and services that BPA might sell to any customer in the marketplace. These products will have prices negotiated under BPA's FPS rate schedule within the cost-based cap set by that rate schedule.

\section{Parties' Comments:}

Few comments were received related to the BPA's intent to offer Non-Subscription Products. Some commenters such as OURCA recommended that all BPA's product offerings, whether for service to requirements or for other purposes, should be at posted cost-based prices. OURCA, SUB01-116.

\section{Evaluation and Decision:}

BPA will offer Non-Subscription products. BPA will offer these Non-Subscription Products to meet the needs of customers that require products and services other than the Core Products offered at the posted rate. The prices for these products will be negotiated under BPA's FPS rate schedule on an as-needed basis.

\section{Slice of System}

Issue:

Should BPA offer a Slice Product? 


\section{Subscription Proposal:}

BPA proposed to offer a Slice of the System (Slice) arrangement in the September 18, 1998, Power Subscription Strategy Proposal. BPA's proposal was based on the PGP proposal, with several BPA modifications to ensure that the proposal met the five principles described by BPA in March 1998.

\section{Parties' Comments:}

Several parties expressed support for BPA's proposal to offer the Slice product. PGP, SUB01-069, at 1; Grant, SUB01-058 at 4; Seattle, SUB01-104, at 2; EWEB, SUB01-107, at 8.

Several reasons were stated for supporting the Slice product. PGP opined that Slice would hedge BPA's risks and not adversely affect other customers. PGP, SUB01-069, at 1. Grant asserted that Slice is an appropriate way to ensure the benefits of the Federal power system in the Northwest remain with those for whom the system was originally constructed, and distributions of benefits, costs, and risks are closely aligned. Grant, SUB01-058 at 4. Seattle asserted that the product has potential to forge long-term partnership between BPA and customers willing to directly assume nearer-term risks in exchange for longer-term benefits of the Federal System. Seattle, SUB01-104, at 2. EWEB asserted that Slice is a way BPA can diversify its risks and meet customer needs. EWEB, SUB01-107, at 8. PGP asserted that the Slice annual true-up mechanism is a risk management tool. PGP, SUB01-069, at 4.

At the same time, concerns were raised by several parties. Several DSI customers stated that BPA is proposing to incur "significant costs" to implement Slice before it has any actual Slice purchase commitments. They express concern that BPA has increased the resource uncertainty around BPA's power service that has motivated BPA to decline to offer DSIs firm power sales contracts in the same timeframe with other customers. Murphy, SUB01-040, at 16.

Inland expressed concern that BPA would 'slice off' power for customers that have the ability to use the Slice and hurt availability or price to other customers. Heitman, Oct. 8, 1998, Public Meeting Transcript at 70.

CRITFC commented that it is important that the consequences of the proposal be fully understood prior to a decision by the Federal government to proceed to implement Slice. They assert that BPA must, under its own guidelines, "assure that Tribal policymakers and elected officials understand the technical and legal issues necessary to make informed decisions ..."CRITFC, SUB01-142, at 3 . They also noted concern about the potential alternative dispute resolution process. They commented that it is imperative that Slice purchasers have no control over how the hydrosystem is operated either directly or indirectly. Federal agencies must be able to make decisions on 
operations that affect fish and wildlife as quickly and efficiently as possible, without any obstruction from customer groups. CRITFC, SUB01-142, at 5.

Several additional cautions were offered. PPC noted that because BPA's products (including Slice) are not fully developed, they should be addressed methodically and systematically after the proposal is finalized and before the Power Rate Case commences. PPC, SUB01-097, at 12.

Several parties expressed cautions on how BPA should proceed with the Slice product. EWEB does not understand or accept new concepts BPA introduced at the October 13, 1998 , Slice meeting, so BPA needs to allow product design discussions to continue into the rate case. EWEB, SUB01-107, at 8.

Grays Harbor commented that BPA must work with customers to make the Slice product viable and allow for sufficient operational flexibility. They opined that the current proposal does not provide enough information for them to provide detailed comments. They propose that BPA continue discussions with its customers so the products in the rate case meet customer needs. Grays Harbor, SUB01-108, at 3.

Springfield commented that product descriptions are loosely defined and it is premature to incorporate a final decision on an aspect of product design at this time. Springfield; SUB0 $1-121$, at 4.

\section{Evaluation and Decision:}

BPA's discussion with its customers over a "Slice of the System" product have been conducted over the last 13 months, based on the PGP proposal. Preliminary analyses of the Slice proposal demonstrate that the Slice product could diversify BPA's risk exposure and lessen risks of financial under-performance. Purchasers of Slice would pay a pre-established portion of BPA's revenue requirement regardless of weather, streamflow, market, or generation output conditions. This assured payment would tend to mitigate BPA's financial risks in the event that any of these conditions put adverse financial pressure on BPA. Conversely, the assured payment would dampen BPA's financial gain when these conditions would otherwise be beneficial to BPA.

An additional feature of the Slice product is the annual (or possibly more frequent) true-up mechanism that would adjust payments by Slice purchasers to comport with actual costs incurred by BPA. This feature would help stabilize BPA's financial picture by sharing unexpected costs, as well as cost savings, with Slice purchasers.

By purchasing a Slice share over a long-term, a Pacific Northwest customer would assure themselves a portion of the benefits of the FCRPS in the form of a purchase of power and services based on the resource capability of the FCRPS. This assurance is similar to but in a different form than that which any purchaser of other Subscription products could obtain for themselves by executing a long-term power purchase 
contract. However, a Slice purchaser would protect itself from costs of future resource additions to FCRPS resources, and would accept the risk of reductions in Federal System capability. It would do this by agreeing to acquire its own non-Federal resources to meet its system load growth or to compensate for any derating of its own or FCRPS resources. In terms of preserving benefits of the system for Pacific Northwest customers, there is little distinction between Slice and other long-term contract purchasers.

The purchase of a Slice share would more directly link the benefits, costs, and risks of the FCRPS to the purchaser's power source. A Slice purchase is more closely aligned to the capabilities of Federal System resources than any other Subscription product. As Federal System capabilities increase or decrease over time, so would the power deliveries under Slice. Slice simplifies the pricing process, and puts the responsibilities and choices of how the customer's net firm power requirements load will be met directly into the hands of the purchaser, in exchange for assuming a portion of actual costs and risks. This arrangement puts the realization of benefits into the purchaser's hands. At the same time, a Slice purchase takes risks out of BPA's hands.

In response to the concern expressed by the DSI representatives, that BPA would be incurring costs by choosing to offer a Slice product, BPA would not incur significant costs to implement Slice before significant purchase commitments were made. As noted in discussion and materials presented at the October 13, 1998, Slice public meeting, potential Slice purchasers would be required to pay all implementation and set-up costs of the Slice. BPA intends to recoup any costs associated with implementing a Slice sale so that those costs are not transferred to other non-Slice purchasers. How these payments will be timed, and what commitments will be required, will be discussed in informal work groups prior to the Subscription rate case.

It is not clear how Slice could increase BPA's resource uncertainty, as suggested by the DSIs. On the contrary, Slice removes BPA's responsibility for meeting Slice purchasers' load at such times as it exceeds the purchaser's share of FCRPS resources. Slice also removes BPA's responsibility for meeting a Slice purchaser's load growth, and Slice removes BPA's responsibility for maintaining or replacing resources to meet the actual loads of Slice purchasers. In fact, Slice would appear to reduce certain resource or purchase power risks and increase BPA's certainty of resources needed to meet its obligations to Slice purchasers.

In order for a purchaser to obtain the Slice product, that purchaser must agree to provide sufficient declared non-Federal resources for the remainder of its consumer loads not served by Slice and have access to other resources and/or the ability to buy and sell in open electricity markets. Selling some portion of the power from FCRPS resources as Slice will make that power unavailable to remaining, non-Slice, customers. However, because Slice purchasers will pay a proportionate share of all costs of BPA's system attributable to it, and those are costs that are shared with non-Slice purchasers, 
there should be no cost shifts to non-Slice customers. Also, since Slice purchasers will avoid paying the costs of risk mitigation for only those risks that Slice purchasers will assume directly, there should be no shifting of risks or costs from Slice purchasers to purchasers of other BPA products. Slice should not adversely affect the prices for Subscription power and other products.

Moreover, Slice does not sell any part of the ownership or right to operation of the FCRPS to the purchaser. Control of the hydrosystem operation will continue to rest with the Federal agencies now charged with making operating decisions. Slice purchasers obtain only that power and service available based on the river conditions and reservoir operations BPA must implement for fish, flood control, or other considerations. BPA will not agree to any dispute resolution with Slice purchasers that could compromise decisionmaking regarding fish and wildlife protection, or any other aspect of river operations.

The Slice product described in the September 18, 1998, Power Subscription Strategy Proposal document provided only enough detail to allow evaluation of moving forward with Slice as a product offering. It was not fully developed nor detailed enough to solicit detailed comment. The concept is clear, however, as is BPA's policy intent regarding the features of the Slice product. The remaining work on Slice is the implementation of the concept and finalization of the product consistent with the guidelines laid out in the final Subscription Strategy and in this ROD. Over the next few months, BPA and interested parties will conduct further public discussions and collaboration to flesh out the issues and details of the Slice product. The results of these efforts will be a detailed Slice product that will be incorporated into the Power Rate Case. If required by policy changes or modifications to this proposal, BPA may issue a subsequent decision paper on the Slice product.

BPA will offer a Slice of the System product. The product has been requested by many customers, and it may be useful for mitigating certain financial risks to BPA, other customers, and the Treasury. This ROD lays out the rationale for BPA's decisions on the offering of a Slice product and its features as they have been made. Various specifics of a Slice product remain to be resolved, however, through discussions with interested parties. Those issues on implementation and product detail will continue beyond the publication of the Subscription ROD. To the extent that features of the Slice product must be resolved prior to the Power Rate Case, BPA will proceed expeditiously to do so.

Issue:

What priority do Slice purchasers have to secondary energy from the FCRPS versus other uses of that secondary energy? 


\section{Subscription Proposal:}

The Subscription Proposal proposed to provide $1000 \mathrm{aMW}$ of interruptible sales to the DSIs, without specifying how those sales would affect secondary energy received by Slice purchasers.

\section{Parties' Comments:}

PGP commented that the offer of interruptible power to DSIs should not affect Slice. They propose that BPA needs to ensure that delivery of Slice matches the Slice customer's preference status and commitment to cover BPA's costs and risks. PGP, SUB01-069, at 2.

\section{Evaluation and Decision:}

BPA sells Federal power consistent with statutes giving preference and priority to its public agency and cooperative customers. The proposed interruptible power product for the DSIs has been dropped from BPA's Power Subscription Strategy as discussed above. To the extent that the Slice product includes a sale of surplus firm power in certain times of the operating year, the public or cooperative customer buying the Slice product would have priority for that amount of surplus firm power over a non-preference customer to receive an offer of that power. Because the Slice product includes a purchase of surplus firm power, the public or cooperative utility request for that surplus power would be met before other requests for surplus power from non-preference customers.

If BPA makes any secondary energy commitments to other customers, that energy will come from BPA's share of the FCRPS remaining after Slice purchases. However, Slice purchasers will pay a proportionate share of any "net" costs (the net of the costs of supplying energy for a specific purpose and the payment received for such energy) that arise from using secondary energy to enhance the constrained FCRPS inventory.

\section{Issue:}

Will the Slice product be available to purchasers by schedule, only, or by dynamic signal?

\section{Subscription Proposal:}

Slice purchasers may obtain their shares by schedule. Any other arrangement would be by negotiation between the purchaser, the PBL and the TBL. 


\section{Parties' Comments:}

Springfield commented that BPA should reconcile that BPA already receives dynamic load signal from potential Slice purchasers and they are almost exclusively in BPA's control area. Springfield, SUB01-121, at 19. Springfield also opposes Slice not being offered by dynamic signal. Springfield, SUB01-121, at 22.

\section{Evaluation and Decision:}

The PGP, originators of the Slice concept, proposed that purchasers have the ability to obtain the power resulting from their ownership of a Slice share through use of "dynamic scheduling." This means that a purchaser would communicate with BPA by electronic request, currently at 4-second intervals. Such signaling is available only for purchasers that operate their own control areas. It is not available for customers within BPA's control area. Although Springfield opposes BPA's proposal that would not assure offering Slice by dynamic signal, Springfield did not present any reason as to why Slice would not work with BPA's current power scheduling protocols. Currently, BPA can set up and track accounts for power sales through its prescheduling methods. it is not clear whether the technical issues for moving to a dynamic signal within a control area are susceptible to resolution.

It is not certain that the BPA PBL will, itself, have the ability io access FCRPS resources by dynamic signal. Consequently, BPA cannot assure that purchasers, including Slice purchasers, will have the ability to access their power purchases of Slice shares by dynamic signal. This dynamic signal feature will be discretionary with BPA and will require negotiation among interested purchasers, the $P B L$, and the TBL.

Moreover, extensive work remains to figure out how to access Slice shares by signal, and to develop the software and acquire the hardware that would allow access to Slice shares by signal. The expected time and expense required for implementation of a direct signal is in addition to the set-up required for scheduled Slice. Since the costs associated with setting up direct signals will be borne by only those customers desiring that service, the logical solution is to first complete the set up for scheduled Slice, distributing the cost among all potential Slice customers, before attempting to set-up for direct signals.

Initially, access to Slice will be by schedule only. Once the algorithm to calculate the hourly Slice entitlement bounds is completed and working to everyone's satisfaction, BPA and interested Slice purchasers will work on developing a strategy for sending a signal to access the purchaser's Slice share. All development work and hardware costs for attempting to accommodate access by direct signal will be borne by the Slice purchaser wanting such access. For Slice purchasers in BPA's control area, direct signal capability will be problematic because the direct signal is intended to be a single signal for each purchaser. BPA recognizes that in working with these Slice purchasers, 
there will need to be a method to differentiate a dynamic Slice signal from any other dynamic signal the customer may have need for or use in its service from BPA.

\section{Issue:}

What costs would customers be responsible for if BPA were to set up a dynamic signal for access to Slice?

\section{Subscription Proposal:}

The Subscription Strategy proposal did not identify specific costs associated with dynamic signals.

\section{Parties' Comments:}

Springfield commented that a "down payment" for negotiating a dynamic signal should reflect only the costs of implementing a variable resource and not other impacts. Springfield, SUB01-121, at 19.

\section{Evaluation and Decision:}

Given the novelty of the Slice proposal and its effec! on dynamic signalling responses, BPA cannot determine that only one set or type of costs will be involved. BPA cannot assume away costs that may later be identified. The set-up costs for implernenting scheduled Slice will be shared among all customers purchasing Slice. The incremental costs to BPA for setting up dynamic signals will be shared among all Slice customers desiring dynamic signals.

\section{Issue:}

Will the Slice product be offered for sale to Pacific Northwest IOUs?

\section{Subscription Proposal:}

The Subscription Proposal stated that Slice would be used to meet net firm power requirements loads in the Pacific Northwest. The document was silent on whether that was limited to public agencies and cooperatives, or whether it included requirements sales to IOUs.

\section{Parties' Comments:}

Several parties representing IOUs support BPA offering the Slice product to IOUs. 
IPC commented that BPA should offer Slice to IOUs for residential and small farm loads as an option to the flat product. They opined that there are cost savings that should be made available to those customers. IPC stated that it looks forward to the process to assure that benefits go to the residential and small farm customers. IPC, SUB01-070, at 2.

IPC, MPC, PacifiCorp, and WWP commented that Slice should be offered to residential and small farm customers of IOUs. They further noted that issues of tracking benefits (of Slice) are before the region's PUCs. Litchfield, SUB01-053, at 5. Puget and PGE also argued that Slice should be offered for residential and small farm customers of IOUs. Puget, SUB01-055, at 4; PGE, SUB01-071, at 3.

MPC opined that a diversity of products, including the Slice, may be in the best interest of various IOUs' residential and small farm customers. They noted that tracking benefits may be harder than for a flat product, but advantages outweigh difficulties. MPC, SUB01-062, at 3.

The State FUCs commented that if Slice is offered, it should be offered to IOU residential customers as well for the power made available in excess of 1050 aMW. State PUCs, SUB01-146, at 11.

On the other hand, Springfield indicated that Slice should be made available only to preference customers. Springfield, SUB01-121, at 16 and 18.

\section{Evaluation and Decision:}

Under section 5(b)(1) of the Northwest Power Act, both preference (public body and cooperative) customers and IOUs are entitled to purchase net firm requirements power from BPA to the extent their firm regional consumer loads exceed their resource capabilities applied to that load. Under section 4(a) of the Bonneville Project Act, BPA is obligated to give preference and priority to public bodies and cooperatives in disposing of electric energy generated on the FCRPS.

The Slice product is a meld of requirements power, surplus (firm and nonfirm) power, and other power products and services. The requirements and surplus power provided to a Slice purchaser are operationally identical. A given set of operational conditions allows production of firm power that can be separated into categories of net firm load requirements, surplus firm, and nonfirm only by after-the-fact accounting.

Before nonfirm and surplus firm power can be offered to IOUs, it must first be offered to public bodies and cooperatives. When a Pacific Northwest public body or cooperative customer is the Slice purchaser, this priority presents no conflict. Any public body or cooperative purchaser of the Slice product would be entitled to first priority to nonfirm or 
surplus firm power as a share of FCRPS output. BPA has discretion as to which public agency customers may purchase surplus firm power or nonfirm in advance of its delivery.

However, if an IOU were the Slice purchaser, the priority to nonfirm and surplus firm power becomes an issue of competing requests from preference customers. In that situation, any nonfirm or surplus firm power generated on behalf of the IOU would have to be offered first to public bodies and cooperatives, before it would be available to the IOU purchaser. That requirement would necessitate inserting a procedural step into the Slice product that would potentially divert Slice power to a public body or cooperative purchaser. The additional step of offering the power to public bodies and cooperatives, and the potential diverting of Slice power, would greatly complicate the Slice product and would be incongruous to the concept and design of the Slice product. A "Slice" product with the additional procedural offering and the potential redirection of power would have a different cost basis, would provide a different set of benefits to its purchasers, and would alter the risks accepted by Slice purchasers and BPA. Such a product would differ greatly from BPA's Slice product.

Under sections 5(b)(5) and (6) of the Northwest Power Act, BPA is unable to declare insufficiency for public customers until BPA's obligations to them exceed the capability of the FBS. A Slice sale to an IOU would commit FBS output to that customer by contract when such generation may need to be allocated to public agency or cooperative loads on a planning basis. A non-preference Slice sale may not comport with the requirement that BPA allocate FBS power first to serve all preference agency load when declaring an insufficiency of Federal resources to meet the public agency and cooperative utility loads.

BPA has offered in the Subscription Strategy to make a flat sale to IOUs as a special settlement offer. In return for the IOUs accepting this special product (a limited amount of power in a flat shape and a financial component), the IOUs would agree to settle the Residential Exchange Program.

BPA is obligated to meet requests for service to requirements of IOUs at a rate established pursuant to section 7(f) of the Northwest Power Act. BPA will not offer the Slice product to IOUs and will not develop a special "Slice" product for service to IOUs. BPA will not offer the Slice product for service to residential and small farm consumers of IOUs under a special settlement offer in exchange for agreement to settle the Residential Exchange Program.

Issue:

What other Subscription products can be purchased in combination with the Slice product? 


\section{Subscription Proposal:}

The Subscription Proposal stated that if BPA and its customers could work through the issues, BPA would consider offering Slice in combination with Actual Partial Service. In materials presented at the October 13,1998, Slice public meeting, and in discussion at that meeting, BPA clarified that Slice could not be purchased in combination with other Core Subscription Products if that combination would result in new BPA risks or costs of service, or shift risks or costs from one product to another. BPA made clear its intent not to offer the basic Slice product in combination with the Actual Partial Requirements with Variable Resources product.

Materials presented and discussed at the October 13,1998, Slice public meeting stated that the Slice product can be purchased in combination with annual firm blocks.

\section{Parties' Comments:}

Comments from Parties varied on what products should be available in combination with the Slice product.

Benton PUD and Springfield support offering, or further investigation of, combining Slice purchases with actual partial service. They opined that BPA should offer the Slice product to actual partial customers. Benton PUD, SUB01-101, at 2. They stated that there should be further investigation of purchasing combinations of Slice and Actual Partial Service products. Springfield, SUB01-121, at 20.

Comments also supported combining Slice purchases with various foims of block service. Springfield proposed that purchases of variable block Core Subscription Products should be allowed in combination with Slice. Springfield, SUB01-121, at 19. PGP proposed that Slice be available for purchase in combination with the Firm Block product (shaped or flat). PGP, SUB01-069, at 2 and 4.

PPC proposed that customers should be able to purchase Slice in combination with other requirements products, such as the flat block. PPC, SUB01-097, at 13.

Both Springfield and PRM opposed the proposal to conduct bilateral negotiations for combining Slice with Actual Partial service. PRM opposed because doing so could signal that BPA would not offer Slice to smaller customers. PRM encouraged BPA to resolve the issues to combine Slice and Actual Partial as soon as possible. PRM, SUB01-087, at 5. Springfield asserted that the ROD, not bilateral negotiations, should indicate how Slice can be combined with other products to yield a "net requirements" arrangement. Springfield, SUB01-121, at 17. However, Springfield did support other arrangements being possible by bilateral negotiation. Id. 
Regarding the purchase of other products and services in combination with Slice, Springfield asserted that BPA should not limit the ability of customers to get purchasing or marketing services from BPA along with Slice. Springfield suggested wording, "Slice purchasers would not be guaranteed to purchasing or marketing services from BPA for uncontracted-for Subscription products. In particular, BPA would be relieved of its obligation to serve a net requirements Slice purchaser's loads through the sale of Subscription Power in times of deficiencies." Further, Springfield asserted that Slice purchasers should not have to pay for purchasing and marketing services if they don't get them. Springfield, SUB01-121, at 19.

Springfield also proposed not prohibiting purchases of ancillary services by Slice purchasers and allowing Slice to be integrated into a Control Area Service package (part of a portfolio of other preference products). Springfield, SUB01-121, at 20.

\section{Evaluation and Decision:}

The fundamental concept behind Slice is that the customer assumes the risk and responsibility for managing the power and resources available to them to meet their consumer loads. Thereby. BPA is relieved of that risk and responsibility. The customer would be responsible for matching its power supply to its own load, which is uncertain either because of load variations, load growth, or variations in resource availability. Since Slice is a bundled product, there are numerous benefits and costs that are considered in the overall equity of the Slice product in relation to BPA and its non-Slice purchasers. Some of the risks accepted by Slice purchasers are variations in loads and weather, and variations in customer and FCRPS resources. If BPA were to combine the Slice product with other "load-based" power products that provide service for those variations, the risk benefits to BPA, other customers, and the Treasury would be eliminated. This would result in a net shift of benefits to the customer. With a fixed annual flat block sale, such a shift would not occur, since the block is a specific amount of power at all times, and thie risk of meeting a customer's actual load or resource variation remains with the customer.

The Slice product proposed by the PGP was founded on the premise that customers, rather than BPA, should be empowered to make their own purchasing and marketing choices, while still retaining access to some of the benefits of the FCRPS.

Consequently, the proposed Slice product did not include purchasing and marketing services, although BPA has made clear that it will consider bilateral arrangements, outside the Slice product, to meet the needs of customers. Similarly, other service packages could be constructed, outside the Slice product, through negotiation with BPA's PBL and TBL.

BPA's Slice product is based on the PGP proposal, which did not include load following or load regulation services that would meet the variations in loads and resources of a customer. Consequently, Slice may be purchased with flat annual blocks. BPA will 
consider bilateral negotiations to offer Slice in combination with variable monthly blocks under the FPS rate schedule.

\section{Issue:}

What rights will BPA retain to buy-back Slice power in excess of a purchaser's net requirements?

\section{Subscription Proposal:}

BPA may establish contract mechanisms to buy-back the surplus power portion of a Slice purchase if and when necessary to assure that BPA can provide service to BPA's other regional firm power loads in the Pacific Northwest, consistent with BPA's statutory or contractual commitments. The surplus power portion is the portion that is in excess of the utility's firm load.

\section{Parties' Comments:}

Grant and the PGP asserted that buy-back rights should be exercised only after all other options, including recall or interruption of other sales under sections 5(c), 5(d), and $5(f)$, have been exhausted. PGP, SUB01-069, at 2. Grant also commented that buy-back should include notification of customer(s) far enough in advance so they can take appropriate contingency actions. Grant also commented that buy-back should occur only for operational and reliability reasons, not economic reasons, and the customer should be adequately compensated for any buy-back. Grant PUD, SUB01-058, at 5.

Springfield commented that recall of Slice should be used only to meet the requirements of preference customers. Springfield suggested that prior to exercising recall, BPA must show it has not made non-recallable short- or long-term non-Subscription sales of power that could have been used to meet requirements of preference customers. Recall should be done as first: (A) recalling Slice purchased by non-preference entities; then $(B)$ recalling the non-requirements portion of Slice to preference entities. Recall of Slice should not allow BPA to inadequately reimburse Slice purchases. The buy-back rate should be at least equivalent to the PF rate with some potential crediting for additional risks the Slice customer may be assuming. Buy-back for other potential in-region commitments could be at a resale rate (with risk crediting) at the Slice customer's option. BPA would need to accommodate Slice customer transmission commitments. Springfield, SUB01-121, at 17.

Springfield also suggested that with buy-back, BPA should fully credit all costs associated with the Slice obligation the purchasers have assumed. Springfield, SUB01-121, at 20. 


\section{Evaluation and Decision:}

Slice is a customized requirements product. The net firm requirements load for which a purchaser is entitled to buy power from BPA is defined elsewhere in this ROD. To determine the maximum percentage of a Slice of FCRPS power that an individual purchaser may buy, the purchaser's net firm load requirements will be calculated as an average annual megawatt (MW) amount. That annual MW amount will, in turn, be used to determine a percent of annual FCRPS output that the net firm load requirement represents. Slice power will be made available on the basis of hourly, daily, and monthly minimum and maximum generation capability of the Federal System, and will be affected by any changes in system conditions. Consequently, the power delivered is highly unlikely to match the actual shape of the hourly, daily, or monthly net firm load requirements of any individual Slice purchaser. Therefore, depending on how much of a purchaser's entitlement the purchaser chooses to receive as Slice, the Federal power available to the purchaser may exceed the individual purchaser's net firm load requirements on certain hours and for certain months.

BPA's responsibility to meet its total Northwest firm power contractual commitments to its customers may at times require use of system power that is firm power above critical water planning. This need in certain periods could conflict with the obligations to provide power to a Slice purchaser when that power obligation exceeds the Slice purchaser's firm requirements load in the same period. In order to assure BPA's ability to meet its total regional firm load, BPA must have the ability to access all FCRPS capabilities. This means that BPA may not have surplus power in excess of its total regional firm power load obligations to deliver to a Slice purchaser, and a contract mechanism would be needed to relieve BPA of the surplus power obligation to Slice purchasers. In terms of the Slice product, this means that BPA must be able to buy-back the amount of power that would have been provided as surplus to a Slice purchaser in order to assure service to BPA's other Pacific Northwest customers. BPA expects to develop objective criteria for activation of the buy-back mechanism, and BPA expects that the mechanism would activate infrequently.

BPA and the Slice purchaser would agree upon a price for the power to be bought back, and upon notice provisions that would permit BPA to exercise the buy-back right. It is most likely that a price at or equivalent to the PF rate would be the pricing mechanism. Hence, to not confer a benefit or loss on BPA and the non-Slice customers, BPA should buy-back power from Slice purchasers at the PF demand and/or energy charges, whichever are applicable to the particular buy-back.

If BPA determines that a buy-back provision is needed to eliminate potential cost shifts, BPA will define the conditions upon which BPA can exercise its buy-back. The conditions could include such terms as BPA exercising recall rights available to it under some extraregional power sales contracts that provide for 60 -day notice. Such notice could be given if it would deliver power when needed prior to exercising the right of 
buy-back. Under section 5(b)(2) of the Northwest Power Act, BPA has the right to terminate deliveries to an IOU customer on five years' notice if the power is needed to meet BPA's preference customer firm requirements. However, such a long-term notice would not be effective in meeting a seasonal need for firm power within an operating year. So, the exercise of a buy-back notice to a Slice purchaser could not reasonably be conditioned upon prior exercise of a five-year notice to IOUs under their firm power contracts with BPA.

Springfield's proposed manner of exercising recall for BPA obligations does not comport with BPA's statutory directives. Further, BPA has no obligation to "show" that it has made non-recallable short- or long-term transactions. Sections 3(a) and (b) of P.L. 88-552 and section 5(b)(2) of the Northwest Power Act specify the standards for exercising recall notices to the purchasers of BPA power products. Springfield and other Pacific Northwest customers currently receive and will continue to receive BPA notices of availability of surplus firm power or excess firm power.

BPA will not limit its use of a buy-back only to meet its firm obligations to preference customers in the Pacific Northwest. Firm obligations to IOUs and DSIs, if any, also are firm obligations that must be met before BPA has any surplus power to deliver to any regional customer. As to whether BPA would limit the use of the buy-back to only operational needs, BPA will further define the buy-back provisions in its inıplementation discussions on Slice. It may or may not be so limited. Importantly, although the Slice purchaser will have the right to buy a portion of its Slice as surplus firm power, the Slice purchaser does not own rights to use the Federal resources. Discussions on the value of the power that may be subject to buy-back also will be a part of the implementation discussions BPA will conduct with its customers.

Issue:

How will the net firm load requirements of Slice purchasers be mapped to percentage shares of FCRPS resources?

\section{Subscription Proposal:}

Rights to purchase Slice shares must be matched to the customer's net firm load requirements, including peaking requirements, under section $5(\mathrm{~b})$ of the Northwest Power Act.

\section{Parties' Comments:}

Grant proposes that the Slice resource inventory should correspond to the inventory available to serve BPA's other requirements customers, and the "snapshot" of inventory should be taken when those resources are known. Grant, SUB01-058, at 5. 
Springfield proposes that resources added should also be added to the Slice resource base. Slice purchasers should receive a share of increased output of FBS improvements, additions, and replacements. Springfield, SUB01-121, at 21.

Springfield also proposes that nonfirm energy not be included in the resources used for mapping to maximum Slice percentages. Springfield, SUB01-121, at 18.

\section{Evaluation and Decision:}

During discussions with the customers, it was agreed that the mapping of a purchaser's maximum Slice percentage would use the utility's net firm load requirements as defined under section $5(b)(1)$ for Subscription purchases.

Using the purchaser's net firm load requirement, there are various ways of mapping a Slice percentage to correspond to the BPA load obligation that would result in the same annual aMW. The specific methodology that will be used is the subject of further discussions with interested parties, prior to the Subscription rate case.

\section{Issue:}

What is the term of contract commitment required for a purchase of the Slice product?

\section{Subscription Proposal:}

The Subscription Proposal stated that to assure that costs of fish and wildife mitigation and enhancement scenarios are not shifted to other customers, Slice commitments must be for at least 10 years. The strategy went on to say that, alternatively, Slice purchasers must make financial commitments that position BPA equally as well as other Subscription purchases to meet post-2006 financial obligations.

\section{Parties' Comments:}

PGP concurred with BPA's proposed duration of at least 10 years, and with BPA's willingness to consider other durations so long as they make financial commitments to BPA comparable to other products for post 2006-obligations. PGP, SUB01-069, at 4.

Grant commented that the requirement for at least 10-year contracts needs some flexibility. Grant expects to have increased non-Federal owned generation in the middle of the 10-year period and would like to see the ability to reduce a Slice purchase and return the resources to BPA to serve load growth of other customers. Grant, SUB01-058, at 5.

Springfield supports a 10 - to 20 -year term, with potential off-ramps for both parties. Springfield, SUB01-121, at 18. 


\section{Evaluation and Decision:}

BPA's proposed Slice product is narrowly defined to provide a balanced set of risks and benefits to both BPA and the purchaser. The product does not envision off-ramps for either BPA or the purchaser. Off-ramps would require BPA to evaluate and predict what cost and revenue effects the loss of a Slice purchase would produce. Also, the Slice is not being offered as an optional product the customer may take, but as one requiring a firm commitment to purchase. The benefit to BPA of a Slice sale comes from the certainty of revenue and reduction in risk. This benefit would not be achieved by off-ramps or conditional purchases. The duration of the product, the commitment to the product by BPA and purchasers, and the periodic true-up mechanism that will be defined for Slice will result in a specific risk profile acceptable to BPA, other customers, and the Treasury. Variations to significant features such as term, cost responsibilities, and true-up for actual expenses, would significantly alter that risk profile. Arrangements other than BPA's proposed Slice product may be possible, but they will not be "Slice" and the pricing of those arrangements will consider a different set of risks and costs than "Slice."

The purchase of Slice will require a fixed commitment by the purchaser of no less than 10 years. Arrangements for commitments of shorter durations are not included in the Slice product.

\section{Issue:}

Is a pilot, or testing, period required for implementation of Slice?

\section{Subscription Proposal:}

The Subscription Strategy proposal stated that BPA was considering the need for a pilot, or testing, period for implementation of the Slice. Subsequent discussions at the October 13,1998, public meeting on Slice clarified that BPA proposed to require a testing period prior to implementing the Slice arrangement on October 1, 2001.

\section{Parties' Comments:}

PGP agrees with the proposal to eliminate the pilot period. They agree with the proposal to conduct a test period prior to implementation to make sure required systems are fully functional. PGP, SUB01-069, at 2.

Springfield supports a pilot test using a low water year or simulation of low water so underdelivery of requirements power can be tested. Springfield, SUB01-121, at 18. 


\section{Evaluation and Decision:}

In order to have a functioning contract by October 1,2001, set-up and development work needs to be started as soon as possible. Some of this work may proceed prior to or during contract negotiations and could inform parties of any needed changes in terms. This work will require the full participation of customers interested in the Slice product. An important part of the set-up is testing the procedures and supporting calculations. It is anticipated that actual power deliveries will be required for the testing phase. The results of these tests will be used to modify and fine-tune the Slice product and the contract.

The Slice product is constructed on a paradigm wherein the purchaser takes responsibility for meeting its loads and BPA is relieved of that responsibility. From BPA's perspective, a delivery of firm requirements power to a Slice purchaser becomes no greater an obligation than a percent share of power the Federal System is capable of producing at a given time. The Slice purchaser has the obligation to fill in all other service from its own resources. BPA will have met its obligation to deliver net requirements service, and the purchaser internally manages the matching of its own resources and loads. There is no need for BPA to include in a Slice test any particular circumstance that from the customer's perspective may be an underdelivery of requirements power. What is delivered from the FCRPS on the hour, day, or month is a portion of the power and service actually available on the FCRPS at that time and there is no other obligation.

It is reasonable to conduct a testing period for a Slice product during the negotiation phase of Subscription and before implementation of a sales agreement on a Slice product on October 1, 2001.

Issue:

Will Slice purchasers pay for cost shifts to other customers, or receive credits for cost shifts away from other customers?

\section{Subscription Proposal:}

The Subscription Proposal stated that if there are cost shifts to or from Slice purchasers, from or to other BPA customers, those costs would be adjustments to the costs to be paid by Slice purchasers.

\section{Parties' Comments:}

PGP commented that the Slice annual true-up mechanism is a risk management tool. PGP proposes that the CRAC does not need to be applied to Slice because the product 
itself guarantees Treasury payments. They also stated that the Power Rate Case should determine the appropriate size of the credit to Slice purchasers in recognition of the benefits to other customers of this guarantee. PGP, SUB01-069, at 4.

\section{Evaluation and Decision:}

Cost shifts between Slice customers and non-Slice customers have been discussed and preliminary evaluations performed by BPA for the public discussions of the Slice product. These studies run for the public meetings were based on several assumptions about the product such as what the customer's load on BPA would be absent Slice. The studies were unable to definitively identify a cost shift from Slice that was not within the "noise" of the studies. The results of the studies were highly dependent on the assumptions used, and changes in assumptions caused results to vary. If a more detailed and refined cost shift analysis is found to be necessary, it would be performed for the Power Rate Case, and it would be likely to add complexity and contention to the rate case.

BPA has stated that it does not want the offer of a Slice product to impact the costs or risks to its customers who purchaser other products from BPA. Customers agree with this principle and suggest that there are a number of mechanisms that may address a cost or risk shift if it occurs, including CRAC and the "true-up" adjustment. BPA cannot, at this time, rule out the use of any mechanism to make adjustments if they are needed. The rate case will more fully address the cost recovery for the Slice product as well as other products.

BPA will develop the Slice product to avoid cost shifts to other customers compared with the other BPA core products. Given the lack of demonstration of significant cost shifts in the preliminary analyses, the sensitivity of results to changing assumptions, and the added complexity and contention that such a study would add, BPA does not intend to perform cost shift analyses for the Power Rate Case.

\section{Issue:}

What information will be provided to Slice purchasers that will enable them to use their Slice shares efficiently?

\section{Subscription Proposal:}

The Subscription Proposal stated that BPA would provide information on the bounds constraining Slice purchasers' use of the product. This information would include real-time minimum and maximum operating constraints, including ramp rates. In addition, the proposal stated that BPA would provide non-proprietary information, but 
would not provide internally developed forecast information such as forecasts of streamflows, generation, or sales.

Discussion, materials presented, and follow-up to the October 13,1998, Slice public meeting clarified that BPA would provide estimated FCRPS generation from natural flows, and 50-year hydro studies for the remainder of each operating year. In general, BPA would provide data on conditions purchasers face, but not on BPA's expected operations.

\section{Parties' Comments:}

Springfield commented that Slice purchasers should be informed in a timely manner of major issues and decisions affecting the operation and output of the system. Springfield asserted that weekly, daily, and hourly notifications are not adequate to arrange for alternative supplies. Springfield proposed that BPA should make a more concerted effort to notify and keep Slice purchasers informed of annual, monthly, and periodic forecasts, including any planned buy-backs. Springfield, SUB01-121, at 22.

\section{Evaluation and Decision:}

Generally, information on the flows and river conditions, including constraints, are available from public sources. BPA has stated that it would provide publicly available information to Slice purchasers as soon as we have it. BPA also develops its own proprietary information on Federal System capabilities based on proprietary streamflow forecasts. The needs of the Slice purchaser to have a reasonable forecast of capabilities should be satisfied through the public information. BPA's need to keep its market-sensitive internal forecasts confidential is significant, given the open wholesale market. BPA currently believes that it can accommodate the needs of the Slice purchaser and BPA by providing forecasts of Federal System capabilities (maximum and minimum generation, rate of change limits, generation from natural streamflows) but not forecasts of BPA's operations.

The basic paradigm of the Slice product is that the purchaser takes its Federal power as if it were a generating resource. The purchaser has the responsibility for meeting its loads and prudently operating its system. BPA is relieved of the responsibility of providing service beyond the power service sold as Slice, based on a percentage of Federal System capability. The responsibilities a purchaser accepts by purchasing the Slice product include managing the purchaser's resources to meet unforeseen resource variations and contingencies. Consequently, although BPA may advise Slice purchasers of anticipated changes in FCRPS operations, BPA does not have any duty to protect purchasers from the consequences of those changes nor any obligation to direct them as to what actions to take in light of changed circumstances. Using the information BPA is reasonably able to provide, the purchaser internally manages the matching of its power purchases, its resources, and its loads. In today's wholesale 
market there are numerous sellers of products on hourly, daily, and weekly bases that are adequate to enable arrangement of alternative supplies.

BPA will provide Slice purchasers forecasts of annual, monthly, and daily capabilities (generation limits and generation from natural streamflows) on an as-needed basis. The specific methodology that will be used will emerge from further discussion with interested parties, prior to the Power Rate Case.

\section{Issue:}

Should there be a matching of costs to be paid by Slice purchasers and benefits received?

\section{Subscription Proposal:}

The Subscription Proposal did not address this issue.

\section{Parties' Comments:}

Springfield commented that BPA has proposed the costs to which Slice purchasers will be exposed, without commensurate consideration to the benefits purchasers will receive. Springfield, SUB01-121, at 20.

\section{Evaluation and Decision:}

The Slice paradigm proposed by the PGP and adopted by BPA has been a bundled approach that does not attempt to balance costs and benefits dollar for dollar. In essence, Slice proponents (the PGP) stated that they would pay all costs faced by other requirements purchasers, with a few narrowly defined exceptions. Further, for parties interested in purchasing the characteristics of Slice, the Slice product provides ample consideration necessary for a contract.

BPA's customers are offered a choice between several different basic forms of service, of which the Slice is only one form. Each public preference agency will have to look to its own system, its future plans, and several other factors in choosing which products to take from BPA.

The Slice proposal presents a different basis for buying a requirements "plus" service from BPA than other core products. It proposes certain benefits and risks to BPA and the purchaser that are, on the whole, balanced. The decision of whether to take this set of benefits and risks is a customer decision. There will be no attempt to match costs and benefits. 
Issue:

Can the PBL identify a single Point of Integration (POI) for all of the resources of the FCRPS?

\section{Subscription Proposal:}

Although not explicitly stated in the Subscription Proposal, BPA's expectation is that Slice power would be produced at all of the FCRPS resources.

\section{Parties' Comments:}

Springfield commented that it is essential that the Slice purchaser know which bus-bar is the POI, and that deference be given in a transmission agreement reflecting the variable output of Slice and lack of notice and firmness. Springfield asserts that if BPA buys back Slice, some consideration must be given to the purchaser's financial commitment to transmission. Springfield, SUB01-121, at 21.

\section{Evaluation and Decision:}

BPA has separated its Transmission and Power functions, and this ROD is not intended to address specific transmission contract issues or policy. Transmission issues related to the Slice product will be addressed in the next transmission rate case; workshops in preparation for the rate case likely will begin next year.

The PBL looks at the Slice product as a system power sale from a designated set of resources, the FCRPS. The PBL has not addressed whether it is consistent with PBL policies or the Slice concept to identify a smaller number of Points of Integrations than the number of FCRPS resources. Further investigation and discussion of this issue among the PBL, the TBL, and potential purchasers will be necessary.

The Slice purchaser's costs of transmission service for the Slice product will not be paid by the PBL in the event of a buy-back because the PBL will have to secure its own transmission for use of any Slice power bought back.

Issue:

What will be the costs of the "regional solution" to the Subscription inventory constraint?

\section{Subscription Proposal}

No specific solution was described in the Subscription Proposal. 


\section{Parties' Comments:}

PGP stated that more discussion is required of the cost to all preference customers of a "regional solution" to the allocation of Federal power. The PGP expects the Slice to reflect appropriate system costs as well as all of the energy that BPA will have available to meet its contractual obligations. PGP, SUB01-069, at 2.

\section{Evaluation and Decision:}

In order to avoid a shifting of costs to non-Slice purchasers, BPA stated that the Slice purchasers would be required to pay the cost of power purchases that were needed on a planning basis to meet all load service requests made under the Subscription process, the "regional solution." As proposed by the PGP, Slice purchasers do not wish to share in the costs of BPA variable power purchases made during their contracts and thus would not expect to share in the MWs obtained by those variable purchases. The firm portion of Slice purchases by a preference customer will be limited to its regional net firm load requirements, and the purchaser will not share in additional purchased MWs. BPA and interested parties will continue to hold public discussions of implementation for Slice prior to the Power Rate Case.

\section{Issue:}

What short-term power purchases would be paid for by Slice purchasers?

\section{Subscription Proposal:}

The Subscription Proposal did not propose a solution to this question.

\section{Parties' Comments:}

Springfield commented that BPA needs to define what short-term power purchase costs would be paid by Slice purchasers. Springfield, SUB01-121, at 20.

\section{Evaluation and Decision:}

This question will be addressed in further public discussions of the Slice product between BPA and interested parties prior to the Power Rate Case, as well as in the rate case itself.

Issue:

What net revenues will Slice purchasers be expected to pay? 


\section{Subscription Proposal:}

The Subscription Strategy document stated that BPA expected Slice purchasers to assume an appropriate share of planned net revenues for risk. The Strategy document also stated that if the rate case and evaluation of risks determined that there are cost shifts, those cost shifts would be adjustments to costs to be paid by Slice purchasers.

\section{Parties' Comments:}

Springfield commented that BPA needs to define what Slice purchasers would be expected to pay toward planned net revenues for risk. Risks and cost shifts need to be clarified. Springfield, SUB01-121, at 20.

\section{Evaluation and Decision:}

The extent to which Slice purchasers are responsible for payments for risks and cost shifts would be rate case issues unless informal discussions with interested parties determine that it is not necessary. BPA is not proposing to conduct cost shift analyses for the rate case.

\section{Issue:}

How will the PBL differentiate costs attributable to Slice versus costs to the transmission rate?

\section{Subscription Proposal:}

This issue was not addressed in the Subscription Proposal.

\section{Parties' Comments:}

Springfield commented that it is uncertain how the PBL proposes to differentiate costs attributable to Slice versus costs to the transmission rate. Springfield, SUB01-121, at 21.

\section{Evaluation and Decision:}

BPA's initial proposal for the Power Rate Case will include BPA's proposed cost assignments. 
Issue:

What will happen to Slice purchasers' stored energy when there is required spill on the FCRPS?

\section{Subscription Proposal:}

The Subscription Proposal noted that Slice purchasers' rights would be proportional to BPA's own capability at any time, including the maximum and minimum rates of delivery in combination with the ability to store and release energy. Materials presented at the October 13, 1998, public meeting on Slice noted that storage accounts would be zeroed out when physical limits of the FCRPS were reached, and that there would be no protection from required spill.

\section{Parties' Comments:}

Springfield commented that BPA should not be able to confiscate stored energy with no provision for repayment or replacement. Springfield, SUB01-121, at 19.

Springfield also requested clarification of the notation in BPA's Slice proposal, "No protection against required spill." Springfield, SUB01-121, at 19.

\section{Evaluation and Decision:}

The Slice purchaser will run the same risk of spilling water as will BPA, in terms of the Federal System operation. BPA would not and has not proposed to confiscate stored energy. However, a Slice purchaser will lose its storage if that purchaser fills its Slice storage account above its upper limit, and there will be no compensation given for such loss.

Spill that is required for non-power purposes will be applicable to both BPA and the Slice purchaser's share. BPA and all Slice purchasers will have the risk of required spill in proportion to their percentage share of power from the system. The spill will be reflected by decreased generating capabilities in certain time periods. Spill due to lack of market is not part of required spill and will be individual to the Slice purchaser, that is, dependent on the purchaser's decisions to take energy out of the system. Such spill is not automatically shared by all Slice participants, although the situation that created the spill may affect all purchasers.

\section{Issue:}

Must BPA know the firm resources that will be applied to the customer's load during the term of the contract? 


\section{Subscription Proposal:}

Materials presented at the October 13,1998 , public meeting on Slice raised the question of whether purchasers need to demonstrate that they will have resources to cover the differences between their loads and Slice.

\section{Parties' Comments:}

Springfield commented that purchasers do not need to demonstrate that they have sufficient resources to serve the difference between Slice and their loads. Springfield, SUB01-121, at 18.

\section{Evaluation and Decision:}

BPA has stated that the Slice product proposed for Subscription is a posted price firm power requirements load service under section $5(b)(1)$ that includes a surplus power sale in certain periods of the year. It is based on the regional firm load of the customer less the customer's firm resources under section $5(b)(1)$. BPA's obligation to sell power to a Slice purchaser is a "net" load calculation. In order for BPA and the customer to know the specific net firm load requirement obligation, BPA and the customer must know the firm resources that will be applied to the customer's load during the term of the contract.

Specifically, BPA must know the firm resources the customer had applied to load prior to the enactment of the Northwest Power Act. These resources are referred to as subsection $5(b)(1)(A)$ resources. BPA must also know the firm resources that the customer has declared to apply to or used for its load under section $5(b)(1)(B)$. Because the statute treats those resources as continuing to be applied, those resources that are $5(\mathrm{~b})(1)(B)$ resources will apply in the post-2001 period, unless BPA determines that the resources are lost due to retirement, obsolescence, loss of contract right, or loss of the resource. BPA has stated that the "continuing application" of section $5(b)(1)(B)$ resources comprehends any generating resources that are currently serving Pacific Northwest loads, long-term contract resources that are serving the customer's loads, and other resources the utility is obligated to take. Contract resources that expire on or before the effective date of the BPA contract and that are not renewed or extended, will not be considered as $5(b)(1)(B)$ resources for the post-2001 period for purposes of Subscription contracts. Thus BPA does have the right and the need to know what firm resources the utility will apply to its loads for its Subscription contract and during that contract.

Issue:

What are the reserve obligations of Slice purchasers? 


\section{Subscription Proposal:}

The Subscription Proposal stated that Slice purchasers would be responsible for operating reserves for the Slice, and the reserves could be provided from Slice or other resources.

\section{Parties' Comments:}

Springfield commented that they do not think customers need to hold "spinning and generation reserves" for Slice. Springfield, SUB01-121, at 18.

Springfield also proposed that reserves would be needed only for the portion of the customer's net requirements that were not able to be served by the Slice product. Springfield, SUB01-121, at 22.

\section{Evaluation and Decision:}

The premises posed by these comments are inconsistent with the Slice concept proposed by the PGP, as modified and adopted by BPA. The Slice product concept is that purchasers will be responsible for their own resource decisions and operations, including maintaining reserves for their Slice share, and not subject to BPA's resource management and marketing decisions.

Issue:

Should Slice be a Core Subscription product?

\section{Subscription Proposal:}

The Subscription Proposal identified Slice as a Customized Product.

\section{Parties' Comments:}

Springfield commented that given that BPA proposes allocation of costs greater than those to meet preference customer general requirements, this product should be a cost-based Subscription product. Springfield, SUB01-121, at 17.

\section{Evaluation and Decision:}

The Slice product as proposed by BPA is a cost-based product to meet a customer's net firm load requirements under section $5(b)(1)$ by providing power in the shape of the FCRPS resources. However, since the Slice product includes power in excess of a purchaser's net requirements in certain periods of the year, it consists of both 
requirements and surplus service. As such, it differs from other core Subscription products, which are based on the customer's net firm load requirements in a load shape that is either actual, or a planned block, and for requirements service only.

Issue:

Which customers may purchase "requirements" service?

\section{Subscription Proposal:}

The Subscription Proposal did not address the definition of "requirements" service.

\section{Parties' Comments:}

Springfield commented that BPA's application of requirements is confusing, indicating that both preference and non-preference requirements customers may purchase requirements products. What is a non-preference requirements customer? According to section $7(b)(3)$ the only entity that falls in this category is a Federal Agency.

Springfield, SUB01-121, at 16.

Springfield questions different cost treatment for preference and non-preference Slice purchasers. Springfield would like clarification. Springfield, SUB01-121, at 21.

Springfield's comments indicate that they would like BPA to define "net requirements" consistent with "general requirements" in section 7 of the Act. Springfield, SUB01-121, at 18.

\section{Evaluation and Decision:}

BPA uses the terms "net firm load requirements" to mean BPA's obligation to sell electric power to a customer that is "net" of the customer's firm consumer loads in the region, less its firm resources applied to that load. Those resources are defined under section 5(b)(1)(A) and (B) of the Northwest Power Act. Elsewhere in this ROD BPA has stated its policy on application of firm resources to regional loads of a customer, and BPA's obligation to offer electric power service less those resources in the post-2001 utility firm requirements power contracts. Because this policy and ROD discuss what BPA's contract obligations may be and what contract forms or product offerings BPA will use to meet its obligations in the post-2001 period under section $5(b)(1)$, BPA has used the terms applicable under that provision. The term "general requirements" is given a specific meaning under section 7 of the Northwest Power Act relating to BPA's rates, not its contract obligations. One clear distinction is that the term "net firm load requirements" includes any regional NLSLs of a customer. Conversely, an NLSL is not part of a customer's "general requirements" for purposes of section 7 rates. 
As to BPA offering net firm requirements load service to customers that are not preference customers, it is not correct that BPA has an obligation only to preference customers under that provision. BPA also has an obligation under that provision, whenever it is requested, to provide electric power to IOUs for their "net" firm requirements loads less their firm resources.

Issue:

Does the CRAC apply to the Slice product?

Subscription Proposal:

The Subscription Proposal did not specifically address application of the CRAC to the Slice product.

\section{Parties' Comments:}

PGP commented that the CRAC does not need to be applied to Slice because the product itself guarantees Treasury payments. The Power Rate Case should determine the appropriate size of the credit to Slice purchasers in recognition of the benefits to other customers of this guarantee. PGP, SUB01-069, at 4.

\section{Evaluation and Decision:}

The design and application of the CRAC will be determined in the Power Rate Case, as will other costs and credits.

\section{PRICING}

\section{A. Public Agency Customers}

Issue:

What rate should apply for requirements sales to BPA's public agency customers? What rate should apply to sales to new public agencies and annexations?

\section{Subscription Proposal:}

The Subscription Proposal favored differentiated rates as a means of managing BPA's risk and recovering resource acquisition costs from the customers that cause BPA to acquire resources to meet their requests for service. Subscription sales to public 
agency customers would be under the PFP rate. PF(1) would be BPA's lowest-cost rate. $P F(2)$ and $P F(1)$ surcharge would reflect the cost of acquiring additional resources. The rates would be applied as follows:

\begin{tabular}{|l|l|}
\hline $\begin{array}{l}\text { Loads currently served by BPA and currently served by } \\
\text { expiring } 5(\mathrm{~b})(1)(\mathrm{B}) \text { contract resources }\end{array}$ & $\mathrm{PF}(1)$ \\
\hline $\begin{array}{l}\text { Loads currently served by } 5(\mathrm{~b})(1)(\mathrm{A}) \text { and }(\mathrm{B}) \text { generating } \\
\text { resources }\end{array}$ & $\begin{array}{l}\mathrm{PF}(1) \\
\text { surcharge }\end{array}$ \\
\hline $\begin{array}{l}\text { Post-Subscription public agency requests for additional } \\
\text { requirements service }\end{array}$ & $\mathrm{PF}(2)$ \\
\hline New Large Single Loads & $\mathrm{NR}(2)$ \\
\hline
\end{tabular}

\section{Parties' Comments:}

Opposing Differentiated Rates. Certain DSIs state that the pricing portion of BPA's Proposal is inconsistent with the Northwest Power Act and lacks internal logic. Murphy, SUB01-040 at 16. These parties state: "If BPA is going to distinguish between existing loads and incremental loads in the price it asks for power, it should do so consistently across ail customer classes." Id. Northern Wasco states that "the Proposal's treatment of tiered rates is inconsistent with the mandates of BPA's governing statutes." Northern Wasco, SUB01-048. Northern Wasco states that public preference customers are entitled on a first priority basis to energy and capacity from the FBS at cost for their net requirements, which includes load growth. Id. Tillamook states that a single PF rate should apply to all public agency customers and BPA should eliminate the concept of tiered rates. Tillamook, SUB01-052.

NRU does not support the notion of tiered rates. Saven, Public Meeting Transcript, Oct. 14, 1998, at 72. NRU states that "BPA does not need to impose a 'tiered rate' during the 2002-2006 period" and supports "the idea of a common rate pool for the requirements purchases of various customer groups." NRU, SUB01-057, at 3. NRU states that BPA should serve existing FBS annexed loads and new publics formed before the end of the Subscription process at "the same melded cost of Priority Firm service as historic loads, rather than through any form of a tiered rate." Id. at 6 .

Grant states that "Northwest public agency and regional preference should be maintained for both the price and availability of Federal power." Grant, SUB01-058 at 2. Grant states that the concept of tiered rates is "not consistent with BPA serving requirements public agency customers at the lowest-cost rate." Id. Grant states that proliferating PF rates would make comparability impossible. Id. Port Angeles states that tiered rates "PF(1) and PF(2)" should be eliminated. Port Angeles, SUB01-064. PGE states that preserving the benefits of the Federal hydrosystem would be 
accomplished most effectively by acquiring resources through bilateral contracts rather than tiered rates. PGE, SUB01-071, at 1.

WPAG opposes tiered rates, stating that tiered rates will discourage public agencies from placing new loads on BPA in the future and give public agencies incentive to maximize the amount of load they place on BPA during the current Subscription period. WPAG, SUB01-073 at 10. WPAG states: "The tiered rates proposal is an answer to a future problem that may never occur, but it is surely a solution that will cause both BPA and its public agency customers serious problems in the near-term." Id. WPAG suggests eliminating tiered rates, including $\operatorname{PF}(2), N R(2)$, and $P F(1)$ surcharge, from the Proposal. Id. at 11.

Benton REA does not support implementation of tiered rates "due to the complexity of implementation." Benton REA, SUB01-075. Benton adds that the tiered rate concept adds to the concern about the DSIs being offered low-cost power while public agencies and IOUs would be required to pay more for load growth or purchases after Subscription. Id. Clark states that tiered rates " are detrimental to BPA's interests and should not be implemented." Clark, SUB01-077 at 3. PNGC opposes the proposal to charge a $P F(2)$ rate to certain public agency loads and opposes the NR rate being equal to the PF rate through the use of FBS replacements. FNGC, SUB01-086 at 2. Snohomish states that "this proposal contradicts the rate directives of the Regional Power Act, which dictate that power sold to the requirements loads of preference customers should be sold at a melded rate based on the lowest-cost resources available from the FBS." Snohomish, SUB01-090 at 2. Snohomish states that tiered rates would discourage the growth of public power. Id. Snohomish also states that "preference customers have a statutory right to purchase power from BPA at the lowest cost-based rate to replace power from a resource lost to any of the four causes specified in the statute." Id. at 3.

PPC states that BPA should eliminate its proposed tiered rate structure. PPC states that BPA should offer a single cost-based PF rate, a melded rate based on the FBS resource cost and on supply conditions. PPC, SUB01-097 at 3-4. Oregon Municipal Electric Utilities (OMEU) supports the comments of PPC and NRU opposing tiered rates, stating in particular that they oppose "different rates for new annexed load." OMEU, SUB01-218. WMG\&T supports a single PF rate, which would eliminate need for a tiered PF rate. WMG\&T, SUB01-099 at 1. Sumas objects to tiered rates due to their risk and complexity. Sumas, SUB01-105 at 2. If BPA does implement tiered rates, Sumas suggests establishing a limit on utility size below which exemptions would be granted. Id. KPUD states that BPA should offer a single cost-based PF rate that is competitive in the market. KPUD, SUB01-111. KPUD opposes the proposals for PF(1) surcharge and $\mathrm{PF}(2)$. Id.

OURCA does not favor tiered rates for public preference customers. OURCA, SUB01-116 at 4-5. OURCA also states that "BPA should ensure that if new public 
agencies are formed, then they are eligible for the lowest cost-based rate regardless of date of formation or territorial origin." Id. Springfield does not favor tiered rates, stating that they would be "punitive to preference customers." Springfield, SUB01-121 at 2. Springfield claims that "imposing these incremental charges on public agencies and cooperatives violates preference and priority rights." Id. at 8 . Springfield also states that BPA should "provide for access to the lowest cost-based power to all requests from public agencies and cooperatives consistent with legal statutes." Id. Springfield states that "BPA could expand the FBS to supply power to IOU customers. Power sold using BPA's existing inventory would be based upon a single rate pool." Id. at 2.

Surprise Valley "wants BPA to meet all of the cooperative's load growth. The wholesale rate would be BPA's lowest cost rate." Surprise Valley, SUB01-149. Clallam states that "Public agency loads (current and future) should have access to firm power from the FBS. PF-1 would be the appropriate rate schedule for these loads. The tiered rate aspects of the proposal for preference power should be eliminated." Clallam, SUB01-150. Terry Mundorf stated that tiered rates should be eliminated. Mundorf, SUB01-175. Public agency requirements loads would be served with FBS resources and FBS replacements at a melded rate: Id. In general, if BPA does not have "uncommitted power supply at the melded rate," incremental loads would be served at the FPS rate schedule for the remainder of the rate period. Id.

Supporting Differentiated Rates. Inland Power \& Light has concerns about new public utilities being served at the PF(1) rate; it urges BPA to stay with the Proposal. Heitman, Public Meeting Transcript, Oct. 8, 1998, at 71. The IOUs "support preserving the substantial economic benefit of the current Federal resources by the application of tiered rates as recommended in the Subscription Proposal." Litchfield, SUB01-053 at 1. MPC states that tiered rates are "critically important mechanisms for facilitating the continuing development of competitive markets in the region," which will benefit all consumers. MPC, SUB01-062 at 2. WWP "fully supports BPA's proposal to use differentiated rates to assign the costs of new resource acquisition to those public agencies placing loads on BPA beyond the initial Subscription period or to displace actual generation resources." WWP, SUB01-066.

CUB states that "the concept of tiered rates is a necessary part of this proposal" to preserve access to the FBS for IOU residential and small farm loads. CUB, SUB01-103 at 3. Seattle favors tiered rates as a means to prevent acquisition at marginal cost when BPA prices at average cost. Seattle, SUB01-104 at 2. The four State PUCs state that the Proposal should not preclude the use of tiered rates; the actual decision should be left to the rate case. State PUCs, SUB01-146 at 8.

\section{Other Comments:}

Canby Utility Board (Canby) states that BPA's proposal is unclear as to what public load is eligible for the PF(1) rate. Canby, SUB01-028. Canby summarizes BPA's proposal 
(as stated above) and questions the consistency with BPA's statement in the Proposal that "public agencies [will] be able to subscribe at the lowest cost-based Priority Firm rate $(P F(1))$ for all load not currently being served by customers' generating resources." Id.

PRM asks that BPA modify its proposal to allow preference customers to purchase up to $50 \mathrm{MW}$ of Federal power at the PF(1) rate to replace any terminated resource, no matter when the resource is terminated. PRM, SUB01-087 at 4. Grays Harbor states that BPA's proposal would "unfairly penalize consumer-owned utilities that have their loads served by generating resources." Grays Harbor, SUB01-108. Grays Harbor supports the PPC's "proposal for addressing sales of power to all publicly owned utility load," and in the alternative supports the PRM proposal. Id.

The Montana League of Cities and Towns states that "new qualified public entities must be treated in the same manner as existing public entities" for allocation and pricing. Montana Cities, SUB01-082. Clearwater states that "preference customers need to have their load growth met by PF(1) power." Thayer, Public Meeting Transcript, Oct. 8, 1998 , at 74.

The Shoshone-Bannock Tribes state that "Tribes should be eligible for a decreased rate that reflects the intent of BPA to fulfill their Trust Responsibility to Tribes."

Shoshone-Bannock, SUB01-119.

Tanner states that full requirements utilities should be served at the PF(1) rate. Tanner also states that load growth of utilities that diversify should be served proportionally at the PF(1) rate and the rest at PF(2). Tanner, SUB01-093. WMG\&T states that if BPA implements tiered rates, "it should allow all territory that gets annexed into the service territory of a public utility to be served at the PF1 rate." WMG\&T, SUB01-099 at 2. WMG\&T proposes a rate break for utilities that sign contracts extending beyond the five-year rate period. Id. It suggests "some decrement of the PF rate--say, 90 percent--whatever that rate was determined to be in 2001 and 2006." Id.

\section{Evaluation and Decision:}

Regardless of the reason that a customer chooses to purchase power from BPA (new publics, annexations, resource obsolescence, etc.), if BPA is not surplus it must acquire additional resources to meet such loads and it must recover the consequent costs. The design of BPA's rates must manage the risk of not fully recovering costs during the rate period if additional and unexpected requests for service are received. The differentiated rates in the Subscription Proposal were designed to accomplish these goals.

While BPA proposed differentiated rates in the Subscription Proposal, BPA is not as concerned with implementing that particular rate design as with achieving the cost 
recovery objectives that arise with serving new loads after sales of power have been made. The final Subscription Strategy does not include differentiated PF(1) and PF(2) rates. For the FY 2002-2006 rate period, sales that are made during the Subscription window and those that are made after the window all will pay the PF rate. New sales made after the Subscription window, however, would be subject to a targeted adjustment charge that would recover the difference between the PF rate and the cost of the resources (power) BPA must acquire, if any, to serve the load. The targeted adjustment charge would be determined for each individual purchaser placing new load on BPA and would be applicable until those "new" loads can be reflected in BPA's next general rate adjustment.

A number of parties argued that a single PF rate should apply to the purchases of preference customers. The Subscription Proposal applied two PF rates to such purchases. With the implementation of the targeted adjustment charge, however, the same PF rate would apply to all preference customers. Some parties also expressed concern about the complexity of implementation of a tiered rate proposal. BPA has chosen not to adopt tiered rates and will work to design the proposed targeted adjustment charge in a manner that will address this concern.

A number of parties argue that preference customers should be able to purchase power from BPA at the lowest PF rate to replace customer resources discontinued for the reasons specified in section 5(b)(1) of the Northwest Power Act. Mundorf, SUB01-175; Snohomish, SUB01-098. BPA agrees that preference customers should be able to purchase power to meet these loads at the PF rate. However, the PF rate must be designed to protect BPA and other customers from costs that arise during the rate period of load being placed on BPA due to loss of customer resources. Because of this need, as noted in the Subscription Proposal, the PF Surcharge rate would apply to load that returns to BPA after being served by $5(b)(1)(A)$ and $5(b)(1)(B)$ resources.

One party suggests that BPA allow preference customers to purchase up to $50 \mathrm{MW}$ of Federal power at the PF rate to replace any terminated resource, regardless of reason. PRM, SUB01-087. Such a proposal, however, would impose costs on BPA during the rate period that were not contemplated during rate development. See ROD section I.A. Customer Resource Replacement.

A number of comments suggested that BPA's proposed differentiated rates were inconsistent with the Northwest Power Act. E.g., Murphy, SUB01-040; Northern Wasco, SUB01-048. While BPA believes that its Subscription Proposal on differentiated rates complied with the Northwest Power Act, BPA is not proposing to use differentiated rates in its final Subscription Strategy. For this reason these arguments are rendered moot. BPA will establish its proposed PF rate in accordance with the Northwest Power Act and other applicable law.

One party argues that Tribes should be eligible for a decreased rate that reflects the intent of BPA to fulfill its trust responsibility to the Tribes. Shoshone-Bannock, 
SUB01-119. BPA must establish its rates in accordance with the Northwest Power Act, and the Act does not establish a special discount for Tribes. Under BPA's final Subscription Strategy, a Tribe that forms a non-profit cooperative utility will have access to Federal power at prices paid by BPA"s preference customers.

One party proposes that BPA provide a rate break for utilities that sign contracts extending beyond the five-year rate period at some decrement of the PF rate established in 2001. WMG\&T, SUB01-099. However, BPA must periodically review and revise its rates no less frequently than every five years. BPA cannot establish rates that would apply after the upcoming five-year rate period. Rates for the period following the upcoming rate period will be established in a subsequent rate case. The issue of whether a discount should apply to long-term contracts must be addressed in that proceeding.

An alternative public power proposal suggested that differentiated rates should be eliminated, and public agency net firm power requirements loads should be served with FBS resources and FBS replacements at a melded rate. In general the comment states that if BPA does not have "uncommitted power supply at the melded rate," incremental loads would be served under the FPS rate schedule for the remainder of the rate period. Mundorf, SUB01-175. This argument appears inconsistent with the Northwest Power Act. If BPA receives a request from a preference customer to buy power for its regional requirements load, BPA is required to offer power to serve the load under section $5(b)(1)$ of the Northwest Power Act at a rate or rates established pursuant to section $7(b)$. Under the definition of surplus power in section $5(f)$ of the Northwest Power Act, BPA does not have power that is "surplus" until it has firsi met all of its 5(b), 5(c), and 5(d) obligations. Surplus sales are made at rates established under section 7(f) of the Northwest Power Act. Public preference customers have the right to purchase Federal power for their net firm power regional consumer load under BPA's requirements rate schedules, and BPA must supply that power with any power it has available before it makes surplus sales.

It should be noted that BPA's Subscription Strategy does not establish any rates or rate designs. The establishment of rates and use of rate design can be determined only in a formal rate hearing under section 7(i) of the Northwest Power Act. The comments and questions referenced above will be addressed in BPA's power rate development process, which includes extensive opportunities for public involvement. While final rate design decisions are not being made in the Subscription Strategy, rate design approaches identified in the Subscription Strategy will be part of BPA's initial power rate proposal, which is expected to be published early in 1999.

Issue:

How should BPA design the PF rate? 


\section{Subscription Proposal:}

The Subscription Proposal's discussion of BPA's rates for public agencies addressed only rate differentiation, the LDD, and indexed cost-based rates. The Proposal did not address rate design but was meant to "constitute the framework that will be the context for BPA's upcoming Power Rate Case that will begin early in 1999."

\section{Parties' Comments:}

ICUA "strongly opposes rate design changes which substantially shift costs between customers, such as reducing the LDD or disproportionately increasing rate components [such as] capacity costs, HLH energy, or generation demand to reflect market value." ICUA, SUB01-072. ICUA urges BPA not to finalize any of the pricing recommendations until the Power Rate Case. Id.

Benton PUD is disappointed that BPA is backing away from its "2 cents in 2000" slogan and now is saying no rate increase. Sanders, Public Meeting Transcript, Oct. 8, 1998, at 58. Benton PUD sees the possibility of significant cost shifting occurring. Id. Benton PUD is concerned about potential changes in billing determinants that can hurt utilities such as Benton that are summer peaking with irrigation load. Benton PUD urges BPA to "provide means for mitigating those cost shifts, like the summer seasonal product." Id. Benton PUD states that "the proposal signals the possibility of changes in billing determinants that could negatively impact utilities that are rural and have significant summer loads." Benton PUD, SUB01-010 at 2.

Nespelem states that BPA should continue the Summer Seasonal Product concept to assist farmers, ranchers, and irrigators. Nespelem, SUB01-024.

Benton REA states that "the Generation demand needs to be adjusted to reflect the true value of the service. However, we urge BPA to retain the current method of determining the peak as it relates to the BPA system peak." Benton REA, SUB01-075.

PNGC is concerned about increases in the demand charge and HLH energy charge, which PNGC claims would hurt rural utilities and those with mostly residential load. PNGC advocates BPA using "an embedded cost basis in designing its rates." PNGC, SUB01-086 at 6. PNGC states that rate mitigation should come in the form of rate design rather than a "targeted mitigation rate or measure." Id. PNGC members are especially concerned about possible increases in demand charges, increases in HLH pricing, and increases in charges for low voltage deliveries. Reiten, Public Meeting Transcript, Oct. 14, 1998, at 86-87.

Wells is opposed to changing the demand billing determinant to "individual customer time of POD peak demand." Wells, SUB01-095 at 2. Wells also "is concerned that the policy decision to accommodate their load growth not be diluted or effectively 
abandoned by changes in the billing determinants." Id. Wells wants "all energy provided at the lowest PF rate and a service feature for Load Variance that has a similar pricing methodology to the current Load Shaping charge." Id.

NRU states that the Load Variance charge methodology needs clarification. Saven, Public Meeting Transcript, Oct. 14, 1998, at 73. NRU states that energy for load growth should be provided at the lowest PF rate, and Load Variance should be priced similar to the current Load Shaping charge. NRU, SUB01-057 at 2. Wells wants "all energy provided at the lowest PF rate and a service feature for Load Variance that has a similar pricing methodology to the current Load Shaping charge." Wells, SUB01-095 at 2.

Reynolds states that BPA's cost-based rates should reflect the cost of service; for example "rates for service to winter-peaking loads" should reflect "expensive market purchases ... to shape the Federal System to meet loads." Reynolds, SUB01-122 at 4.

\section{Evaluation and Decision:}

BPA's Subscription Strategy does not establish any rates or rate designs. The establishment of rates and use of rate design can be determined only in a formal rate hearing under section 7(i) of the Northwest Power Act. The comments and questions referenced above will be addressed in BPA's rate development process, which includes extensive opportunities for public involvement. While final rate design decisions are not being made in the Subscription Strategy, rate design approaches identified in the Subscription Strategy will be part of BPA's initial power rate proposal, which is expected to be published early in 1999. The framework of the PF rate and the low density discount are addressed in section III.A. of this document; indexed rates are addressed in section III.G.

Issue:

How should NLSLs be priced?

\section{Subscription Proposal:}

The Subscription Proposal stated that NLSLs would be priced at the NR(2) rate.

\section{Parties' Comments:}

Alcoa addresses the issue of industries in public agency service territories that currently are served by BPA as DSIs, and in the future may be served by a public agency. Alcoa states that BPA should not serve such loads as NLSLs at the NR(2) rate, but rather should serve them "under a PF rate or at least a competitive NR(1) rate." Alcoa, 
SUB01-050. Northwest Alloys, Inc. (NW Alloys) supports the Alcoa position. NW Alloys, SUB01-083.

\section{Evaluation and Decision:}

The companies that addressed this issue posit a future in which certain DSIs are not served directly by BPA but rather by the local utilities in whose service territories they reside. They believe BPA should serve those loads at a rate other than the NR(2) rate as defined in the Subscription Proposal. The Subscription Strategy, however, does not determine whether any particular load, industrial or otherwise, is an NLSL. Such determinations are made on a case-by-case basis when the issue arises. In 1992 BPA stated its treatment of DSI customers who transferred their power service to a local utility and the issue of the application of NLSL provisions to the transferred load. This Subscription does not modify or change this policy or BPA's interpretation of section 3(13) of the Northwest Power Act. NLSL Treatment of Utility Service to DSI Expansion; And Initiating a Northwest Power Act Section 5(d)(3) Process to Increase DSI Contract Demand, ROD, November 16, 1992.

Similarly, the Subscription Strategy does not establish the rate that applies to NLSLs. BPA notes, however, that section 7(b)(1) of the Northwest Power Act provides for the establishment of the rate that applies to the general requirements loads of public body, cooperative, and Federal agency loads within the Pacific Northwest (and Residential Exchange loads), commonly known as the PF rate. 16 U.S.C. $839 \mathrm{e}(\mathrm{b})(1)$. Section 7(b)(4) of the Northwest Power Act provides that the term "general requirements" means "the public body, cooperative, or Federal agency custoiner's electric power purchased from the Administrator under section $839 \mathrm{c}(\mathrm{b})$ of this title, exclusive of any NLSL." 16 U.S.C. $839 \mathrm{e}(\mathrm{b})(4)$. NLSLs therefore cannot be served at the PF rate.

Section 7(f) of the Northwest Power Act provides for the establishment of rates that apply to "all other firm power sold by the Administrator for use in the Pacific Northwest." In the event that industrial loads are determined to be NLSLs, they shall be served at a rate developed pursuant to section 7(f). BPA is no longer proposing rates called $N R(1)$ and NR(2). BPA is proposing an NR rate that would apply to NLSLs and requirements purchases of IOUs other than purchases under the Subscription settlement proposal for the Residential Exchange Program. As noted previously, however, the establishment of rates can be determined only in a formal rate hearing under section 7 (i) of the Northwest Power Act. The comments referenced above will be addressed in BPA's power rate development process. While final rate design decisions are not being made in the Subscription Strategy, rate design approaches identified in the Subscription Strategy will be part of BPA's initial power rate proposal, which is expected to be published early in 1999. 


\section{Stair-Stepped Rates}

Issue:

How should BPA's power rates be structured for the five-year rate period?

\section{Subscription Proposal:}

The Proposal did not address this issue. BPA's Proposal did, however, provide various incentives for customers to choose between three-year contracts, five-year contracts, and contracts longer than five years.

\section{Parties' Comments:}

No parties commented on this issue.

\section{Evaluation and Decision:}

Parties' comments (see ROD section IV.D.) on long-term contracts versus short-term contracts focused mainly on the concern over cost underrecovery and the uncertainty that exists in the electric utility industry. BPA believes that offering short-term contracts will give customers more economic choices. Short-term contracts are a BPA advantage if markets are high and BPA faces increased costs, but a disadvantage if market prices are low and there is not a corresponding decrease in BPA costs. Longer-term contracts can create greater financial and power supply certainty for both BPA anid its customers, but they also limit flexibility as market conditions change.

As explained fully in section IV.D., BPA has decided that, to further diversify its revenue stream, it will allow customers to have a portfolio of purchases with different rate periods within a long-term contract. BPA expects this will result in a more diverse portfolio of BPA sales. BPA believes that customers will want to take advantage of the portfolio option BPA offers because there are advantages to them of varying their Federal power purchase commitments. There are advantages to BPA also. In the future, BPA will find it beneficial to avoid the expiration of all contracts on the same date, the "contract cliff" BPA faces in 2001. BPA will encourage variations in contract lengths with its customers in Subscription contracts from 3 to 20 years. BPA's rates will establish choices with rates that expire at different times. Customers will be allowed to diversify their BPA Federal power purchases by choosing different contract lengths or by committing to rate periods of varying lengths within the same contract. If load amounts are staggered into different rate periods BPA will not face the same revenue cliff it does today. 
BPA expects its costs will be higher in the later years of the rate period because of the unpredictability of certain costs in those years due to market volatility, fish and wildlife funding, and resource capability. To account for the potential increase in its costs, BPA intends to develop a two-part, stair-stepped posted power rate. The rate will step up in the fourth year of the rate period. The three-year rate will recover forecasted costs, including risk, for that period. The two-year rate will cover the costs forecasted for those two years, including any increased costs and risks.

A customer may choose to enter into a contract of three years or longer. The rate for a three-year contract will be the lower-step rate established for the first three years of the 2002-2006 rate period. For longer contracts, the rate for the first three years will be the same lower-step rate, and the rate for the next two years will be the higher-step rate established for years four and five of the 2002-2006 rate period. For a customer who signed a three-year contract and subsequently signed a contract for years four and five, the rate for the fourth and fifth years will be established through a later 7(i) process.

It is important to note that the entire five-year posted two-part rate is the "lowest cost-based rate." BPA proposes to average the first three years of the rate period and then the last two years, to develop the entire five-year rate. This concept will be more fully developed in the Power Rate Case initial proposal. In addition, BPA will post a five-year average rate to be applied to the pre-Subscription contracts BPA has already entered into for the post-2001 rate period.

\section{Low Density Discount}

Issue:

Should BPA eliminate the kilowatthour-to-investment $(\mathrm{K} / \mathrm{I})$ ratio as a criterion for calculating the LDD?

\section{Subscription Proposal:}

The Subscription Proposal stated that BPA plans to continue the LDD, with changes in rate design and implementation that would be made a part of BPA's initial power rate proposal. One change BPA proposed was elimination of the $\mathrm{K} / \mathrm{I}$ ratio in the calculation of the LDD. The proposed changes would be targeted at assuring that LDD benefits go to customers with truly low system densities as envisioned by the Northwest Power Act.

\section{Parties' Comments:}

A number of parties suggested that the $K / /$ ratio should be retained during the next rate period, arguing that the Northwest Power Act requires the establishment of the LDD and therefore it should continue. NRU, SUB01-057; ICUA, SUB01-072; PNGC, 
SUB01-086; WPAG, SUB01-073; ORECA, SUB01-085; Tanner, SUB01-093; PPC, SUB01-0097; WMG\&T, SUB01-099; KPUD, SUB01-111; Surprise Valley, SUB01-149; Clallam, SUB01-150.

A number of parties indicated that the Subscription Proposal was vague and gave no justification for consideration of the proposed removal of the K/I ratio. NRU, SUB01-057; WMG\&T, Inc., SUB01-099; KPUD, SUB01-111; Surprise Valley, SUB01-149.

Some parties indicated a willingness to work with BPA on proposed changes to assure that LDD benefits continued to low density systems. NRU, SUB01-057; ICUA, SUB01-072; Benton REA, SUB01-075.

Some parties believed if changes were made to the LDD, the current combined $K / I$ and C/M cap of 7 percent should be maintained and possibly increased. NRU, SUB01-057; ICUA, SUB01-072; Clearwater, SUB01-049; PNGC; SUB01-086; Wells, SUB01-095; Big Bend, SUB01-140, 141; Surprise Valley, SUB01-149.

Some parties expressed concern about the power discounted by the LDD being used in an open access environment to procure power load being served by other utilities. Burley, SUB01-047; Northern Wasco, SUB01-048; Port Angeles, SUB01-064; WPAG, SUB01-073.

\section{Evaluation and Decision:}

Section 7(d)( 1 ) of the Northwest Power Act provides that "[i]n order to avoid adverse impacts on retail rates of the Administrator's customers with low system densities, the Administrator shall, to the extent appropriate, apply discounts to the rate or rates for such customers." 16 U.S.C. $839 \mathrm{e}(\mathrm{d})(1)$. While some parties argue that the LDD is required by the Northwest Power Act, this provision clearly provides the Administrator with broad discretion in the establishment and design of the LDD.

A number of parties indicated that the Subscription Proposal was vague and did not justify the proposed removal of the $\mathrm{K} / \mathrm{I}$ ratio. As noted above, the Subscription Proposal suggested elimination of the ratio to assure that LDD benefits go to customers with truly low system densities as envisioned by the Northwest Power Act. In particular, BPA was concerned about the increase of $\mathrm{K} / \mathrm{l}$ program costs as a result of more customers purchasing substations from BPA. Many customers supported retention of the $\mathrm{K} / \mathrm{I}$ ratio and believed that if changes were made to the LDD, the current cap of 7 percent should be maintained or increased.

After consideration of the parties' comments, BPA now proposes to continue use of the present LDD methodology without eliminating the $K / /$ ratio. BPA has indicated its intent to control future costs, however. Any increase in the LDD would be contrary to this effort. Therefore, BPA does not anticipate increasing the 7 percent cap on the LDD. 
Furthermore, BPA has determined that the impact on the $\mathrm{KJI}$ ratio resulting from customers purchasing substations from BPA is minimal. This issue will be addressed in greater detail in the rate case. BPA intends to work with its customers in rate case workshops to explore options for limiting this cost exposure.

Some parties expressed concern about the power discounted by the LDD being used in an open access environment to procure load being served by other utilities. BPA did not take any position on this issue in the Subscription Proposal and BPA will not address this issue in the final Subscription Strategy. BPA notes that this issue likely will be raised and addressed in BPA's upcoming Power Rate Case. In addition, BPA anticipates the review of other issues in the rate case including the impact on the LDD of possible enactment of a Federal or State "rural universal charge" similar to the LDD; identification of billing determinants; and simplification of implementation and data procedures.

It should be noted that BPA's Subscription Strategy does not establish any rates or rate designs. The establishment of rates and rate design can be determined only in a formal rate hearing under section 7 (i) of the Northwest Power Act. The comments and questions referenced above will be addressed in BPA's power rate development process. While final rate design decisions are not being made in the Subscription Strategy, rate design approaches identified in the Subscription Strategy will be part of BPA's initial power rate proposal, which is expected to be published early in 1999.

\section{B. Residential Exchange}

Issue:

Should BPA run the $7(b)(2)$ rate test in the rate case?

\section{Subscription Proposal:}

The Subscription Proposal states that, consistent with the Northwest Power Act, the section $7(b)(2)$ rate test will be run in the rate case. A PF Preference Rate and a PF Exchange Rate will be published. If the $7(b)(2)$ rate test does not trigger, the PF Preference and PF Exchange Rates will be equal. However, if the 7(b)(2) rate test does trigger, then the PF Preference Rate and the PF Exchange Rate will differ.

\section{Parties' Comments:}

The PPC notes that the $7(b)(2)$ rate test should be run in the rate case to implement the Residential Exchange for any $10 \mathrm{U}$ choosing to participate in the section 5(c) Residential Exchange. PPC, SUB01-097. 
Lower Valley argues that there is opposition to creating any commitments to residential and small farm customers of IOUs that cause any incremental costs of serving those loads to be borne by public utilities. Lower Valley, SUB01-081.

\section{Evaluation and Decision:}

The PPC notes that the section $7(b)(2)$ rate test must be run in the next BPA general rate case. This is required by law and, as noted in the Subscription Proposal, BPA proposes to conduct the section $7(b)(2)$ rate test in the next general rate case. BPA points out, however, that parties have previously been able to reach settlements in the rate case. BPA's intent to conduct the section $7(b)(2)$ rate test should not be perceived as discouraging parties from discussing settlement of any rate case issues. Absent a rate case settlement on this issue, BPA will conduct the section $7(b)(2)$ rate test in the next general rate case.

\section{IOU Residential and Small Farm Loads}

Issue:

What rate should apply to IOU Subscription sales?

\section{Subscription Proposal:}

The Subscription Proposal provides that instead of participating in the Residential Exchange Program, IOUs would be able to purchase a specified amount of power under Subscription for their residential and small farm consumers in settlement of their Residential Exchange rights. IOUs' net firm load requirements purchases would be at the New Resources NR(1) rate, a rate established under section $7(f)$ of the Northwest Power Act.

\section{Parties' Comments:}

PNGC argues that firm sales to the IOUs under section 5(b)(1) of the Act should be made at an NR rate that includes any FBS which is surplus to the needs of preference customers plus the full cost of any additional resources needed to meet this additional obligation. PNGC, SUB01-086.

The DSIs argue that the rate for IOU Subscription net firm load requirements sales must be established pursuant to section 7(f) of the Northwest Power Act. Murphy, SUB01-040. 
Springfield argues that the sale to the IOUs must be a surplus power sale. Springfield, SUB01-121.

OURCA argues that any direct purchase of power by the lOUs must not increase or negatively impact in any way the rate charged to the public preference customers. OURCA, SUB01-116.

Many public agency customers argue that the IOU residential load should have access to 1500 aMW of Federal power at a melded rate for the 2002-2006 rate period. Further, this should be under essentially the same terms and conditions as preference agencies. NRU, SUB01-057; Snohomish, SUB01-090; PPC, SUB01-097; Springfield, SUB01-121; Mundorf, SUB01-175.

\section{Evaluation and Decision:}

BPA's Subscription Proposal suggested that Subscription power sales to IOUs would be net firm power load requirements sales pursuant to section $5(b)(1)$ of the Northwest Power Act. Some parties noted that sales to the IOUs should be founded instead on BPA's authority to sell "in lieu" power under section 5(c)(5) of the Northwest Power Act. BPA also has authority to sell power to the IOUs under section 5(f) of the Northwest Power Act. Power sales under each approach are subject to specific statutory and contract conditions. These conditions often depend on the facts that apply to a particular utility. BPA believes that BPA and its customers have not had a sufficient opportunity to thoroughly review the details involved in the implementation of power sales to IOUs under the different approaches. BPA's Subscription Strategy therefore does not adopt any specific approach at this time. BPA will consult with its customers before determining the appropriate manner of making Subscription power sales to the IOUs. It is possible, however, generally to address the rates that would apply to each approach.

A number of parties addressed the establishment of a rate for net firm load requirements sales to IOUs. The parties correctly note that the rate for requirements sales to IOUs is established pursuant to section $7(f)$ of the Northwest Power Act, which provides that such rates shall be based upon "the cost of the portions of FBS resources, purchases of power under section $839 \mathrm{c}(\mathrm{c})$ of this title and additional resources which, in the determination of the Administrator, are applicable to such sales." 16 U.S.C. 839e(f). BPA will establish rates for any IOU net firm load requirements sales in a manner consistent with these directives.

Historically, BPA has established a number of rates under section $7(f)$ of the Northwest Power Act (e.g., Surplus Firm Power (SP), FPS, NR). Because these rates may apply to different types of service (although all these types of service are subsumed under section 7(f)), BPA believes that it would provide greater clarity to use a different name than $N R(1)$ for the rate that applies to the IOUs' Subscription sales, if such sales are 
requirements sales. For this reason, if IOU Subscription sales are requirements sales, BPA's initial rate proposal should contain a Residential Load $(R L)$ rate instead of the $N R(1)$ rate.

In the event that BPA's Subscription sales to IOUs are in lieu sales under section 5(c)(5) of the Northwest Power Act, the applicable rate would be developed pursuant to section 7(b) of the Northwest Power Act. Section 7(b) provides that "[t]he Administrator shall establish a rate or rates of general application for electric power sold to meet the general requirements of public body, cooperative, and Federal agency customers within the Pacific Northwest, and loads of electric utilities under section 5(c). Such rate or rates shall recover the costs of that portion of the FBS resources needed to supply such loads until such sales exceed the FBS resources. Thereafter, such rate or rates shall recover the cost of additional electric power as needed to supply such loads, first from the electric power acquired by the Administrator under section 5(c) and then from other resources." 16 U.S.C. $839 e(b)(1)$. BPA will establish rates for any in lieu sales to IOUs in a manner consistent with these directives.

It should be noted that BPA's Subscription Strategy does not establish any rates. The establishment of rates can only be determined in a formal rate hearing under section 7(i) of the Northwest Power Act. While final rate decisions are not being made in the Subscription Strategy, rate design approaches identified in the Subscription Strategy will be part of BPA's initial power rate proposal, which is expected to be published early in 1999.

Issue:

Should BPA state that the rate used to sell Subscription power to the IOUs will be "equal" to the PF Preference rate as opposed to "approximately equal"?

\section{Subscription Proposal:}

The Subscription Proposal provides that instead of participating in the Residential Exchange Program, IOUs may agree to a settlement of the Residential Exchange Program in which they could purchase a specified amount of power for their residential and small farm consumers at the New Resources NR(1) rate, a rate approximately equivalent to the PF Preference PF(1) rate.

\section{Parties' Comments:}

Many parties commented that BPA should strive to eliminate the "approximately equal" in describing the $N R(1)$ rate relative to the PF(1) rate. They argue that BPA should serve like-situated residential customers across utility boundaries with equivalent and consistent price and terms. Idaho Senate, SUB01-051; Litchfield, SUB01-053; IIPA, 
SUB01-056; Wash. Attorney Gen., SUB01-059; WWP, SUB01-066; Gov. of Montana, SUB01-068; PGE, SUB01-071; CUB, SUB01-103.

Many public agency customers commented that the IOU residential loads should have access to 1500 aMW of Federal power at a melded rate for the 2002-2006 rate period. Further, this should be under essentially. the same terms and conditions as preference agencies. NRU, SUB01-057; Snohomish, SUB01-090; PPC, SUB01-097; Springfield, SUB01-121; Mundorf, SUB01-175. The IOUs state that Subscription power should be offered under essentially the same terms and conditions as preference agencies. Litchfield, SUB01-053, WWP, SUB01-066; Gov. of Montana, SUB01-068; PGE, SUB01-071; Benton PUD, SUB01-077.

WMG\&T notes that any CRAC applicable to the PF rate must also be applicable to sales to the IOUs. WMG\&T, SUB01-099. WMG\&T argues that all BPA customers should share the risks of revenue under-recovery or cost overruns. Id.

\section{Evaluation and Decision:}

As noted previously, BPA has not yet determined whether Subscription sales to IOUs will occur as net firm power load requirements sales under section 5(b) of the Northwest Power Act or as in lieu sales under section 5(c)(5) of the Northwest Power Act.

Requirements sales would be made at what was previously characterized as the $N R(1)$ rate, now referred to as the $R L$ rate. In lieu power sales would be made under the PF rate schedule. The following discussion, while framed around the $N R(1)$ and $P F(1)$ rates noted in the Subscription Proposal, applies equally to both $R L$ and $P F$ rates.

Numerous parties commented that BPA should strive to eliminate the term "approximately equal" in describing the NR(1) rate (now RL or PF rate) relative to the $\mathrm{PF}(1)$ rate, claiming that BPA should serve like-situated residential customers across utility boundaries with equivalent and consistent price and terms. These parties argue that the two rates should be identical. BPA understands the parties' arguments regarding the level of the NR(1) rate (now RL or PF rate) relative to the PF(1) rate. The Subscription Strategy signals BPA's expectation that the rate for these IOU sales will be approximately equal to the PF rate. BPA must establish its rates consistent with the rate directives contained in section 7 of the Northwest Power Act, however, and in hearings conducted in accordance with the procedures specified in section 7(i) of the Act. For this reason, BPA cannot state that the RL or PF rates used for Subscription sales to the IOUs will be set at any particular level. The level of the RL and PF rates can be established only in a section 7(i) hearing. While it is possible that the RL and PF rates would equal the PF Preference rate, BPA cannot make such a statement at this time. 


\section{Direct Service Industries}

Issue:

How should BPA price sales to DSIs?

Subscription Proposal:

The Subscription Proposal noted that the IP rate would equal the PF(1) rate plus the Industrial Margin, adjusted for reserves.

\section{Parties' Comments:}

A member of the United Steelworkers of America stated that BPA should not provide rate discounts to Kaiser Aluminum. Lalicker, SUB01-027. Kootenai states that "the DSI class priority needs to follow public agency and IOU residential and small farm customers" and DSIs should pay for additional resources needed to serve their loads. Kootenai, SUB01-060 at 2.

WMG\&T states that BPA "should not predetermine the outcome of the upcoming Power Rate Case by deciding that the IP rate will be roughly equal to the PF rate." WMG\&T, SUB01-099 at 3. URP states that an IP rate based on the PF(1) rate plus Industrial Margin minus value of reserves is not justified, because that price would be below the value of the power. URP, SUB01-120 at 2. Instead, the value of such power "would be best determined by conducting an auction open to all." Id.

A number of comments stated that BPA should not short-change IOUs by subsidizing big business. E.g., Corven, SUB01-074. A number of comments stated that BPA should sell to the citizens of the Northwest low cost power "instead of subsidizing aluminum smelters and other DSIs." E.g., Holm, SUB01-124.

A number of DSIs state that BPA should make its PF and IP rate schedules available for sales of "surplus Federal power (e.g., secondary energy) to regional loads that requested Subscription service but did not receive a full allocation." Murphy, SUB01-098 at 4. Springfield advocates selling "remaining inventory" to DSIs; the rate would be BPA's lowest cost-based rate. Springfield, SUB01-121 at 11. PPC takes the position that the rates charged the DSI customers must reflect any augmentation costs incurred by BPA to meet DSI loads. PPC, SUB01-193. On the other hand, some DSIs suggested that BPA should address in the rate case the reasonable use of its power purchase authority to augment the system to "meet Subscription requests at melded rates." Early, SUB01-078, at 2. See also, Kaiser SUB01-096, at 3. The Spokanes urged BPA not to sell power to the DSIs at rates comparable to the $\mathrm{PF}(1)$ rate, or at below market rates. Spokanes, SUB01-092. Port Townsend, a BPA DSI customer, 
reminded BPA that its most important energy considerations are certainty of supply and stable rates. Port Townsend, SUB-01-092.

\section{Evaluation and Decision:}

The establishment of rates for BPA's DSI customers is governed by section 7(c) of the Northwest Power Act. 16 U.S.C. 839e(c). Simply stated, the Act provides that BPA's rate for DSIs is to be based on BPA's applicable wholesale rates to its public body and cooperative customers and the typical margins included by such customers in their retail industrial rates as adjusted for the value of power system reserves made available to BPA through rights to interrupt or curtail service to the DSIs. BPA's development of the IP rate will comport with the Northwest Power Act's directives.

Suggestions that BPA should establish the IP rate at a particular level or through an auction process do not appear to comport with the statutory directives. As noted previously, BPA does not preclude the possibility that the IP rate will equal the PF rate. The Subscription Strategy signals BPA's expectation that the IP rate will be approximately equal to the PF rate. However, BPA must establish its rates consistent with the rate directives contained in section 7 of the Northwest Power Act and in hearings conducted in accordance with the procedures specified in section 7(i) of the Act. For this reason, BPA cannot state that the IP rate used for Subscription sales to the DSIs will be set at any particular level. The level of the IP rate can be established only in a section 7(i) hearing. While it is possible that the IP rate would equal the PF Preference rate, BPA cannot make such a statement at this time.

The suggestion that BPA should use the PF and IP rate schedules for sales of surplus Federal power (e.g., secondary energy) is difficult to understand. The PF and IP rate schedules are for firm power sales to meet regional loads. Surplus Federal power is sold pursuant to the FPS rate schedule, and nonfirm energy is sold under the NF rate schedule. BPA will apply the applicable rate schedules for the type of power being sold.

It should be noted that BPA's Subscription Strategy does not establish any rates or rate designs. The establishment of rates and use of rate design can be determined only in a formal rate hearing under section 7 (i) of the Northwest Power Act. The comments referenced above will be addressed in BPA's rate development process, which includes extensive opportunities for public involvement. The issue of the possible rate treatment of any augmentation undertaken by BPA to meet DSI loads is addressed at section I.C. While final rate design decisions are not being made in the Subscription Strategy, rate design approaches identified in the Subscription Strategy will be part of BPA's initial power rate proposal, which is expected to be published early in 1999. 


\section{E. General Transfer Agreements (GTAs)}

Issue:

Should BPA continue GTA service to preference customers for deliveries of Federal power through the end of the next rate period?

\section{Subscription Proposal:}

BPA proposed to continue existing GTA service to customers for delivery of Federal power through the 2002-2006 rate period. As proposed, this service would not be available to new preference customers or to existing preference customers for service territory expansions. For GTA agreements that expire during this time, BPA would attempt to negotiate extensions through 2006 or arrange for open access tariff transmission to replace the GTA for delivery of Federal power to GTA points of delivery. Any GTA charges directly assigned to customers would conform with the TBL's Direct Assignment guidelines. For most circumstances the result would be direct assignment of only the Low. Voltage Delivery Charge, where applicable. GTA customers would purchase ancillary products, such as load regulation, from the TBL.

\section{Parties' Comments:}

Parties' comments pertaining to GTAs focused primarily on the relationship between the availability of GTA service for deliveries of Federal power, and non-Federal power; the allocation of costs of GTA service between the power and transmission business lines; and the expansion of existing GTA service to new service territories. In addition, a number of parties raised comments on the scope and timing of BPA decisionmaking on GTA issues.

With regard to the scope of the GTA issues and the timing of their resolution, the PPC stated that a long-term solution was needed prior to the close of the Subscription window. PPC, SUB01-097. The PPC, Idaho Falls, and NRU agreed that any solution should address the circumstances unique to power deliveries to preference utilities in southern Idaho, including the South Idaho exchange issue. PPC, SUB01-097, SUB01-193; Idaho Falls, SUB01-100; NRU, Public Meeting Transcript, Oct. 14, 1998. WPAG felt that BPA should make a firm disposition of all GTA issues prior to the start of the Subscription process and carry those determinations forward through the transmission rate case. WPAG, SUB01-073. Springfield suggested that a bifurcated rate case would put GTA customers at a disadvantage when evaluating how much Subscription power they will require to serve native load. Springfield, SUB01-121. WPAG agreed, saying that deferring the transmission rate case until after the Power Rate Case leads to great uncertainty over resolution of GTA issues, particularly with 
respect to transfers of non-Federal power that are key to the utilities' diversification decisions. WPAG, SUB01-073.

Benton REA indicated its support for continued service for delivery of Federal power to GTA customers. Benton REA, SUB01-075. Noting that GTA customers currently pay only the BPA transmission rate to get their power delivered, ICUA stated that BPA's Idaho customers have a heightened interest in this issue because these customers depend on GTA service to take delivery of their Federal power purchases. ICUA, SUB01-072. PPC suggested that BPA should condition the IOUs' "eligibility to purchase from the 1500 aMW upon successful resolution of any outstanding GTA issues." PPC, SUB01-097.

Canby and WWP both suggested that service to newly annexed load or newly created public agency customers should be provided through current or amended GTAs. Canby, SUB01-028; WWP, SUB01-066. Sumas argued that increased GTA costs should not be directly assigned to Washington GTA customers annexing areas within their Urban Growth Area because such a policy would "effectively 'yoid' a major piece of Washington State environmental policy." Sumas, SUB01-105.

\section{Evaluation and Decision:}

BPA proposes to continue existing GTA service to currerit load for delivery of Federal power through the 2002-2006 rate period. Continuation of GTA service for Federal power deliveries is consistent with BPA's historical practice and inelps promote the widespread use of Federal power. In essence, BPA views this decision as the continuation of a longstanding commitment to accommodate deliveries for existing preference load.

Service under the GTAs will not be available to new preference customers or to existing preference customers for service territory expansions. There are several reasons for this decision. BPA believes that provision of GTA service is grounded in an affirmative obligation to serve BPA's historical preference load and to assist GTA customers in avoiding unexpected cost shifts during the transition to a competitive market. Thus, the GTAs provide a means of ensuring that these customers receive requirements power service that is comparable to directly served preference customers. The rationale to continue this treatment is not compelling with respect to new load coming into service under FERC's current regulatory regime, which envisions transmission service being provided under open access tariffs.

Further, the GTA contracts were negotiated for the benefit of specific customers to be served at specific points of delivery. As a matter of contract interpretation, GTA service simply may not contemplate service to new entities or annexation of additional service territory. Nor can that issue be resolved through a unilateral BPA decision, but must be accomplished instead through the mutual consent of the parties to the GTAs. 
Therefore, the PBL does not intend to extend GTA service for Federal deliveries to newly formed preference customers or make it available for service territory expansions of existing customers.

For GTA agreements that expire during the 2001-2006 timeframe, BPA will attempt to negotiate extensions through 2006 , or to acquire open access tariff transmission service, including ancillary services, to replace the GTA for delivery of Federal power to existing GTA points of delivery. Any GTA charges that are directly assigned to customers will be based on the principles articulated in the TBL's Direct Assignment guidelines. In most circumstances, only the Low Voltage Delivery Charge, where applicable, is expected to be directly assigned. In the event of GTA costs associated with significant Energy Imbalance "overruns," PBL will reserve the right both to require individual GTA customers to pre-schedule energy deliveries and to directly assign any Energy Imbalance charges incurred. This is most likely to occur in situations where large industrial loads fluctuate with no advance notice, although it may arise in other situations as well. This result is consistent with the comments, which reflect little support for direct assignment of GTA costs.

Issue:

Should PBL provide for the delivery of non-Federal power to GTA points of delivery?

\section{Subscription Proposal:}

PBL would not provide for delivery of non-Federa! power to GTA points of delivery.

\section{Parties' Comments:}

The issue of whether to provide GTA service for delivery of non-Federal power generated conflicting commentary. Governor Kitzhaber of Oregon stated that BPA's proposal would result in pancaked transmission rates to GTA customers who choose non-Federal power over Federal power. Kitzhaber, SUB01-067. PNGC also noted that different treatment of Federal and non-Federal power results in pancaked transmission rates for those customers served by GTAs and effectively eliminates the ability of many publics to diversify. PNGC, SUB01-086; Reiten, Public Meeting Transcript, Oct. 14, 1998. PNGC also argued that such diversification benefits BPA by reducing reliance on the FBS, which in turn lessens the pressure on BPA to acquire resources. Id.

ICUA voiced a similar view, saying GTA customers need to diversify their power providers through access to the bulk power market in order to mitigate the market risk imposed by utilizing BPA as a sole source. ICUA, SUB01-072. ICUA also asserted that pancaked rates would result in a 200-1000 percent increase in the transmission rates paid by southern Idaho GTA customers. ICUA, SUB01-072. 
The ICUA also invoked the historical background of the GTAs in support of their positions. ICUA noted that Idaho utilities lobbied Congress to quash BPA plans to extend Federal transmission facilities into southern Idaho, with the result that Idaho utilities constructed the lines presently used to transfer Federal power to BPA's southern Idaho customers. ICUA, SUB01-072. According to the comment, this state of affairs led the House Appropriations Committee to address the inability of BPA and the southern Idaho utilities to negotiate transfer agreements, saying "there should be no discrimination against future preference customers in any way." ICUA, SUB01-072.

Commenters also raised legal issues. PNGC argued that failure to treat Federal and non-Federal power similarly may expose BPA to challenges under FERC comparability principles. PNGC, SUB01-086; Reiten, Public Meeting Transcript, Oct. 14, 1998. ICUA stated that providing non-Federal transmission service over the GTAs arguably gives rise to a discrimination claim, but a party seeking similar service under Federal Power Act section 211 may not obtain an order requiring such service because GTA service is not covered by the open access rules. ICUA, SUB01-072. ICUA also asserted that transmission owners are under no obligation to provide open access service in place of GTA service to wheel non-Federal power. ICUA, SUB01-072. WPAG commented that the costs of wheeling non-Federal power under GTAs that permit such wheeling should be allocated to transmission rates. Mundorf, SUB01-73.

Commenters' views were varied with respect to how the issue should ultimately be resolved. Benton REA believes that, where GTAs do not specifically preclude non-Federal deliveries, BPA should make arrangements for such service for customers who desire it. Benton REA, SUB01-075. WPAG is in accord. SUB01-73. Springfield, by contrast, stated that BPA should permit delivery of non-Federal power where third parties are willing to amend existing GTAs to allow nonfirm power transactions.

Springfield, SUB01-121. Representative Crane and Senator Hansen of Idaho, IPC, and Governor Kitzhaber agreed that amendment of the GTAs was a proper avenue for extending GTA service to non-Federal deliveries. Idaho State Senate, SUB01-051; IPC, SUB01-070; Kitzhaber, SUB01-067.

IPC posited that, if non-Federal deliveries are permitted under some GTAs, the same service must be made available in all instances, and IOUs must be allowed to use it to reach any BPA customer that desires to move any portion or all of its load to the IOU. IPC, SUB01-070. With respect to the southern Idaho utilities, PNGC concluded that southern Idaho utilities must have access to non-Federal power and pay only the BPA transmission rate to get it there. PNGC, SUB01-086. WWP takes the view that the PBL should not provide for non-Federal delivery. WWP, SUB01-066.

\section{Evaluation and Decision:}

BPA concludes that it is not appropriate for the PBL to provide for the delivery of non-Federal power under the GTAs. In the era of deregulation, it is anomalous, at the 
very least, for the PBL to actively promote the marketing of non-Federal power by its competition to its own customers. In today's marketplace, the PBL functions as a merchant for the sale and disposition of Federal power. It is not an entity engaged in making arrangements for the transmission of non-Federal power.

As the parties' comments indicate, there are historical, legal and contractual issues surrounding whether the GTAs may be used for the transmission of non-Federal power. Resolution of all these issues at this juncture is not necessary. The Subscription Strategy is intended to address issues related to the sale and disposition of Federal power by the PBL, not the sale and disposition of non-Federal power by competitors of the PBL. Accordingly, as part of this Subscription proposal, BPA has determined that the PBL will continue to provide for the delivery of Federal power under existing GTAs, but will not provide for the delivery of non-Federal power under the GTAs.

Issue:

How should costs for service under the GTA be allocated?

\section{Subscription Proposal:}

The costs for GTA service would be carried in the PBL revenue requirement.

\section{Parties' Comments:}

The issue of cost allocation generated the most comments and the widest diversity of opinions. WWP favored direct assignment of GTA costs, stating that GTA costs should be borne only by those using the GTAs. WWP, SUB01-066. NRU, ICUA, and Weils generally agreed that GTA costs should be spread widely, not targeted, except that GTA costs could be targeted to the degree that similar costs of the Federal transmission system are targeted. NRU, SUB01-057; ICUA, SUB01-072; Wells, SUB01-095.

Lower Valley, Tanner, WRECA, PPC, and Sumas all took the position that GTA costs should not be directly assigned. Lower Valley, SUB01-081; Tanner, SUB01-093; WRECA, SUB01-094; Sumas, SUB01-105. Lower Valley, WRECA, and Sumas argued that, because GTAs saved all BPA ratepayers the cost of expanding the transmission system, GTA customers should not be required to bear those costs through direct assignment today. Lower Valley, SUB01-081; WRECA, SUB01-094; Sumas, SUB01-105. Tanner stated that direct assignment would severely hamper the competitiveness of smaller utilities. Tanner, SUB01-093. Tanner also asserted that GTA service provided to it by Puget Sound Energy suffers from a very poor outage record, making it less desirable than the service BPA would have provided, had it built its own facilities. Id. This result, Tanner argues, would make direct assignment even more unfair. Id. 
Clearwater and NRU suggested that, because GTAs made construction of Federal transmission facilities unnecessary, those costs could legitimately be rolled into either power or transmission rates. Clearwater, SUB01-049; Thayer, Public Meeting Transcript, Oct. 8, 1998; NRU, SUB01-057. Clearwater recommended that GTA costs be rolled in to either the NT transmission rate or the PF-1 power rate. Thayer, Public Meeting Transcript, Oct. 8, 1998. ICUA stated that failure to treat GTA costs similar to costs associated with BPA's own transmission system would place an enormous economic hardship on GTA customers. ICUA, SUB01-072.

A number of commenters viewed GTA service as a power cost and favored rolling those costs into power rates. DSIs, Tillamook, NRU, WWP, and WPAG argued that GTA costs are power costs because they were incurred to widely distribute the benefits of Federal power. Murphy, SUB01-040; Tillamook, SUB01-052; NRU, SUB01-057; WWP, SUB01-066; WPAG, SUB01-073. Both Wells and WMG\&T stated that GTA costs should be recovered through power rates. Wells, SUB01-095; WMG\&T, SUB01-099. Clearwater suggested rolling GTA costs into the PF-1 rate. Clearwater, SUB01-049; Thayer, Public Meeting Transcript, Oct. 8, 1998.

The DSIs argued that it is unfair to deny the DSIs access to Federal power and at the same time expect them to subsidize delivery of non-Federal power to GTA customers by including the costs of non-Federal deliveries in transmission rates. Murphy, SUB01-040. NRU and Tanner stated that GTA costs should be recovered through transmission rates; nonetheless, they recommended that GTA costs be recovered through power rates because GTA customers need price certainty in Subscription. which cannot be achieved if GTA issues are not resolved until the transmission rate case. NRU, SUB01-057; Tanner, SUB01-093.

Other commenters, including WRECA and PPC, argued that GTA costs should be recovered through transmission rates. WRECA, SUB01-094; PPC, SUB01-097. PNGC took the position that all preference customers should be able to get both Federal and non-Federal power delivered by paying BPA's transmission rate, concluding that GTA costs for both Federal and non-Federal deliveries, including open access replacement for delivery of non-Federal power, should be rolled in to transmission rates. Reiten, Public Meeting Transcript, Oct. 14, 1998; PNGC, SUB01-086. This approach, PNGC asserted, would eliminate pancaked rates and put BPA in a leadership role with regard to a comprehensive solution to that problem, perhaps through establishment of an ISO. PNGC, SUB01-086. Lower Valley argued that including GTA costs in transmission rates makes sense from a functional and operational perspective, while continued inclusion of GTA costs in power perpetuates a contentious issue. Lower Valley, SUB01-081.

CRITFC raised the question of whether placing GTA costs in power rates would increase the likelihood of CRAC charges or a transmission surcharge. CRITFC, SUB01-142. Burley suggested that BPA either continue GTA service forever as part of NT service for both Federal and non-Federal power or construct a power line. Burley, 
SUB01-047. Similarly, PPC recommended that BPA consider acquiring the IOU transmission facilities used to provide GTA service and roll the acquisition cost into BPA transmission rates. PPC, SUB01-097. Arguing that GTA service is the functional equivalent of network service, ICUA concluded that FERC orders and opinions interpreting the Federal Power Act and Energy Policy Act of 1992 allow no discrimination among Federal transmission purchasers and thus require BPA to treat GTA costs in the same fashion as the costs of BPA's own transmission system. ICUA, SUB01-072.

WPAG and Benton REA took the more limited view that the costs of non-Federal deliveries should be rolled in to transmission rates as a means of eliminating pancaked transmission rates. WPAG, SUB01-073; Benton REA, SUB01-075. Benton REA stated that "BPA" should bear all of the costs of GTAs while Governor Kitzhaber indicated that "Bonneville" should pay the cost of wheeling non-Federal Power to GTA customers. Benton REA, SUB01-075. Big Bend said that costs to customers served by GTAs should be the same as costs to customers served directly. Big Bend, SUB01-141. Finally, the Northwest State utility commissions continue to recommend that BPA strive to conform to the Federal Power Act, which will have implications for GTA cost allocations between transmission and power in the upcoming rate cases. State PUCs, SUB01-146.

\section{Evaluation and Decision:}

BPA's initial proposal for the Power Rate Case will include a proposal that GTA costs for Federal deliveries be allocated to the PBL and will not include a proposal to allocate costs to the PBL related to the delivery of non-Federal power under the GTAs.

Some commenters indicated that the costs of GTA service for Federal deliveries should be allocated to transmission rates as a means of mitigating pancaked rates. However, a proposal to allocate GTA costs for Federal deliveries to the PBL does not preclude consideration of alternatives for mitigation of other aspects of the pancaking problems at a later time. In light of BPA's historical treatment of its legal obligation to its preference customers, and to GTA customers in particular, the cost of wheeling Federal power over a third party's transmission system can reasonably be considered a power cost.

As Lower Valley suggests, the issue may well remain contentious, but there is no guarantee, or any particular indication, that a different outcome would be any less contentious. As for concerns regarding an increased risk of a CRAC or transmission surcharge, the same concern could be raised in reference to any cost that may be included in power rates. Thus, the relevant question is the appropriateness of placing such costs in power, not what effect that decision might have on risk of a CRAC or transmission surcharge. These issues may all be addressed in the Power Rate Case. 
In sum, BPA believes that inclusion of these costs in BPA's power rate case initial proposal revenue requirement strikes a reasonable balance.

\section{F. Conservation and Renewables}

Issue:

Should BPA include a Conservation and Renewables Discount mechanism in BPA's initial rate proposal?

\section{Subscription Proposal:}

Subscription goal number four described the need to provide market incentives for the development of conservation and renewables; specifically, to develop a proposal that would provide discounts off BPA's posted rates for power customers who voluntarily choose to finance their own development of conservation or renewable resources.

\section{Parties' Comments:}

BPA received over 70 comment letters on the conservation and renewables discount concept: 44 were supportive, 13 were opposed, the rest (13) provided comments on specific issues without indicating whether they were supportive or opposed to the Conservation and Renewables Discount concept. Seventeen people provided comments on the Conservation and Renewables Discount concept during BPA's two public meetings: 9 were supportive, the rest commented but didn't indicate if they were for or against the idea. The DSI representatives and several small utilities were opposed to the Conservation and Renewables Discount concept. E.g., Murphy, SUB01-040; Northern Wasco, SUB01-048; NRU, SUB01-057; Port Angeles, SUB01-064; Benton REA, SUB01-075; Early, SUB01-078; ICNU, SUB01-109. They felt the proposed rate discount would disadvantage their loads and cause their rates to be higher than necessary. In addition, the DSIs felt it was inappropriate to make any Conservation and Renewables Discount policy decisions in the Subscription process since the idea was new and the details of the program were not available for review and comment. E.g., Alcoa, SUB01-050; Vanalco, SUB01-054; Early, SUB01-078. URP is opposed to the Conservation and Renewables Discount because: (1) utilities have financial incentive not to implement conservation because doing so will increase their rates; and (2) utilities will spend their funds ineffectively. URP, SUB01-120. The public interest groups, several medium and large preference customers and the IOUs who commented were supportive of the Conservation and Renewables Discount approach. E.g., Snohomish, SUB01-025; League of Oregon Cities, SUB01-037; Tillamook, SUB01-052; MPC, SUB01-062; PGE, SUB01-071; ICUA, SUB01-072; Sierra Club, SUB01-089; EWEB, SUB01-107. Many applauded BPA for stepping up and 
demonstrating leadership in finding ways to continue the Pacific Northwest's strong legacy in the development of conservation and renewable resources.

\section{Evaluation and Decision:}

BPA realizes that the Conservation and Renewables Discount concept caught some parties by surprise. However, the review period and the Conservation and Renewables Discount Working Group will provide a forum for participating in the Conservation and Renewables Discount design. Although no longer being asked to acquire resources, BPA wants to continue its leadership role in supporting energy conservation and renewable resource development in the region. Accordingly, BPA believes it is important to create opportunities for the states and other stakeholders to step up and contribute to the region's energy future. This leadership includes proceeding with BPA's fourth Subscription goal of "providing market incentives for the development of conservation and renewables, as part of a broader BPA leadership role in the regional effort to capture the value of these and other emerging technologies." Also, by this action, BPA is facilitating the Comprehensive Review's goal of supporting conservation and renewables through local action.

BPA will continue discussions on the Conservation and Renewables Discount policy issues that reed to be resolved prior to the initial rate proposal through the Conservation and Renewables Discount Working Group and its six subcommittees. To facilitate these discussions, BPA is presenting below its tentative "leanings" on 10 policy issues that will shape the Conservation and Renewables Discount mechanism in BPA's initial power rate proposal. These are not final decisions, but rather indications of the direction BPA's initial rate proposal will take when published early in 1999.

issue:

What should be the level of the Conservation and Renewables Discount?

\section{Subscription Proposal:}

No specific level was proposed.

\section{Parties' Comments:}

The comments ranged from suggesting that BPA should not provide any conservation and renewables incentives, e.g., Surprise Valley, SUB01-149, to suggesting that BPA should commit up to $\$ 90$ million for the Conservation and Renewables Discount, e.g., NWEC, SUB01-114. Some who responded viewed the Comprehensive Review's 3 percent of retail sales to be a floor, e.g., EPUD, SUB01-011; Seattle, SUB01-138. Others suggested that it should be a ceiling, e.g., PPC, SUB01-135. The PPC and 
many small/medium preference customers indicated that the discount should be limited or capped at \$30 million. E.g., WRECA, SUB01-094; PPC, SUB01-097; Springfield, SUB01-121. Public interest groups and some of the larger preference customers advocated a larger commitment. E.g., NWEC, SUB01-137; Seattle, SUB01-138; Friends of the Earth, SUB01-169. Some of the public interest groups were concerned that a discount level of $\$ 30$ million would not result in any incremental conservation or renewable resource activity. E.g., URP, SUB01-120.

\section{Evaluation and Decision:}

BPA does not want to jeopardize the competitive level of its rate structure because of the Conservation and Renewables Discount mechanism. However, it is important that the incentive have a real impact on the amount of conservation and renewable resource development in the region. BPA is concerned that the Conservation and Renewables Discount not be used to cover the conservation and renewable resource investments that are already in power customers' plans. BPA intends to use its power rates to support power customers who voluntarily choose to finance their own development of conservation or renewable resources. Specifically, in the rate case BPA plans to propose a base discount not to exceed 0.5 mills per kilowatt-hour up to a total annual discount of $\$ 30$ million. This base discount would be dollar-for-dollar. Very small customers would have requirements that reflect the capabilities of these types of customers. BPA is also considering whether, if BPA's actual financial performance turns out to be substantially better than the rate case plan, to offer an additional discount. The first $\$ 15$ million of a "dividend" distribution (see ROD section II.A.2.) would go to customers who carry out incremental conservation and renewable activities. This money could be leveraged with a 2-for-1 discount structure, to create an incentive for significant additional investment. This rate discount should provide an incentive for customers to meet the Comprehensive Review's goal of supporting conservation and renewables through local action. BPA also will take into consideration actions by the states such as uniform public benefits charges. BPA plans to rely on a regional forum to propose measures that would qualify for the discount. BPA has a strong desire that the Conservation and Renewables Discount amount be supplemental to the amount power customers were planning to spend on these types of activities (i.e., incremental conservation and renewable resource investments).

\section{Issue:}

Should the amount of the discount funds available to any given power customer be leveraged (i.e., to increase the investment by power customers beyond the direct credit amount) to facilitate customers moving closer to the Comprehensive Review's 3 percent of retail sales target? 


\section{Subscription Proposal:}

Nothing was mentioned in the proposal on this issue.

\section{Parties' Comments:}

The public interest groups and the larger utilities felt strongly that some type of leveraging mechanism should be mandatory before receiving any of the Conservation and Renewables Discount funds. E.g., Sierra Club, SUB01-089; Snohomish, SUB01-090; Solar Energy Assn. of Oregon (SEAO), SUB01-091; EWEB, SUB01-107; NWEC, SUB01-137. They suggested a variety of mechanisms (leveraging with a uniform percent discount, leveraging with a threshold, achieving an investment of at least 3 percent of retail sales before qualifying for the discount, etc.). The PPC and the medium/small power customers, in general, felt no leveraging was appropriate. E.g., NRU, SUB01-157; Benton PUD, SUB01-101; PPC, SUB01-135. Their concern was that too many customers would not participate if they did not get a dollar returned for the dollar invested.

\section{Evaluation and Decision:}

BPA beiieves that the "dollar for dollar" approach will encourage the maximum number of power customers to participate in the Conservation and Renewables Discount. BPA's actions need to complement and support the Comprehensive Review's recommendation that the States pass appropriate public purposes legislation. BPA will work to obtain voluntary commitments from partial requirements customers and IOUs to use the Conservation and Renewables Discount funds to supplement their planned investments in conservation and renewables; if that occurs, then leveraging becomes less of an issue. BPA will propose that a dollar of value or cost (an issue yet to be determined; there is a Conservation and Renewables Discount Working Group subcommittee looking into this issue) contributed will get a dollar in return (a dollar spent by power customers will get a dollar off the wholesale power bill) for the first $\$ 30$ million of discount value without a threshold up to a cap defined by $0.5 \mathrm{mill} / \mathrm{kWh}$ times the load placed on BPA. BPA is also considering whether, if BPA's actual financial performance turns out to be substantially better than the rate case plan, to offer an additional discount. The first $\$ 15$ million of a "dividend" distribution (see ROD section II.A.2.) would go to customers who carry out incremental conservation and renewable activities. This money could be leveraged with a 2 -for- 1 discount structure, to create an incentive for significant additional investment, on top of the base discount. This rate discount should provide an incentive for customers to meet the Comprehensive Review's goal of supporting conservation and renewables through local action. BPA will also take into consideration actions by the states such as uniform public benefits charges. BPA plans to rely on a regional forum to propose measures that would qualify for the discount. 
Issue:

Should BPA have the right to conduct financial audits for those activities which power customers claim a Conservation and Renewables Discount?

\section{Subscription Proposal:}

Nothing was mentioned in the proposal on this issue.

\section{Parties' Comments:}

Many power customers felt that local control and accountability for the funds spend on the Conservation and Renewables Discount program was desirable. Nespelem, SUB01-024; Tillamook, SUB01-052; NRU, SUB01-057; WPAG, SUB01-073; Clark, SUB01-077; Lower Valley, SUB01-081; PPC, SUB01-135.

\section{Evaluation and Decision:}

$\mathrm{BPA}$ is required to review and monitor its program activities to make sure the funds are used in an appropriate manner for the purposes for which the program was designed. BPA will have the right to conduct financial audits for those activities which a Conservation and Renewables Discount credit is claimed. The provisions governing such audits will be contained in the General Rate Schedule Provisions.

\section{Issue:}

Should there be an exemption for power customers whose Conservation and Renewables Discount level is too small to be cost effective for implementation of qualifying measures or activities?

\section{Subscription Proposal:}

Nothing was mentioned in the proposal on this issue.

\section{Parties' Comments:}

Comments from medium and small utilities on this topic included: exempting small utilities (such as those under 25 aMW), e.g., NRU, SUB01-057; the Conservation and Renewables Discount could disadvantage smaller utilities which have a high percentage of total costs for distribution and other non-power supply functions, e.g., NRU, SUB01-057; Wells, SUB01-095; this charge combined with other billing determinant charges may have the cumulative effect of making the BPA resource 
unaffordable for some of BPA's historically smaller customers, e.g., Wells, SUB01-095; Surprise Valley, SUB01-149; as proposed, the Conservation and Renewables Discount will likely result in small rural utilities with stagnant or slow growing economies subsidizing the larger utilities with vibrant economies, e.g., Port Angeles, SUB01-064. Most public interest groups felt that 100 percent participation in the Conservation and Renewables Discolint should be encouraged. E.g., NRDC, SUB01-113; NWEC, SUB01-114.

\section{Evaluation and Decision:}

The cost of implementing an appropriate qualifying measure may be higher than the amount of the Conservation and Renewables Discount available to the utility. The administrative and reporting requirements for getting the discount only exacerbate the situation. Although many utilities have a strong conservation and renewables ethic and want to provide choices to their consumers, it must be recognized that several of these utilities have very limited staff capabilities in the conservation and renewables arena and a small amount of load to work with in achieving meaningful conservation and renewables results. They should receive the credit without meeting the administrative and reporting requirements. An exemption from the Conservation and Renewables Discount will be available for very small utilities (threshold to be determined; there is a Conservation and Renewables Discount Working Group subcommittee looking into this issue). Small utilities, however, will continue to be encouraged to voluntarily support conservation and renewables investments in their service territories.

Issue:

Should BPA allow power customers to voluntarily pool their Conservation and Renewables Discount credits?

\section{Subscription Proposal:}

Nothing was mentioned in the proposal on this topic.

\section{Parties' Comments:}

Several comments suggested that a pooling arrangement was logical and could facilitate broader participation by power customers. E.g., PPC, SUB01-097; Benton PUD, SUB01-101. In addition, some recommended that customers should be able to "trade" or sell their conservation and renewables credits to customers that have more opportunities to use them. E.g., EWEB, SUB01-107; KPUD, SUB01-111; PPC, SUB01-135. 


\section{Evaluation and Decision:}

BPA believes that voluntary pooling would encourage maximum power customer involvement, especially in those situations where customers may have accomplished most of the cost-effective conservation in their service areas. In addition, there are significant administrative efficiencies that can be achieved by several power customers sharing staff, resources, program designs, promotional materials, and so on. BPA will propose that associations of power customers that serve to more efficiently manage conservation and/or renewable resource efforts (e.g., CARES, OMECA) can use the Conservation and Renewables Discount dollars available to all member customers as a pool of funds to be managed as they see fit across all of the member utilities' service areas for qualifying measures and activities. (BPA has no "leaning" with respect to the "tradable" credits idea at this time; there is a Conservation and Renewables Discount Working Group subcommittee looking into this issue.)

\section{Issue:}

Who should be responsible for developing the list of measures/activities that would qualify for the Conservation and Renewables Discount?

\section{Subscription Proposal:}

BPA plans to rely on a regional forum to propose measures that would qualify for the discount, thus making it simple to administer. Specifically, BPA is developing a proposal that would provide discounts off its posted rates when power customers rneet regionally developed performance criteria.

\section{Parties' Comments:}

The comments ranged from BPA developing the list in collaboration with others, e.g., CUB, SUB01-103; Atmosphere Alliance, SUB01-172; to using the Regional Technical Forum (RTF), e.g., SEAO, SUB01-091; NRDC, SUB01-113; NWEC, SUB01-137; PPC, SUB01-135; Seattle, SUB01-138; to letting each State administer the funds for public purposes as they see fit, e.g., URP, SUB01-120.

\section{Evaluation and Decision:}

BPA expects that the RTF will be a regional entity supported by the NWPPC and that it will bring together the appropriate technical expertise to do the required tasks in a professional manner. This responsibility is a logical extension of the Council's power planning duties. BPA will propose using the RTF list as developed. BPA will request that the NWPPC use its RTF to develop the list of qualifying measures and activities. An important component of the list will be the inclusion of the energy savings and value 
for each measure/activity listed. BPA anticipates the list will be completed by the end of calendar year 2000 . In the initial power rate proposal, BPA will indicate that it will use the RTF-developed list of qualifying measures for the Conservation and Renewables Discount.

\section{Issue:}

How extensive should the list of qualifying measures/activities be?

\section{Subscription Proposal:}

Nothing was presented in the proposal on this issue, but it was mentioned that BPA should take into consideration actions by States such as uniform public benefits charges.

\section{Parties' Comments:}

A majority of the Conservation and Renewables Discount comments supported having a robust list of measures and activities that qualify for the discount. E.g., WPAG, SUB01-073; PPC, SUB01-097. Many of the comments suggested specific activities and projects that should be included on the pre-approved list. E.g., Clearwater, SUB01-049; NRU, SUB01-057; ICUA, SUB01-72; Central Lincoln, SUB01-136.

\section{Evaluation and Decision:}

In order to maximize power customer participation in the Conservation and Renewables Discount program, it is necessary to have a broad range of measures, projects, and activities that qualify for the discount. This gives power customers more flexibility to design programs that will meet the needs of their consumers. In addition, an expansive list supports the region in capturing all the cost-effective conservation and renewable resource opportunities that are available. The list of qualifying measures and actions eligible for the Conservation and Renewables Discount should be extensive. It should include the full range of standard conservation measures and demand-side energy efficiency activities, and program designs and protocols for conservation in unique facilities and situations, such as large commercial and industrial sites. Also included would be peak-load management efforts, renewable resource and green power options, transmission and distribution system efficiencies, and appropriate distributed generation options such as fuel cells and photovoltaics. Also included would be State-mandated public purpose utility activities, and alternatives for contributing funds to energy-related organizations and activities such as the Bonneville Environmental Foundation, Northwest Energy Efficiency Alliance (NEEA), and local low-income weatherization programs. Also included would be "reductions in electric power consumption as a result of increases in the efficiency of energy production." 
Issue:

Where should the accountability for tracking the savings accomplished through the Conservation and Renewables Discount reside?

\section{Subscription Proposal:}

Nothing was presented in the proposal on this issue.

\section{Parties' Comments:}

The PPC and several utilities suggested that accountability should remain at the local utility/Board level since it is their money. NRU, SUB01-057; PNGC, SUB01-086; Wells, SUB01-095; PPC, SUB01-135. One party suggested that BPA should report program accomplishments annually. State of Oregon, SUB01-067. Most public interest groups wanted a clear demonstration that real, measurable energy savings and renewable energy supplies are being achieved. CUB, SUB01-103; NRDC, SUB01-113; NWEC, SUB01-114. Many comments stressed the importance of keeping the amounts of information utilities are required to collect to a minimum. NRU, SUB01-057; WPAG, SUB01-073; Wells, SUB01-095.

\section{Evaluation and Decision:}

The implementation of the Conservation and Renewables Discount must be simple with a minimum of tracking and reporting at the local level. Power customer participation will be enhanced if the administrative burdens associated with the program are kept to the bare essentials. The RTF can consolidate the customer specific information to develop State and regional level reports on program accomplishments. Regional evaluations should be an important component of the Conservation and Renewables Discount program, but this information will not be used to make retroactive adjustments. They will be used to modify energy savings levels for qualifying measures in future years. Accountability at the power customer level is financial only (tracking and reporting the money spent on qualifying measures). Energy savings performance evaluations will be conducted, but only at the regional level, with appropriate power customer involvement, for the purposes of making periodic adjustments to the savings credited to measures and program designs.

\section{Issue:}

Should BPA specify an allocation of expenditures between the categories of conservation, renewable resources and low-income weatherization? 


\section{Subscription Proposal:}

Nothing was mentioned in the proposal on this issue. However, the Comprehensive Review recommendations included an annual allocation of funds to conservation, renewable resources and low-income energy services (see Table 1 of the Comprehensive Review of the Northwest Energy System Final Report at 28).

\section{Parties' Comments:}

Some public interest groups indicated that an allocation is needed to be consistent with the Comprehensive Review recommendations and thereby provide more certainty for developers of renewable resources. WACTED, SUB01-063; Renewables Northwest Project, SUB01-134. The PPC indicated that any allocation should be determined locally. PPC, SUB01-135.

\section{Evaluation and Decision:}

Specific allocation requirements for power customers are not appropriate because most power customers do not have the full range of funding categories available. It would reduce local discretion and create additional administrative and reporting requirements. This type of allocation is better managed at a regional level where periodic reviews and adjustments can facilitate achieving the Comprehensive Review's recommendations over time. BPA will not specify any power customer-level allocation or requirement for expenditures between the categories of conservation, renewable resources and low-income weatherization. If there are any unclaimed Conservation and Renewables Discount funds, BPA is proposing that they be used to assist the region in achieving the allocation specified in the Comprehensive Review recommendations.

Issue:

Should power customers maintain local control in developing and managing the Conservation and Renewables Discount effort?

\section{Subscription Proposal:}

Although this is was not addressed directly in the proposal, the proposal stated that the Conservation and Renewables Discount should provide greater incentive for utilities and DSIs to meet the Comprehensive Review's goal of supporting conservation and renewables through local action. 


\section{Parties' Comments:}

The PPC and most of the preference customers supported local control with the power customers having maximum flexibility to customize the package of qualifying measures to meet the needs of their consumers. Tillamook, SUB01-052; NRU, SUB01-057; WPAG, SUB01-073; Wells, SUB01-095; PPC, SUB01-135.

\section{Evaluation and Decision:}

The benefit provided under the Conservation and Renewables Discount goes to the customers, and they are in the best position to determine how it should be used in their service areas, and are accountable to their own customers or members. All decisions about what the power customer does with respect to the Conservation and Renewables Discount are up to the customer (i.e., whether to participate, amount of participation, what sectors to address, which qualified measures to use, the means, whom to partner with, and all elements of any program design). Therefore, it is appropriate for power customers to maintain local control over developing and managing their Conservation and Renewables Discount efforts.

\section{G. Indexed Cost-Based Rates}

Issue:

Should BPA offer indexed cost-based rates?

\section{Subscription Proposal:}

Customers under the PF and NR rate schedules would have the option to convert their fixed-price requirements rates to a cost-based market-indexed price, adjusted for BPA's risk. Customers also could choose to purchase surplus firm power indexed to the California-Oregon Border (COB), New York Mercantile Exchange (NYMEX), or other mutually agreed-to market locations.

\section{Parties' Comments:}

PPC states that BPA should permit "market-indexed rates for customized products only upon a customer's request." PPC, SUB01-097 at 2. PPC states that "BPA should establish posted, cost-based rates for all of its requirements products." PPC, SUB01-097 at 8. PPC adds that "Customized and Non-Core products used for requirements service may deviate from posted prices due to demonstrable effects on BPA's costs, and customers may agree to market-indexed prices for such requirements products." PPC, SUB01-097 at 8. ICNU states that it is "interested in BPA developing a feasible indexed-rate power product." ICNU states that BPA should establish the 
index and the discount amount at the beginning of the rate case. ICNU, SUB01-109 at 2. Springfield states that BPA's proposal for indexed cost-based rates "should be clarified and follow the guidelines of the law. BPA should provide a detailed financial risk management policy, follow national and international standards for trading in commodities futures, and provide for an independent legal review of its ability to offer this type of product." Springfield, SUB01-121 at 3. Springfield also states that BPA should not require any entity to purchase a cost-based, market-indexed rate. Springfield, SUB01-121 at 12. Several IOUs stated that BPA should not offer marketindexed rates. The IOUs stated that "BPA is ill-suited to accept financial risks" because there is a chance that the market index would fail to recover BPA's full cost. Litchfield, SUB01-053. The IOUs also argued that it is inappropriate to require one customer to provide insurance for another and recommended that customers interested in such features consult private intermediaries. Id.

\section{Evaluation and Decision:}

The parties' comments that market-indexed rates should be available only upon a customer's request are well taken. BPA does not intend to impose mandatory market-indexed rates. Currently it is BPA's intent to offer indexed cost-based rates in the Power Rate Case initial proposal. At a customer's option, the posted rates for requirements products could be converted to a market-indexed price. The market-indexed price would be adjusted for BPA's risk and would be designed to achieve revenues equivalent to the posted rates at the time the contract is signed. BPA believes that it can assess and mitigate market risk as effectively as any other entity in the market and will design market-indexed rates to recover the costs of the power sold. In addition, customers could choose to purchase surplus firm power at prices indexed to the COB, NYMEX, or other mutually agree-to market locations. The rate indexed to market would not be fixed but by definition would rise or fall with market prices. The purposes of the indexed rate would be to: (1) increase diversity in BPA's product offerings to customers; (2) stand as an alternative to take-or-pay contract provisions; and (3) provide a product alternative to customer end-use consumers, particularly industrial and large commercial loads seeking market-based electric rates.

It should be noted that BPA's Subscription Strategy does not establish any rates or rate designs. The establishment of rates and use of rate design can be determined only in a formal rate hearing under section 7(i) of the Northwest Power Act. The comments referenced above will be addressed in BPA's rate development process, which includes extensive opportunities for public involvement. While final rate design decisions are not being made in the Subscription Strategy, rate design approaches identified in the Subscription Strategy will be part of BPA's initial power rate proposal, which is expected to be published early in 1999 . 


\section{CONTRACT ELEMENTS}

\section{A. Bilateral Contract Negotiations}

Issue:

Should BPA conduct bilateral negotiations with its customers?

\section{Subscription Proposal:}

BPA will conduct bilateral negotiations with its customers based on the decisions in the Subscription Strategy.

\section{Parties' Comments:}

Three comments directly addressed the BPA's proposal to conduct bilateral negotiations, but the comments discussed in the next section on standard contract provisions were intertwined with this issue. Grant affirmed BPA's proposal asking BPA to design a Subscription process that meets the needs of the customers for bilateral negotiaticns on many issues. Grant, SUB01-058. URP noted a concern that bilateral negotiations may lead to negotiations beyond the pubiic's view. URP, SUB01-120. ICUA asked that BPA allow certain associations, such as ICUA, to negotiate contracts on behalf of their customers. ICUA, SUB01-072.

\section{Evaluation and Decision:}

BPA did not receive many direct comments on this proposal. Grant supports the proposal and URP expresses concern that negotiations will be out of public view. ICUA would like customer associations to have the ability to negotiate contracts on behalf of their members. Given the competitiveness of the current wholesale power market, bilateral negotiations are necessary from both the purchaser's and seller's points of view. BPA recognizes the concern expressed by URP, but believes that the Subscription Strategy and ROD set the basic public policy direction of BPA's new contracts and products in the competitive market. On some issues, the use of a standardized set of common contract provisions should alleviate much of URP's concern. It is intended that negotiations will be based upon the power products BPA is offering to its customers. In addition, bilateral negotiations of contract terms will be made consistent with the Subscription Strategy policy decisions. In considering the ICUA's request, BPA also will allow customer associations to negotiate on behalf of their members, as agent for their members who are BPA customers, if the customer so requests. 
BPA affirms its proposal to conduct bilateral contract negotiations based upon the Subscription Strategy policy decisions. BPA will conduct bilateral negotiations of contract terms with its customers that will be consistent with the Subscription Strategy policy decisions.

\section{B. Standard Contract Provisions}

Issue:

Should BPA contracts contain a standard set of provisions?

\section{Subscription Proposal:}

On certain topics or terms, BPA contracts will have a set of standard provisions that are intended to be non-negotiable and consistent across all Subscription contracts.

\section{Parties' Comments:}

BPA received about 20 comments on standard contract provisions. Comments reflected a general agreement for some form of standard contract or contract provisions for certain terms and conditions. Murphy, SUB01-040; Attorney General of Washington, SUB01-0059; Kitzhaber, SUB01-067; OPUC, SUB01-004; URP, SUB01-120; PPC, SUB01-097; Grant, SUB01-058. Comments made by the DSIs and URP recommended that BPA offer a standard form contract. Other comments focused on BPA developing specific standard provisions. Some commenters expressed specific concerns that the provisions developed for the issue of cost recovery allocate risk fairly between power and transmission. Murphy, SUB01-040; Early, SUB01-078; WWP, SUB01-066; Litchfield, SUB01-053; NWEC, SUB01-114. Some comments suggested adding other contract provisions to BPA's proposed list, such as notice provisions for a return to a PF purchase, NRU, SUB01-057; PNGC, SUB01-086; recall provisions for sales to nonpreference customers, OURCA, SUB01-116; Springfield, SUB01-121; and price and follow-on rights, NWEC, SUB01-114.

\section{Evaluation and Decision:}

BPA's proposal to conduct bilateral negotiations is predicated upon the desire of most customers to negotiate individual contracts. Given the current competitiveness in the wholesale power market, bilateral negotiations are desirable from the points of view of both the purchaser and the seller. In 1996, BPA successfully negotiated on an individual customer basis amendments to the existing 1981 contracts or entirely new contracts. BPA believes that this type of approach is more responsive to individual customer needs and necessary for success in today's market. At the same time, BPA is aware that there is a regional interest in some issues affecting all customers and 
seeing some form of standard provisions, such as cost recovery, that will limit the potential shift of risk to other parties.

Comments made by the DSIs recommended the development of standard provisions as the next step in the process. The DSIs, IOUs, and NWEC all expressed concern that contract provisions on cost recovery must allocate risk fairly between BPA's power and transmission service. In response to such comments, BPA recognizes the need to establish a set of standardized provisions on this and some other topics before bilateral negotiations are concluded. In particular, variations in the language on cost recovery for each customer could raise the same concern, a shift of risk between customers. BPA will propose a CRAC as part of its power rates, to be established in the upcoming power rates section 7(i) proceeding. See section II.A. for discussion of BPA's risk management framework.

The PPC noted public power's willingness to work with BPA to develop a list of common contract provisions. With regard to these comments, the provisions listed in BPA's proposal were intended to be illustrative, not definitive, and included administrative provisions (statutorily required provisions, billing and payment, and delivery) as well as other provisions that go to the heart of the business relationship. Administrative provisions generally are standardized to improve administrative efficiency.

in response to concerns raised in comments on the Suoscription Proposal, BPA will issue draft language for public comment on three key contract provisions: cost recovery, uncontrollable forces, and dispute resolution. After public comment, the final language on these provisions is intended to be used consistently in all Subscription contracts, although there may be limited exceptions, such as potential additional dispute resolution language for Slice contracts. BPA believes that making the language in these provisions standard in all contracts will aid in limiting any shift in risk between customers. Besides those provisions being reviewed, BPA plans, to the extent possible, to standardize most of its other contract provisions to streamline and increase the automation of contract administration.

\section{Contract Types}

Issue:

Should BPA offer both umbrella and commercial type contracts?

Subscription Proposal:

BPA is indifferent between umbrella and commercial type contract arrangement. 


\section{Parties' Comments:}

The DSIs commented that the distinction between "umbrella/subsidiary" contracts and "commercial" contracts appears to be artificial. Murphy, SUB01-040. The DSIs assume all of the contracts will address rights to follow-on contracts and BPA's stranded costs. Id.

\section{Evaluation and Decision:}

The concept for umbrella and commercial contract arrangements was discussed very early in the Subscription Work Group. BPA agrees with the DSIs' comment that the distinction has become artificial. BPA believes that it can offer a variety of terms and products, a portfolio approach, through bilateral negotiations. BPA no longer sees a need to maintain the distinction between contract types. Therefore, BPA will not maintain a distinction between umbrella and commercial contracts. BPA will not offer umbrella contracts because there is no practical reason to do so and no effective distinction. The contracts BPA offers will be flexible enough to meet the needs of individual customers and to allow customers to purchase power with a portfolio of the rate choices offered to that customer group.

\section{Contract Length}

\section{Issue:}

Should BPA provide incentives to customers to choose between contracts with varying durations?

\section{Subscription Proposal:}

BPA's Proposal provided various incentives for customers to choose between three-year contracts, five-year contracts, and contracts longer than five years.

\section{Parties' Comments:}

Most comments expressed general support for the BPA proposal on varied contract terms. Murphy, SUB01-040; Tillamook, SUB01-052; EWEB, SUB01-107; KPUD, SUB01-111. EWEB commented that flexible contract terms would make BPA a more attractive business partner. EWEB, SUB01-107. KPUD noted that varied contract lengths would give BPA and customers flexibility to meet their mutual interests. KPUD, SUB01-111. Other comments addressed the following specific issues:

- Specific Duration for IOUs: BPA should limit the IOU residential power sales to 10 years to ensure enough power is available for public agencies. Springfield, 
SUB01-121; Snohomish, SUB01-090. BPA should assure that it will not recall power sold to IOU's' residential and small farm load; a long-term contract may be a means to accomplish this. Fair and Clean Energy Coalition, Public Meeting Transcript, Oct. 14, 1998, at 93.

- Short-Term Contracts: BPA should reconsider its emphasis on short-term contracts and encourage long-term contracts. MPC, SUB01-062. There is concern about the risk of cost underrecovery that is created with short-term contracts if they expire in a time of low market prices. Id.; Murphy, SUB01-040; Litchfield, SUB01-053. In the current environment of uncertainty in the electric utility field, BPA should not be offering new contracts for periods longer than 5 years. URP, SUB-120.

- Long-Term Contracts: The framework negotiated for Subscription needs to stand as a long-term framework (15-20 years) for future Subscription processes. Clearwater, SUB01-049. Long-term would mean no need to resort to allocation caps and incremental resource acquisition. MPC, SUB01-062. BPA should generally create financial incentives for long-term contracts and offer a PF discount in 2006 for those who make long-term commitments to purchase. WMG\&T, SUB01-099.

\section{Evaluation and Decision:}

BPA is encouraged by the overall support reflected in the comments on the proposal to offer contracts of varying duration. BPA believes this is a necessary step that must be taken to avoid future revenue cliffs created when the majority of BPA contracts expire at the same time. BPA would like contracts with durations ranging from 3 to 20 years. However, the duration of a contract will be based on the service requested by the customer consistent with the minimum durations stated in this policy

With regard to specific comments on the duration of contracts with IOUs, BPA would like contracts with the IOUs for service to residential and small farm load to vary as well. As required by statute, BPA remains obligated to meet future public agency net firm loads under contracts consistent with section 5(b)(1) of the Northwest Power Act, whether through the current FBS, power returning to the region, or acquisition of power. In response to the comment made by the Fair and Clean Energy Coalition, BPA will enter into contracts with IOUs for their net firm load requirements, if requested. Contracts longer than five years will be consistent with section $5(b)(2)$ of the Northwest Power Act and section 5(a) of the Bonneville Project Act.

Comments made by the DSis, IOUs, and URP on long-term contracts versus short-term contracts focused mainly on the concern over cost underrecovery and the uncertainty that exists in the electric utility industry. BPA believes that offering short-term contracts will give customers more economic choices. Short-term contracts are a BPA advantage 
if markets are high and BPA faces increased costs, but a disadvantage if market prices are low and there is not a corresponding decrease in BPA costs. Comments made by Clearwater and MPC focused on the stability associated with long-term contracts. Indeed, longer-term contracts do create greater financial and power supply certainty for both BPA and its customers, but they also limit flexibility as market conditions change. WMG\&T commented that a rate discount should be provided as an incentive to customers under long-term contracts. BPA is open to the idea of an incentive for longer-term contracts and encourages WMG\&T to bring its proposal to the next Power Rate Case. In response to this comment, BPA has advanced its thinking on its proposal as follows.

To further diversify its revenue stream, BPA will allow customers to have a portfolio of purchases with different rate periods within a long-term contract. Full Service customers may commit to buy power for as long as 20 years at the applicable rates BPA establishes, but choose to purchase under different BPA PF rates applicable for an amount of purchases for a specific period. For example, they could initially purchase part at the three-year rate and part at the five-year rate. At the expiration of each rate period, these Full Service customers would be obligated to purchase at the then applicable PF rate or rates. Actual Partial customers would have a similar right except that when a specific purchase commitment period expires, such customers may choose to serve that load with a declared resource. However, consistent with BPA's decision to encourage longer-term contracts, BPA's commitment to supply power for the customer load at the then lowest cost-based rate would end when the customer's BPA power purchase commitment expires for a particular load. BPA expects this will result in a more diverse portfolio of BPA sales.

BPA believes that customers will want to take advantage of the portfolio option BPA offers because there are advantages to varying their Federal power purchase commitments. Possible benefits of a three-year purchase include avoiding the proposed step-up in rates and getting the chance for lower rates if BPA costs are reduced. On the other hand, a five-year purchase at the five-year rates creates rate certainty for the full five years. For longer contracts BPA plans to create contractual incentives about access to the lowest cost PF rate schedule.

In the future, BPA will find it beneficial to avoid the expiration of all contracts on the same date, the "contract cliff" BPA faces in 2001. BPA will encourage variations in contract lengths with its customers in Subscription contracts from 3 to 20 years. BPA's rates will establish choices with rates that expire at different times. Customers will be allowed to diversify their BPA Federal power purchases by choosing different contract lengths or by committing to rate periods of varying lengths within the same contract. If load amounts are staggered into different rate periods BPA will not face the same revenue cliff it does today. 


\section{E. Future Price Guarantees}

Issue:

Should BPA offer option fees and follow-on rights to secure future rights to purchase Federal power at BPA's then lowest cost-based rate?

\section{Subscription Proposal:}

To be guaranteed the right to continue purchasing at BPA's then lowest cost-based rate, a customer would either pay an option fee or make a 10-year purchase commitment.

\section{Parties' Comments:}

BPA received almost 40 comments on its proposed option fee approach. The overwhelming majority of those comments, largely from BPA's preference customers, called on BPA not to include option fees in its final Subscription Strategy. PPC, SUB01-097; NRU, SUB01-057; ICUA, SUB01-072; WRECA, SUB01-094; WPAG; SUB01-073; OURCA, SUB01-116; WMG\&T, SUB01-099; PNGC, SUB01- 086; Surprise Valley, SUB01-149; Clallam, SUB01-150; Nespelem, SUB01-024; Inland, Public Meeting Transcript, Oct. 8, 1998, at 66; Clearwater, SUB01-049; Northern Wasco, SUB01-048; Grant, SUB01-058; Kootenai, SUB01-060; Port Angeles; SUB01-064; Benton PUD, SUB01-101; Sumas, SUB01-112; KPUD, SUB01-111; McMinnville, SUB01-112; Springfield, SUB01-121; Benton REA, SUB01-075; Clark. SUB01-077; Snohomish, SUB01-090; Tanner, SUB01-093; Wells, SUB01-095; Big Bend, SUB01-140. ICUA's comment that option fees (along with follow on rights and take-or-pay provisions) "violates the intent and spirit of BPA's legal obligation to its preference customers" captures the essence of most of the comments. ICUA, SUB01-072 at 4. Some comments also provided input on improvements and clarifications BPA should make if BPA carried forward the concept of option fees.

Not all comments expressed opposition to option fees. Seattle commented that option fees along with tiered rates diminish the perceived value of preferential access to BPA, but that their absence could force BPA into greater acquisitions of power, which would dilute the value of the existing system. Seattle, SUB01-104. The IOUs commented that if BPA includes an option fee it should be uniform for all customers and either bundled in the power rates or a cost-based rate. Litchfield, SUB01-053. Other commenters expressed support for option fees. Sierra Club, SUB01-089; MPC, SUB01-062; State PUCs, SUB01-146. 


\section{Evaluation and Decision:}

As reflected in their comments, public power overwhelmingly objects to BPA's proposal on option fees. The concept of option fees emerged from the Comprehensive Review when it was assumed that BPA's rates would be above market. BPA needed to encourage its customers to purchase what might be otherwise power sold at market. In its comments, Snohomish pointed out that this assumption is no longer valid since BPA power is likely to be competitively priced with BPA facing the new concern over sufficient inventory. Snohomish concluded that BPA no longer needs the option fee to encourage customers to buy the power. Snohomish, SUB01-090 at 4.

In response to the concerns raised by BPA's preference customers, BPA has decided not to implement option fees at this time. As a policy matter BPA still believes option fees could be implemented consistent with its statutory directives, but BPA is persuaded that they are not needed based on expected market conditions. Without the option fee BPA needs another means to encourage some long-term purchases. As an incentive to lead customers to make long-term purchases, BPA will contractually guarantee access to the then-applicable lowest cost-based rate for the Federal power purchased and for the length of time the customer commits to purchase that power from BPA. BPA intends to assure that this guarantee will provide benefits to these customers that make a longer-term commitment. One approach that would provide such a benefit is described in section III.A. of the Subscription Strategy. No contraciual guarantees to the lowest PF will be included beyond a customer's contract term.

It should be noted that BPA's Subscription Strategy does not establish any rates or rate designs. The establishment of rates and use of rate design can be determined only in a formal rate hearing under section 7(i) of the Northwest Power Act. The comments referenced above will be addressed in BPA's rate development process, which includes extensive opportunities for public involvement. While final rate design decisions are not being made in the Subscription Strategy, rate design approaches identified in the Subscription Strategy will be part of BPA's initial power rate proposal, which is expected to be published early in 1999.

\section{Issue:}

Should BPA offer future price guarantees?

\section{Subscription Proposal:}

A customer who wants a price guarantee beyond 2006 may ask BPA to secure that guarantee for them from the financial markets. The price a customer will pay will reflect the cost that BPA incurs to provide the guarantee. 


\section{Parties' Comments:}

One comment addressed BPA's proposal on future price guarantees. The IOUs discussed the risks associated with offering price guarantees and concluded that "providing customers with insurance for market price risk is not an appropriate role for the Federal government and BPA should not offer this product." Litchfield, SUB01-053 at 7 . The IOUs recommended that BPA direct customers interested in this type of business relationship to private intermediaries offering this product.

\section{Evaluation and Decision:}

The original idea behind the price guarantee was that if BPA's prices were above market BPA could create value by offering price certainty in the future when market prices were either unknown or expected to be higher than BPA's costs. This tool was seen as one way BPA could fill in potential revenue valleys. Since market prices are now projected to be above BPA's cost-based rate, the main reason for this product is gone. BPA recognized this change in its Proposal, which relied on a market provider of this product. The difference between BPA's Proposal and the IOUs' proposal is minimal. Rather than act as the agent securing price guarantees from the market, BPA would provide information to a requesting utility about who could provide the price insurance service it wants. BPA recognizes this nuance and has decided to adopt the IOU proposal for now. However if the perception of BPA's price relative to market changes, BPA may reconsider this decision and offer price guarantees as a revenue tool. BPA will not offer future price guarantees at this time. Customers that want such an arrangement can purchase it from other providers in the market.

\section{F. Take-or-Pay}

Issue:

Should BPA require a "take-or-pay" provision in its Subscription contracts?

\section{Subscription Proposal:}

Previous BPA power sales contracts gave customers considerable flexibility to increase or reduce their purchases by adding or removing non-BPA power supplies on relatively short notice. BPA proposes to mostly eliminate this flexibility in the new Subscription contracts. However, eligible customers will still be able to purchase requirements service in which BPA absorbs load fluctuations due to weather, plant closures and load growth. The risk of load loss due to retail access is a largely new risk factor that must be managed differently. BPA has used the term "take-or-pay" to describe the contractual situation where customers will bear the risk of losing load due to retail open 
access whether that access is voluntary or legally mandated. Most customers are expected to mitigate their take-or-pay risk by having "at risk" consumers sign power purchase contracts in the event of legally mandated retail open access laws. In addition, BPA plans to offer products for those customers who do not mitigate this risk themselves.

\section{Parties' Comments:}

Public agency utility customers commented that BPA should reconsider its proposal on take-or-pay type contracts for Full and Partial Service customers and urged BPA to eliminate it. In addition some of these commenters noted that since market prices are expected to be higher than BPA's price, the risk is minimal. PPC, SUB01-193; Big Bend, SUB01-141; Surprise Valley, SUB01-149; WPAG, SUB01-073; ICUA, SUB01-072; WRECA, SUB01-094. The Northwest Power Act does not intend that BPA can impose additional charges on customers' flexibility to increase or decrease their requirements under section 5(b)(1). OURCA, SUB01-116; SUB, SUB01-121. OURCA recommended that BPA modify the proposal by eliminating the take-or pay obligation and continue the treatment under the current power sales contract. OURCA, SUB01-116 at 6 . NRU opposes the proposal and suggested that if BPA can demonstrate a need for protection from retail access load loss, it should be limited to tiuly larger loads (if any) of a utility, noting that BPA in some pre-Subscription contracts exempted loads under 250 kilowatt from retail access load loss "take-or-pay" responsibilities. NRU, SUB01-057 at 1. Sumas noted BPA should not adopt the take-or-pay approach due to the complexity of implementation at the retail level. Sumas, SUB01-105 at 2. Murphy expressed an opposing view and called on BPA to strengthen the take-or-pay elements in utility contracts and asserted that there is "no reason BPA should bear any risk of retail access." SUB01-40.

\section{Evaluation and Decision:}

Most of BPA's public utility agency customers oppose BPA's proposal to include "take-or-pay" provisions in Subscription contracts. Some of the DSIs expressed their support for BPA's proposal with concern that the proposal was not strong enough on take-or-pay. The financial risk associated with load loss due to retail access is a relatively new one, caused by emerging competition at the wholesale and potentially retail level. The risk is beyond BPA's control and depends on the actions of individual States or Congress, which continue to weigh the option of establishing retail access legislation. Montana already has passed such legislation. Once legislation is passed, individual consumers may choose alternative suppliers. As a wholesale power supplier, BPA's business relationship is with the utility, not the end-user. BPA believes that placing the risk of retail access load loss on the utility creates the most direct means of dealing with the potential for load loss, utility to end-use consumer. 
The comment that risk is minimal actually highlights another reason BPA believes take-or-pay is necessary. As seen in recent years, market prices can fluctuate significantly. BPA believes it needs to design its Subscription contracts so that BPA continues to be financially sound even if market prices are below BPA's rates.

Take-or-pay makes BPA revenues more reliable in the unlikely event that BPA rates are above market and reduces BPA exposure to market price fluctuations.

OURCA and SUB commented that take-or-pay is inconsistent with the Northwest Power Act. Nothing in the Northwest Power Act prohibits BPA from including take-or-pay provisions in its contracts under section $5(b)(1)$. Under section 2(f) of the Bonneville Project Act, the Administrator is authorized to enter into contracts using the terms and conditions she deems necessary. Given the large economic risk and uncertainty surrounding retail access, it is both necessary and reasonable for the Administrator to insist upon terms and conditions in Subscription contracts to mitigate the financial risk BPA faces by actions not in the Administrator's control.

Nonetheless, in light of the comments advising BPA to eliminate take-or-pay or assume more of the risk associated with retail access, BPA will revise its proposal to balance the implementation concerns noted by the publics and still continue the principle that the cost of retail access risk follow the cause. BPA will assume the risk of retail access load loss only under the following two circumstances: The customer is a Full Service customer and the load lost to retail access is less than $250 \mathrm{akW}$; or, if the cusiomer purchases power from BPA for a contract term of three years or less. BPA chose the 250 akW threshold because it believes that larger loads are the most likely targets for early action on retail access. The decision on the three-year term is based on BPA's decision to encourage staggered contract terms.

\section{G. Contract Mitigation Measures}

\section{Conversion to Excess Federal Power (EFP)}

Issue:

Should BPA offer to convert PF power to Excess Federal Power (EFP) to mitigate against the effects of take-or-pay?

\section{Subscription Proposal:}

Allow the conversion of PF purchases to EFP if the EFP is available and the customer loses load due to retail access and cannot serve the load with its take-or-pay power purchase obligation. A conversion to EFP will allow the customer to resell the power. Before making the conversion, however, BPA will have the option of reducing the 
customer's take-or-pay obligation and taking back the power. Once this option is exercised, the customer's right to purchase the amount of power associated with the load loss at the lowest cost-based rate in its follow-on contract will be permanently reduced.

\section{Parties' Comments:}

Conversion to EFP as proposed is a "lose/lose" proposition to customers because BPA would exercise the EFP conversion option only when market prices are low and customers would lose money. WPAG, SUB01-073; OURCA, SUB01-116; Benton REA, SUB01-075; PRM, SUB01-087. If BPA does not eliminate the take-or-pay obligation from contracts, then BPA's customers should have the right to convert purchases to EFP where loads change due to retail load loss. PPC, SUB01-097. The option that is proposed to be at BPA's discretion, should instead be at the customer's discretion. SUB, SUB01-121; KPUD, SUB01-111.

\section{Evaluation and Decision:}

BPA's decision whether or not to exercise the option to reduce the customer's take-or-pay obligation will be driven by our statutory obligation to meet its firm loads and the current load/resource balance. BPA will evaluate requests to convert to EFP on an individual basis based on the Federal System circumstances when the request is made. The decision is not based on BPA's view of market prices as suggested in the comments. If EFP is not available, then BPA will not be able to make the conversion and will take the power back to serve load or resell. If EFP is available then BPA plans to make the conversion.

The EFP Policy ROD issued on September 18, 1996, among other things provides an overview of BPA's final policy on EFP and adopts the final policy on EFP. The process outlined in that ROD states that each year BPA will determine the total amount of EFP available for marketing based upon a specific calculation. The results of such determinations will be included in an annual notification to BPA's then-existing regional customers. BPA also may send this notification to non-regional customers. The annual notice may contain the amount of excess or surplus power available for disposition as determined by BPA.

BPA will offer conversion to EFP, when available, as an option to mitigating the effects of take-or-pay. BPA's decision on whether to exercise its option to reduce the customer's take-or-pay obligation, concurrent with disapproving the conversion to EFP, will be based upon BPA's statutory obligations to meet firm loads and its load/resource situation. 


\section{Walled-Off Loads}

Issue:

Should BPA offer Walled-off Loads?

\section{Subscription Proposal:}

Prior to execution of the contract, BPA and a Full Service customer may agree that neither will provide service to a specific retail load that has another supplier and is not requesting service. A specified portion of the load of a Full Service customer may be excluded from the utility's purchase and will not be eligible for service at PF(1). These loads must be separately metered on an hourly basis. The utility will be responsible for purchasing from BPA only the remaining portion of its load and must hold BPA harmless from any third-party claim. This service will be available only before the contract is signed and not during the term of the contract.

\section{Parties' Comments:}

ICNU supports the walled-off load concept, and urges BPA to work with ICNU and BPA's customers in defining and developing this concept. ICNU, SUBO1-109. Some parties argued that walled-off loads should be available to all customers, not just full requirements customers. Springfield, SUB01-121, KPUD, SUB01-111; ICNU, SUB01-109; PPC, SUB01-097. Springfield argued that walling-off load shculd be made available at any time, upon request. Springfield, SUB01-121. Central Lincoln PUD included an attached letter from one of its industrial consumers, Georgia-Pacific (GP) Corporation, in which GP indicates its interest in the concept of "walled-off load" and expressed a concern for ancillary services. Central Lincoln, SUB01-106 at 1.

\section{Evaluation and Decision:}

As BPA has not totally eliminated take-or-pay for load loss associated with retail access, BPA has decided to offer an additional contractual means for customers to mitigate that risk. Unlike other means available to customers for mitigation, walling-off load is offered as a means to act proactively to avoid preclusion of load from accessing the retail market once it is deregulated. The Subscription Strategy maintains this as an approach available for customers to mitigate retail access load loss risk. The decision to allow only full service or give partial service customers the ability to wall-off load will be decided on a case-by-case basis. 


\section{H. Product Mitigation Measures}

Issue:

Should BPA offer products for those customers who do not mitigate the take-or-pay risk themselves?

\section{Parties' Comments:}

PPC commented that the means BPA has proposed to make available to mitigate the take-or-pay risk conversion to EFP, insurance product, remarketing, and walling-off load are helpful, but inadequate. PPC, SUB01-097 at 11-12. Barring elimination of the take-or-pay obligation, the recommendations should be made available. Id. KPUD argues that options for relieving take-or-pay obligations are clearly deficient and discriminatory. KPUD, SUB01-111.

\section{Evaluation and Decision:}

As discussed above, BPA will not eliminate the take-or-pay obligation, but has agreed to revise its proposal. BPA's proposed options do not discriminate between customers in a way that unfairly impacts them. For example, customers with their own resources have the operational flexibility to adjust for losses in load, even those that might occur because of retail load loss. BPA is not proposing to offer such customers all the available means to reduce their risk. Therefore, BPA will offer customers several means they can include in their contracts to mitigate the risk of take-or-pay. They can accomplish this by choosing between specific contract provisions, such as conversion to EFP, when available, and walling-off load, or through two products being offered in BPA's Power Products Catalog--insurance and remarketing. Customers choosing either insurance or remarketing may postpone selection until the State(s) in which they operate pass retail access legislation and it becomes effective. In consideration of the inability of customers to predetermine when States may pass retail access legislation, BPA will allow customers a limited period (e.g., 120 days) to make their selection. In some cases, it may not be possible to offer mitigation if the customer has lost the load prior to selecting a mitigation measure.

\section{Insurance}

Issue:

Should BPA offer an Insurance Product? 


\section{Subscription Proposal:}

The customer may purchase an Insurance Product to reduce the financial risk associated with retail load losses under firm power take-or-pay contracts if the law mandates retail open access.

\section{Parties' Comments:}

McMinnville and Canby request that BPA flesh out the insurance concept and give additional information about the details of how to purchase insurance. McMinnville, SUB01-112; Canby, SUB01-028. They expressed concern that the price of insurance may cause them to be at a competitive disadvantage. Id.

\section{Evaluation and Decision:}

As BPA has not totally eliminated take-or-pay for load loss associated with retail access, BPA feels that is in the customer's best interest if we offer a means to mitigate that risk. This mitigation option is also meant to help customers avoid the additional costs they must pass on to their end-users and thus become uncompetitive.

In response to the customers' concerns about the details of the Insurance Product, we encourage the customers to review the Power Products Catalog and use their Customer Account Executive to answer any questions or concerns they may have. BPA will move forward with the insurance proposal as an option to mitigate the effects of take-or-pay.

\section{Remarketing}

Issue:

Should BPA offer a Remarketing Product?

\section{Subscription Proposal:}

The customer may purchase a product that uses BPA's services to remarket the power to an alternate source if the customer loses load due to retail open access. The customer must continue to pay for the power, but BPA will provide a credit to the customer for the amount of energy remarketed based on a formula using the Dow Jones Mid-Columbia Daily Diurnal Index or some similar index. The product catalog available at the time of the proposal noted that the remarketing credit would be limited to the sum of PF and the remarketing fee owed to BPA. 


\section{Parties' Comments:}

Few written comments specific to the remarketing product were received. However, there were comments, such as one from the Port Angeles, SUB01-064, questioning the fairness of the BPA proposal. They felt that customers should have the ability, when remarketing benefits were available because of good market conditions, to recoup the losses that would be experienced in bad market conditions.

\section{Evaluation and Decision:}

BPA's position in relation to the original proposal has not changed, but the final product catalog will not limit the credit to the sum of PF and the remarketing fee owed to BPA. By not placing an upper cap on the potential remarketing credit, customers' possible risks in bad markets will be balanced by the possible benefits under good market conditions.

\section{Customer Pooling of Requirements Purchases}

\section{Issue:}

To what extent is BPA able to deal with poolers under its enabling legislation? To what extent is BPA willing to encourage pooling that is permitted by law?

\section{Subscription Proposal:}

At the time of the proposal, legislation was pending that would have allowed BPA to sell power to a "joint operating entity" enabling customers who create a joint operating entity to purchase "pooled" requirements power from BPA. BPA has had a policy based on the directives and purposes in the Bonneville Project Act and the Northwest Power Act of selling power to individual utility customers based on the difference between their resources and the consumer load that the utility serves. BPA will remain open to examining alternative pooling arrangements in light of whatever statutory flexibilities exist.

\section{Parties' Comments:}

McMinnville argued that in its opinion BPA has the authority to permit pooling, and concerns that BPA has regarding resale of PF power can be accommodated.

McMinnville, SUB01-112. PRM commented that even though the "joint operating entity" legislation has so far failed, BPA can engage in some form of pooling and that the benefits of pooling are such that BPA and its customers should pursue the concept as fully as possible. PRM, SUB01-087. OURCA argued that there are no legal barriers preventing BPA from allowing certain types of pooling arrangements, but BPA may 
need to remove certain administrative barriers. OURCA, SUB01-116. OURCA added that the proposal recognizes BPA's statutory directives to sell power based on the public preference customers' net requirements. OURCA is confident that it can work with BPA to develop an appropriate mechanism to ensure that BPA meets its statutory obligations to serve the net requirements of its public preference customers, to the extent the customer desires. Id. Springfield is in favor of pooling, is encouraged by BPA's initial proposal, and agrees with OURCA's views on pooling. Springfield, SUB01-121. Grant does not share BPA's belief that there are limited opportunities for customers to engage in joint management of power purchases from BPA and encourages BPA to include terms allowing pooling if it reduces requirements loads on BPA. Grant, SUB01-058. Port Angeles commented that power pooling should be a viable option, and the Subscription process should facilitate utility participation in power pools. Port Angeles, SUB01-064.

\section{Evaluation and Decision:}

Parties commenting on this proposal expressed a general belief that BPA can legally enter into pooling agreements for the sale of requirements power. However, based upon a longstanding legal interpretation of the Bonneville Project Act and the Northwest Power Act, BPA's policy is not to enter into requirements contracts with a pooling entity. Rather, BPA's statutory obligation is to sell net firm load requirements power to each individual uitility customer based on its individual loads and resources. Only in this manner can BPA determine if it has met its obligation to provide net firm load requirements service to that customer. In contrast, selling to a pooling entity would make it difficult, if not impossible, for BPA to know if it has met its statutory obligation. Therefore, BPA will not change its policy.

The proposed "joint operating entity" legislation, if passed, would have amended section 5(b)(1) of the Northwest Power Act to allow BPA to sell power to a joint operating entity to meet the firm power loads of public bodies and cooperatives that are members of such entity. Because this legislation did not pass, BPA will continue to explore options for pooling type arrangements with preference customer groups within the limits of existing statutes. An example of pooling arrangements BPA has entered into with pooling entities in the past is sales of surplus firm power. 


\section{v. CONCLUSION}

After participating in an extensive public process; evaluating the NEPA considerations in the NEPA ROD for the Power Subscription Strategy; and based on the evaluations of the issues in this ROD, I have decided to adopt and implement BPA's Power

Subscription Strategy. The Power Subscription Strategy is consistent with the Fish and Wildife Funding Principles and BPA remains fully committed to those principles. BPA will begin bilateral negotiations during which customers will make Federal power purchase commitments and execute individual contracts. BPA is offering a variety of power products and pricing to address customers' needs. This will make the purchase of Federal power more attractive to customers, resulting in reliable and predictable BPA. revenues which will provide financial stability over time to help provide public benefits, avoid stranded costs and reduce the need to invoke risk management strategies. This decision is consistent with BPA's Market-Driven approach for participation in the increasingly competitive electric power market. BPA is responding to customers' needs while ensuring the financial strength necessary to produce the public benefits that are of concern to the people of the Pacific Northwest. Making Power Subscription contracts available to customers is a prudent business and public policy decision that reflects the values of the region.

Issued in Portland Oregon, on December 21, 1998.

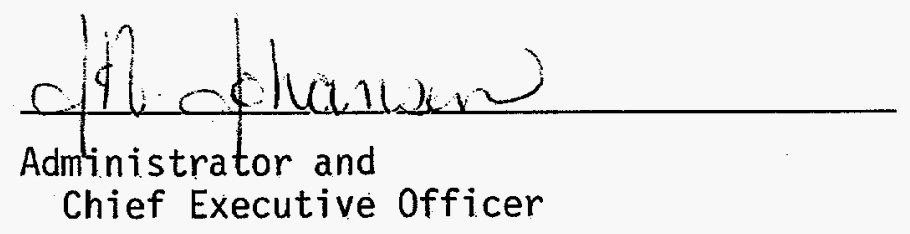




\section{APPENDIX A \\ LIST OF COMMENTERS}

\section{Comment}

\section{Log No.}

SUB01-004

SUB01-022

SUB01-023

SUB01-024

SUB01-025

SUB01-026

SUB01-027

SUB01-028

SUB01-029

SUB01-030

SUB01-031

SUB01-032

SUB01-033

SUB01-034

SUB01-036

SUB01-037

SUB01-039

SUB01-040

SUB01-041

SUB01-042

SUB01-043

SUB01-044

SUB01-045

SUB01-046

SUB01-047

SUB01-048

SUB01-049

SUB01-050

SUB01-051

SUB01-052

SUB01-053

SUB01-054

SUB01-055

SUB01-056

SUB01-057

SUB01-058

SUB01-059

SUB01-060

SUB01-061
Affiliation

Oregon Public Utility Commission

Enron Power Marketing, Inc.

Idaho Power Company

Nespelem Valley Electric Co-Op, Inc.

Snohomish County Public Utility District No. 1

Bellevue Chamber of Commerce

USWA Local 7945 Member

Canby Utility Board

Island District Economic Development Council

Kalispel Natural Resource Department

Washington Water Power

Emerald People's Utility District

Skagit County Board of Commissioners

No Affiliation

Skagit Valley College

League of Oregon Cities

Reynolds Metals Company

Direct-Service Industries

Pierce County, Office of the County Executive

No Affiliation

Economic Development Association of Skagit County City of Auburn Washington

Metropolitan King County Council

No Affiliation

City of Burley, Idaho

Northern Wasco County PUD

Clearwater Power Company

Aluminum Company of America

Idaho Legislative Council Joint Committee on

Electrical Utility Restructuring

Tillamook People's Utility District

Investor-Owned Utilities

Vanalco, Inc.

Puget Sound Energy, Inc.

Idaho Irrigation Pumpers Association, Inc.

Northwest Requirements Utilities

Public Utility District No. 2 of Grant County

Attorney General of Washington

Kootenai Electric Cooperative, Inc.

City of Kirkland Washington
Name of Commenter

Ron Eachus

Michael W. McDonald

Jan Packwood

William C. Miller, Jr.

Charles Moon

Peter Horvitz

Robert Lalicker

John H. Hammond, Jr.

John E. Hitt

William T. Towey

Gary G. Ely

Jeffrey K. Shields

Harvey Wolden

Audrey Smith

Lydia Ledesma-Reese

Bob McPheeters

John R. Amos

Paul M. Murphy

Doug Sutherland

Matthew V. Andrews

Gregg Davidson

Charles A. Booth

Louise Miller

Mavis Norton

Dile J. Monson

Dwight Langer

Raymond J. Thayer

J. A. Speer

Ron Crane/John Hansen

Patrick Ashby

Jim Litchfield

Noel Shelton

Joe Quintana

Randall C. Budge

John D. Saven

Don Godard

Robert F. Manifold

Robert L. Crump

Michaele Muse 
Comment

Log No.

SUB01-062 The Montana Power Company

SUB01-063

SUB01-064

SUB01-065

SUB01-066

SUB01-067

SUB01-068

SUB01-069

SUB01-070

SUB01-071

SUB01-072 Ida

SUB01-073

SUB01-074

SUB01-075

SUB01-076

SUB01-077

SUB01-078

SUB01-079

SUB01-080

SUB01-081

SUB01-082

SUB01-083

SUB01-084

SUB01-085

SUB01-086

SUB01-087

SUB01-088

SUB01-089

SUB01-090

SUB01-091

SUB01-092

SUB01-093

SUB01-094 Washington Rural Electric Cooperative Association

SUB01-095 Wells Rural Electric

SUB01-096 Kaiser Aluminum and Chemical Corporation

SUB01-097 Public Power Council

SUB01-098 Direct Service Industries

SUB01-099 Western Montana Electric Generating and

Transmission Cooperative, Inc.

SUB01-100 City of Idaho Falls

SUB01-101 Public Utility District No. 1 of Benton County

SUB01-102 Washington State Representative, 24th Dist.

SUB01-103 Citizen's Utility Board of Oregon

SUB01-104 Seattle City Light/City of Seattle

SUB01-105 City of Sumas

SUB01-106 Central Lincoln People's Utility District
Name of Commenter

Robert P. Gannon

KC Golden

Robert J. Titus

Joan M. Simpson

T. M. Matthews

John A. Kitzhaber, M.D.

Mick Robinson/Dave Fisher

Gary Zarker

James C. Miller

Alvin Alexanderson

Roy Lewis Eiguren

Terence L. Mundorf

J.S. Corven

Charles L. Dawsey

Jesse Tanner

James L. Sanders

Michael B. Early

Chuck Eberdt

Bill and Iris Jackson

James R. Webb

Thomas J. Schneider

G. A. Turnbow

Philip E. Batt

Sandra Flicker

Dave Piper

G. R. Garman

Richard G. Ferreira

Jim Baker

Mark Schinman

David Robison

Bruce Wynne

Elmer G. Sams

Aaron C. Jones

Donald $\mathrm{H}$. Angell

Pete Forsyth

C. Clark Leone

Paul M. Murphy

William K. Drummond

Mark Gendron

James $W$. Sanders

Jim Buck

Jason Eisdorfer

Gary Zarker

David Davidson

Paul Davies 
Comment

Log No. Affiliation

SUB01-107 Eugene Water \& Electric Board

SUB01-108 Grays Harbor Public Utility District

SUB01-109 Industrial Customers of Northwest Utilities

SUB01-110 No Affiliation

SUB01-111 Klickitat PUD

SUB01-112 McMinnville Water and Light

SUB01-113 Natural Resources Defense Council

SUB01-114 NW Energy Coalition

SUB01-115 Northwest Energy Efficiency Alliance

SUB01-116 Oregon Utility Resource Coordination Association

SUB01-117 Pacific Northwest Waterways Association

SUB01-118 Pierce County Coop Power Association

SUB01-119 The Shoshone-Bannock Tribes

SUB01-120 Utility Reform Project and Lloyd K. Marbet

SUB01-121 Springfield Utility Board

SUB01-122 Reynolds Metals Company

SUB01-123 No Affiliation

SUB01-124 No Affiliation

SUB01-125 No Affiliation

SUB01-126 No Affiliation

SUB01-127 No Affiliation

SUB01-128 No Affiliation

SUB01-129 No Affiliation

SUB01-130 No Affiliation

SUB01-131 No Affiliation

SUB01-132 Port Townsend Paper Corporation

SUB01-133 NW Energy Coalition

SUB01-134 Renewable Northwest Project

SUB01-135 Public Power Council

SUB01-136 Central Lincoln People's Utility District

SUB01-137 NW Energy Coalition

SUB01-138 Seattle City Light, City of Seattle

SUB01-139 Parkland Light and Water Company

SUB01-140 Big Bend Electric Co-Operative, Inc

SUB01-141 Big Bend Electric Co-Operative, Inc.

SUB01-142 Columbia River Inter-Tribal Fish Commission

SUB01-143 Washington State Senator, 33rd Dist.

SUB01-144 No Affiliation

SUB01-145 Northwest Energy Efficiency Council

SUB01-146 Idaho, Montana, Oregon, and Washington State Public Utilities Commissions

SUB01-147 City of Maple Valley

SUB01-148 Washington State Senator, 26th Dist.

SUB01-149 Surprise Valley Electrification Corp.

SUB01-150 Public Utility District No. 1 of Clallam County

SUB01-151 No Affiliation
Name of Commenter

Randy L. Berggren

Stephen W. Romjue

Ken Canon

Pam Jensen

Brian L. Skeahan

John L. Harshman

Sheryl Carter

Steve Weiss

Margaret Gardner

Dave Bouchard

Glenn Vanselow

10 Coop Utilities

Keith Tinno

Daniel W. Meek

Steve L. Loveland

Steve Waddington

C. Y. McGaerigle

Donna M. Holm

Kenneth R. Skinner

Frank Fry

Clara Gange

Jerome C. Baer

Rollo K. Van Slyke

Walter W. Kirschman

John H. Wolch

Bruce McComas

Nancy Hirsh

Peter West

Maureen Carr

M. Kay Moxness

Comment Not Signed

Jim Todd

James R. Sherrill

David R. Barden

David R. Barden

Ted Strong

Julia Patterson

Ardell S. Peterson

Stan Price

14 PUC Commissioners

Laure Iddings

Bob Oke

Dan Silveria

Michael Mclnnes

John H. Farrens, Jr. 
Comment

Log No.

Affiliation

SUB01-152 No Affiliation

SUB01-153 No Affiliation

SUB01-154 No Affiliation

SUB01-155 No Affiliation

SUB01-156 Piazza Construction, Inc.

SUB01-157 No Affiliation

SUB01-158 No Affiliation

SUB01-159 No Affiliation

SUB01-160 No Affiliation

SUB01-161 No Affiliation

SUB01-162 No Affiliation

SUB01-163 No Affiliation

SUB01-164 No Affiliation

SUB01-165 Central Lincoln People's Utility District

SUB01-166 No Affiliation

SUB01-167 No Affiliation

SUB01-168 Washington State Representative, 5th Dist.

SUB01-169 Friends of the Earth, Northwest Office

SUB01-170 No Affiliation

SUB01-171 Washington State Representative, 41st Dist.

SUB01-172 Atmosphere Alliance

SUB01-173 City of Portland, Commission of Public Works

SUB01-174 City of Bellingham Washington

SUB01-175 Western Public Agencies Group

SUB01-176 Washington State Representative, 40th Dist.

SUB01-177 No Affiliation

SUB01-178 Oregon PUC; Northwest Aluminum Company

SUB01-179 No Affiliation

SUB01-180 Washington State Senator, 23rd Dist.

SUB01-181 Douglas Electric Cooperative

SUB01-182 No Affiliation

SUB01-183 No Affiliation

SUB01-184 No Affiliation

SUB01-185 Washington State Representative, 42nd Dist.

SUB01-186 No Affiliation

SUB01-187 No Affiliation

SUB01-188 Insurance Services

SUB01-189 No Affiliation

SUB01-190 No Affiliation

SUB01-191 No Affiliation

SUB01-192 No Affiliation

SUB01-193 Public Power Council

SUB01-194 No Affiliation

SUB01-195 No Affiliation

SUB01-196 No Affiliation

\author{
Name of Commenter \\ David Sharer \\ Elmer Clausen \\ Bertan J. Roundy \\ Geraldine R. Jackson \\ John J. Piazza \\ Clifford L. Burkey \\ Gene R. Crnick \\ Alison M. Arnold \\ Philip T. Rosser \\ Edward J. Hertel \\ Dick and Kay Remillard \\ John and Shirlee Fisher \\ Dolly Gelsleichter \\ Michael L. Wilson \\ Jim DiPeso \\ Beverly Smith-Griebel \\ Brian Thomas \\ Shawn Cantrell \\ Jim Edelson \\ Mike Wensman \\ Rhys Roth \\ Erik Sten \\ Mark Asmundson \\ Terry Mundorf \\ Jeff Morris \\ Frank R. Fahland \\ Ron Eachus; Brett Wilcox \\ William M. Davidson \\ Betti L. Sheldon \\ Dave Sabala \\ Dean Salt \\ Dolores H. McMillen \\ Violet Blanton \\ Georgia Gardner \\ John LaVillette \\ Maurice Thoresen \\ Kenneth Andrus \\ Edward L. Drury \\ William R. Hughes \\ Jack A. Austin \\ Jim Seifert \\ C. Clark Leone \\ Leslie J. Groce \\ Robert L. Vaughan \\ Roberta A. Gallagher
}




\author{
Comment \\ Log No. Affiliation \\ SUB01-197 No Affiliation \\ SUB01-198 No Affiliation \\ SUB01-199 Washington Public Utility Districts Association \\ SUB01-200 Elf Atochem North America, Inc. \\ SUB01-201 No Affiliation \\ SUB01-202 No Affiliation \\ SUB01-203 No Affiliation \\ SUB01-204 Northwest Energy Review Transition Board \\ SUB01-205 No Affiliation \\ SUB01-206 No Affiliation \\ SUB01-207 No Affiliation \\ SUB01-208 No Affiliation \\ SUB01-209 No Affiliation \\ SUB01-210 No Affiliation \\ SUB01-211 City of Algona \\ SUB01-212 Washington State Representative, 42nd District \\ SUB01-213 No Affiliation \\ SUB01-214 Makah Tribal Council \\ SUB01-215 Snohomish County Public Utility District Board of \\ Commissioners \\ SUB01-216 City of Issaquah \\ SUB01-217 Makah Tribal Council \\ SUB01-218 Oregon Municipal Electric Utilities \\ SUB01-219 State of Oregon, Office of the Governor \\ SUB01-220 U.S. House of Representatives (OR 4th \& WA 6th)
}

Name of Commenter

Keith $\mathrm{H}$. and Hazel M. Christen

Barbara L. Workman

Steve Johnson

Gene Spina

R. A. Sievers

Beth Asher

Dixie Lee Sievers

John Etchart

Raymond $\mathrm{H}$. McMillen, Jr.

Edward E. and Beverly

Preston

Leonard R. Comer

Peg and Tag Frazier

Taimi Dudley

John D. Cole

Glenn R. Wilson

Georgia Gardner

Charles B. Kimber

Ben Johnson, Jr.

Charles Moon, et al.

Ava Frisinger

Ben Johnson, Jr.

Tom O'Connor

John A. Kitzhaber, M.D.

Peter DeFazio and Norm

Dicks

$\begin{array}{ll}\begin{array}{l}\text { Public Meeting } \\ \text { City \& Date } \\ \text { Spokane, 10/8 }\end{array} & \begin{array}{l}\text { Affiliation } \\ \text { Kootenai Electric Cooperative, Inc. } \\ \text { Spokane, 10/8 }\end{array} \\ \text { Direct-Service Industries } \\ \text { Spokane, 10/8 } & \text { Sierra Club } \\ \text { Spokane, 10/8 } & \text { Modern Electric Water Company } \\ \text { Spokane, 10/8 } & \text { Benton County Public Utility District } \\ \text { Spokane, 10/8 } & \text { City of Cheney } \\ \text { Spokane, 10/8 } & \text { Inland Power \& Light Company } \\ \text { Spokane, 10/8 } & \text { Avista Energy } \\ \text { Spokane, 10/8 } & \text { ALUMAX (ALCOA) } \\ \text { Spokane, 10/8 } & \text { Kaiser Aluminum } \\ \text { Spokane, 10/8 } & \text { Benton County Public Utility District } \\ \text { Spokane, 10/8 } & \text { Clearwater Power Company } \\ \text { Spokane, 10/8 } & \text { League of Women Voters }\end{array}$

\author{
Name of Commenter \\ Robert Crump \\ Paul Murphy \\ Jim Baker \\ Mike Baker \\ Jim Sanders \\ Bill Drummond \\ Tom Richardson \\ Dick Heitman \\ Steve Fisher \\ Bruce Mizer \\ Pete Forsyth \\ Jim Sanders \\ Ray Thayer \\ Joyce Jones
}


Public Meeting

City \& Date

Spokane, $10 / 8$

Spokane, $10 / 8$

Portland, 10/14

Portland, 10/14

Portland, 10/14

Portland, 10/14

Portland, 10/14

Portland, 10/14

Portland, 10/14

Portland, 10/14

Portland, 10/14

Portland, 10/14

Portland, 10/14

Portland, 10/14

Portland, 10/14

Portland, 10/14

Portland, 10/14

Portland, 10/14

Portland, 10/14
Affiliation

WA Environmental Council \& ID Conservation League Spokane Neighborhood Action Programs

No Affiliation

ALUMAX (ALCOA)

Direct-Service Industries

Washington Water Power (Avista Corporation)

Public Power Council

Public Power Council

Puget Sound Energy, Inc.

Reynolds Metals Company

League of Women Voters

WA Dept. of Community, Trade, \& Econ. Devel.

NW Energy Coalition

Lane County Housing Authority \& Community Services

Northwest Requirements Utilities

Pacific Northwest Generating Cooperative

NW Energy Coalition

Sierra Club

Renewable Northwest Project
Name of Commenter

Lupito Flores

Larry Stuckart

Al Canada

Bruce Mizer

Paul Murphy

Jeff Schlect

Maureen Carr

Alan Hicks

Don Kari

Steve Waddington

Adele Newton

Howard Schwartz

Sara Patton

Craig Satein

John Saven

Pat Reiten

Steve Weiss

Marcia Anderson

Rachel Shimshak

(PBLLAN-X:IHQ5F01ISUBSCRIBIRODISUBTAC.DOC) 